\title{
Gabriel Tamashiro
}

\section{Desenvolvimento de um sistema de comunicação baseado em middleware para aplicações robóticas}

Dissertação apresentada à Escola de Engenharia de São Carlos da Universidade de São Paulo, como parte dos requisitos para obtenção do título de Mestre em Ciências.

Área de concentração: Dinâmica de Máquinas e Sistemas.

Orientador: Prof. Assoc. Marcelo Becker

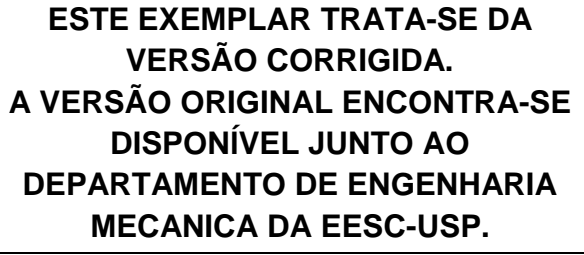

São Carlos

2014 
AUTORIZO A REPRODUÇÃO TOTAL OU PARCIAL DESTE TRABALHO, POR QUALQUER MEIO CONVENCIONAL OU ELETRÔNICO, PARA FINS DE ESTUDO E PESQUISA, DESDE QUE CITADA A FONTE.

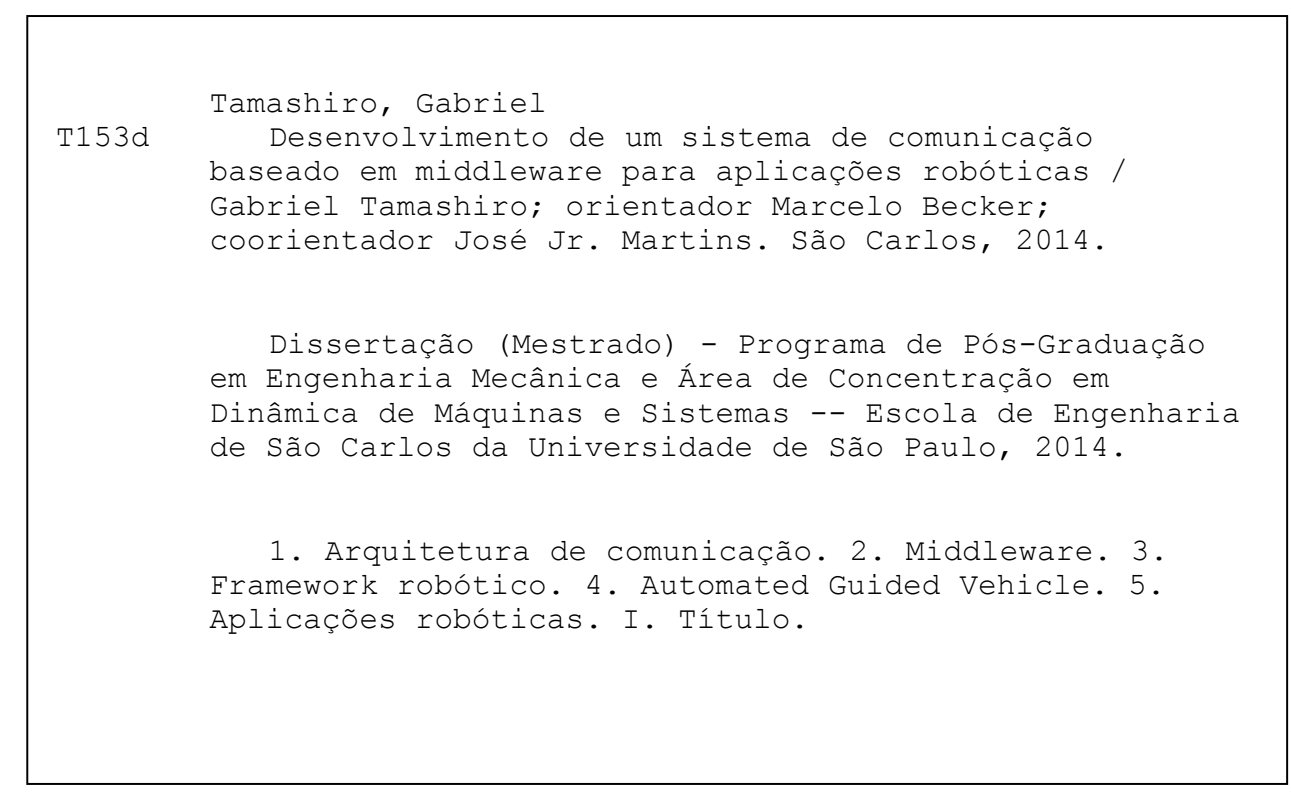




\section{FOLHA DE JULGAMENTO}

Candidato: Bacharel GABRIEL TAMASHIRO.

Título da dissertação: "Desenvolvimento de um sistema de comunicação baseado em middlewares para aplicações robóticas ".

Data da defesa: 12/02/2014

\section{Comissão Julgadora:}

Prof. Associado Marcelo Becker (orientador)

(Escola de Engenharia de São Carlos/EESC)

Prof. Dr. José Martins Junior

(Escola de Engenharia de Piracicaba/EEP)

Profa. Associada Kalinka R. Lucas Jaquie Castelo Branco (Instituto de Matemática e Computação/ICMC)
Resultado:

APROVADO

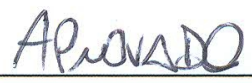

Coordenador do Programa de Pós-Graduação em Engenheira Mecânica:

Prof. Associado Marcelo Areias Trindade

Presidente da Comissão de Pós-Graduação:

Prof. Titular Denis Vinicius Coury 

Dedico este trabalho aos meus pais, Celso e Izabel, por sempre me guiarem e permitirem chegar onde estou, e à Camilla, por todo o carinho e incentivo nas horas de desespero. 



\section{Agradecimentos}

Agradeço ao professor Dr. Marcelo Becker por oferecer a possibilidade de trabalhar junto ao grupo e por me aconselhar durante o projeto.

Agradeço ao professor Dr. José Martins Junior pela paciência e todos os conselhos e ideias que contribuíram para este trabalho.

Agradeço aos amigos da equipe do projeto de empilhadeiras robóticas pela paciência, apoio e conselhos. Em especial, agradeço à Kelen Cristiane Teixeira Vivaldini pela amizade, discussões e idéias que ajudaram a guiar meus estudos, e à Livia Martinelli Tinelli também pela amizade, e por todas as sugestões e ajuda ao longo do projeto.

Agradeço à USP e todos os funcionários com quem tive contato por me proporcionar este excelente ambiente de aprendizado e pesquisa que moldaram meu conhecimento.

Agradeço ao CNPq pela ajuda financeira proporcionada pela bolsa de mestrado.

Agradeço aos amigos e familiares por todo o apoio e incentivo que sempre me motivaram e animaram.

Agradeço, acima de todos, a Deus por me guiar e capacitar para cruzar todos os desafios impostos no dia a dia. 

"Feliz aquele que transfere o que sabe e aprende o que ensina." (Cora Coralina) 



\section{Resumo}

GABRIEL, T (2014). Desenvolvimento de um sistema de comunicação baseado em middleware para aplicações robóticas. 105p. Dissertação (Mestrado) - Escola de Engenharia de São Carlos, Universidade de São Paulo, São Carlos, 2014.

O aumento no número de dispositivos móveis com crescente capacidade de processamento traz como incentivo o desenvolvimento de sistemas distribuídos que possam explorar estas novas tecnologias. Dentro dos sistemas distribuídos, os mecanismos que permitem a troca de dados entre os processos que o constituem, possuem um papel importante para o desempenho da aplicação. Uma abordagem interessante para implementar estes mecanismos é por meio do uso de middlewares. O middleware abstrai as funcionalidades básicas oferecidas pelo sistema operacional e hardware para oferecer serviços de alto nível aos desenvolvedores. Estes serviços permitem aos desenvolvedores se concentrarem somente na lógica interna de suas aplicações, reduzindo também seu custo de manutenção. Incentivado pela necessidade de um mecanismo que garantisse a troca de informações entre as unidades de um sistema autônomo para o gerenciamento de AGVs (Automated Guided Vehicle), desenvolvido pelo grupo de mecatrônica da Universidade de São Paulo, este trabalho propõe uma arquitetura de comunicação baseada em middlewares que é inspirada no paradigma de comunicação RMI (Remote Method Invocation) para suprir a troca de dados necessária por meio do conceito de objetos distribuídos. Para apresentar o uso da IDL (Interface Definition Language) disponibilizada pela arquitetura proposta, uma demonstração de como acrescentar novos serviços à arquitetura é descrita. Para avaliar o desempenho da arquitetura e analisar o comportamento dos serviços oferecidos, testes de tempo de resposta, throughput e disponibilidade foram realizados. Pode-se verificar que a arquitetura proposta, além de apresentar um desempenho satisfatório para a operação do sistema de AGVs, proporcionou uma estrutura que pode ser facilmente adaptada para futuras alterações no projeto sem modificar diretamente as definições da arquitetura de comunicação.

Palavras-chaves: Arquitetura de comunicação. Middleware. Framework robótico. Automated Guided Vehicle. Aplicações robóticas. 



\begin{abstract}
GABRIEL, $T$ (2014). Development of a communication architecture based on middleware for robotic applications. 105p. M.Sc Dissertation (Master) - Escola de Engenharia de São Carlos, Universidade de São Paulo, São Carlos, 2014.

The increase in the process capacity of mobile devices has motivated the development of distributed applications that exploit new technologies. In distributed applications, the mechanisms that enable the exchange of data among the application processes play an important role in their performance. An interesting way to deal with such an exchange is to adopt middleware to handle communication. The middleware abstracts the functionalities provided by the underlying operational system and hardware and offers a set of high-level services, which assist developers in working directly with the logic of the application and reducing its maintenance costs. Motivated by the necessity of a mechanism that ensures the exchange of information among the units of an AGV (Automated Guided Vehicle) system designed by the University of São Paulo, this dissertation develops a communication architecture based on middleware. The architecture is inspired in the RMI (Remote Method Invocation) paradigm to enable the data exchange based on the concept of distributed objects. An IDL (Interface Definition Language) was conceived for the architecture and a demonstration of how new services can be added to the structure was conducted. To validate the performance of the proposed middleware and its services, tests of network response time, throughput and availability were carried out. The architecture showed a satisfactory performance for the operation of the AGV system and provided a structure that can be easily adapted for future changes in the project.
\end{abstract}

Keywords: Communication architecture. Middleware. Robotic framework. Automated Guided Vehicle. Robotic applications. 



\section{Sumário}

1. INTRODUÇÃO

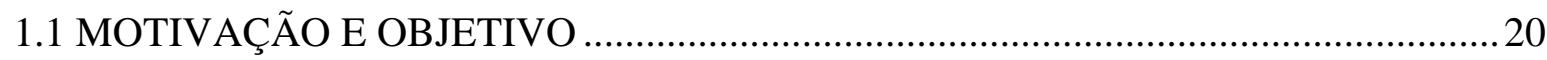

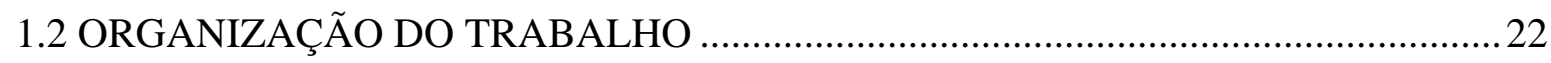

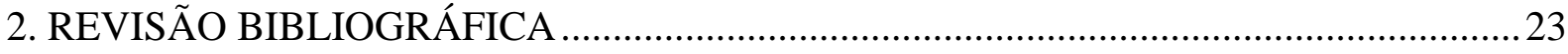

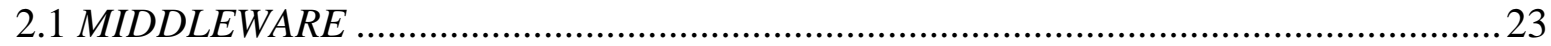

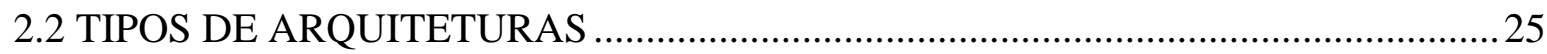

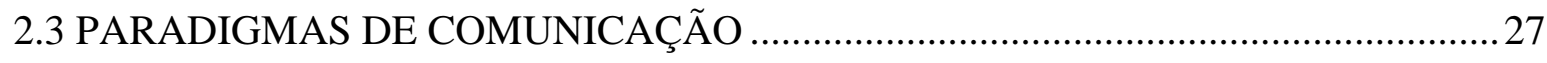

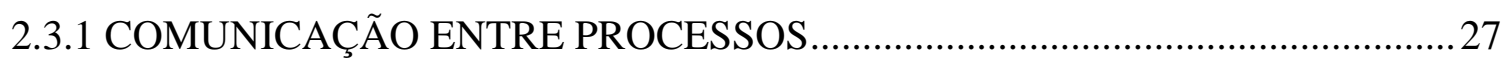

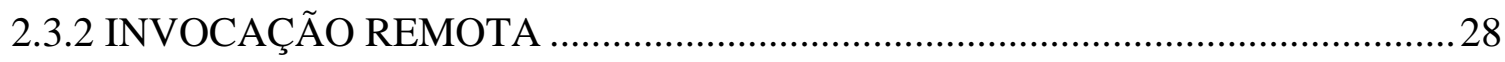

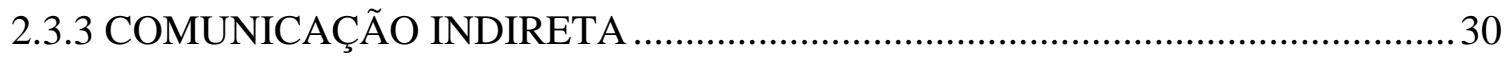

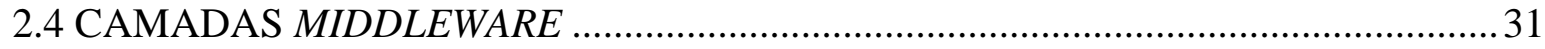

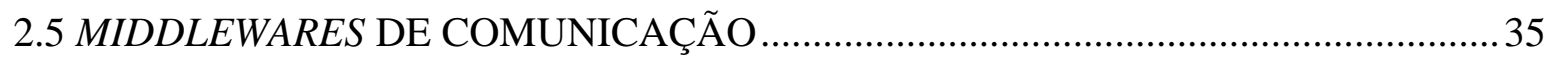

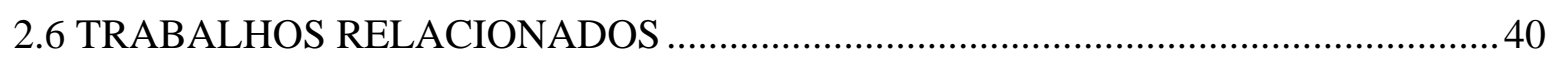

2.6.1 FRAMEWORKS PARA APLICAÇÕES ROBÓTICAS.........................................4

2.8 TESTES UTILIZADOS NA ÁREA DE REDES PARA AVALIAR O DESEMPENHO DE ARQUITETURAS DE COMUNICAÇÃO.......................................................... 44

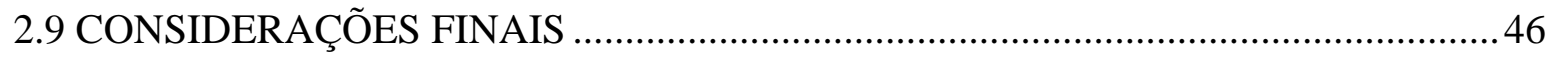

3. ARQUITETURA DE COMUNICAÇÃO PROPOSTA .....................................................4

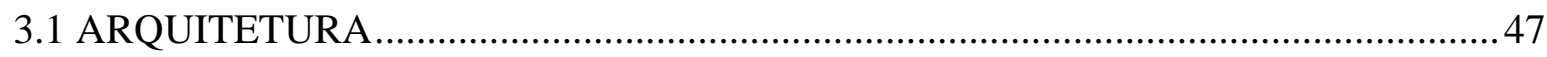

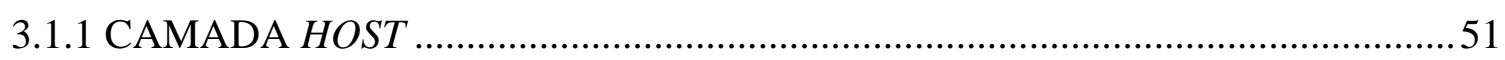

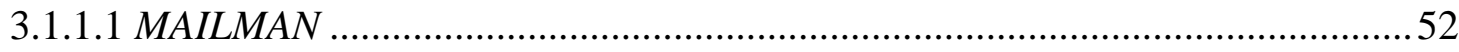

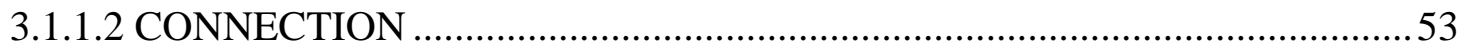

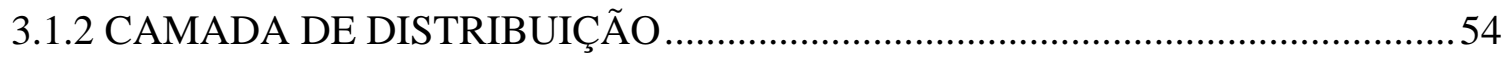

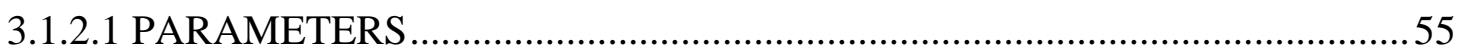

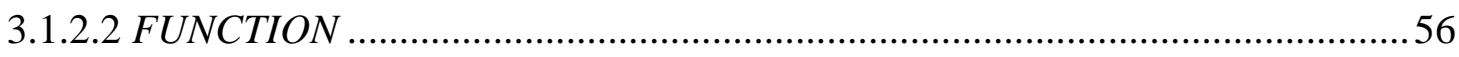

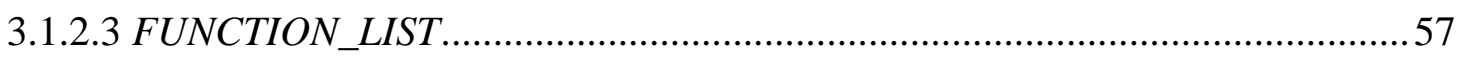

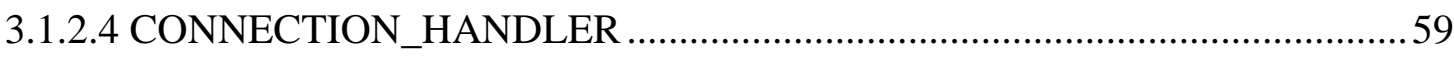

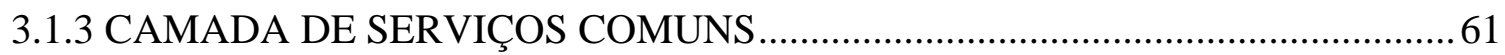

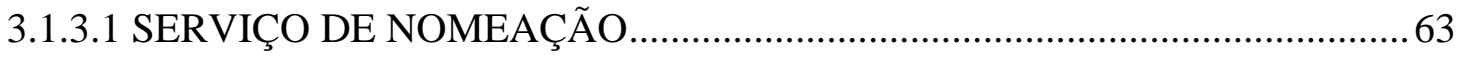

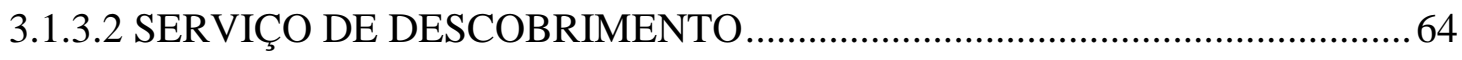

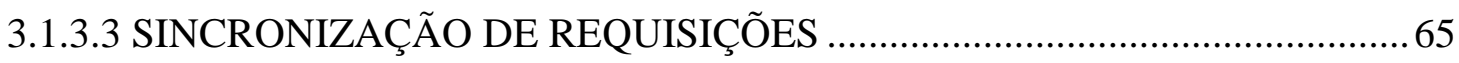




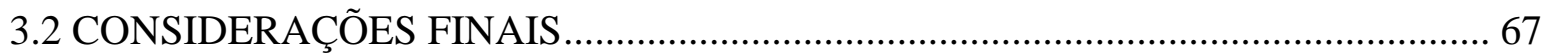

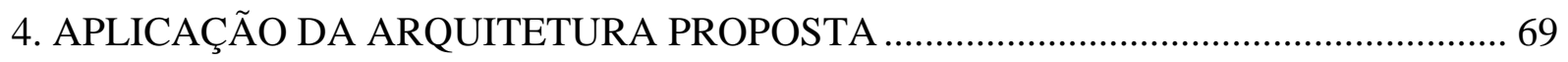

4.1 IMPLEMENTAÇÃO DE UM SERVIÇO BASEADO EM SISTEMAS PUBLISH-

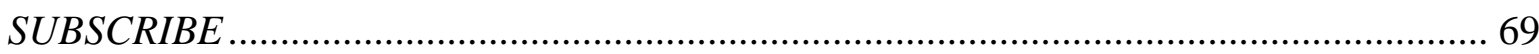

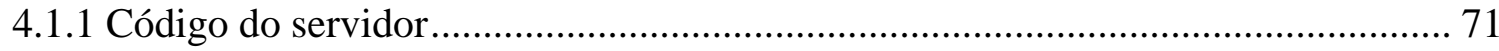

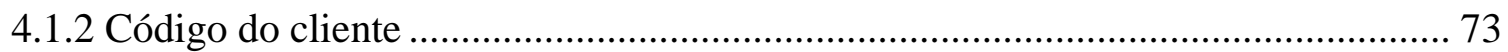

4.2 APLICAÇÃO DA ARQUITETURA PARA O PROJETO DO AGVS ....................... 75

4.3 EXEMPLO DE INTEGRAÇÃO DA ARQUITETURA DE COMUNICAÇÃO COM

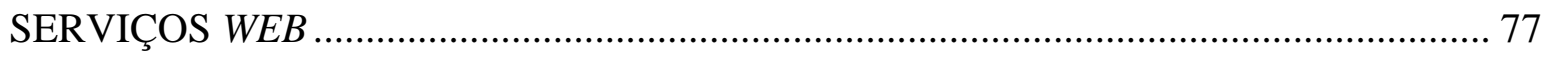

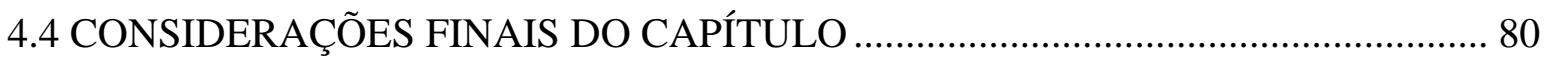

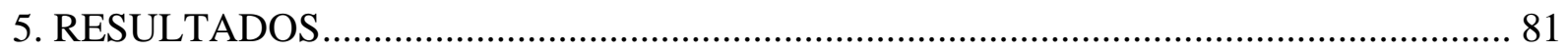

5.1 TESTES DE TEMPO DE RESPOSTA, GERAÇÃO E PROCESSAMENTO DE

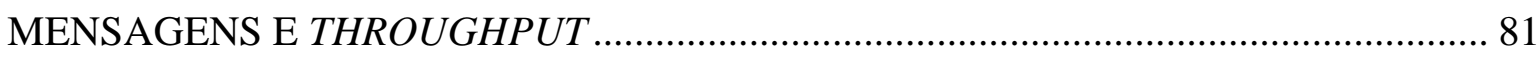

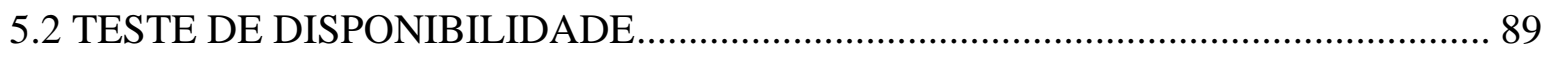

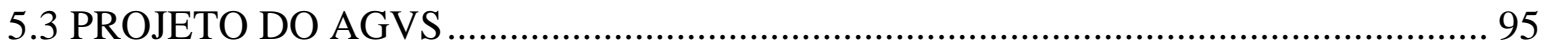

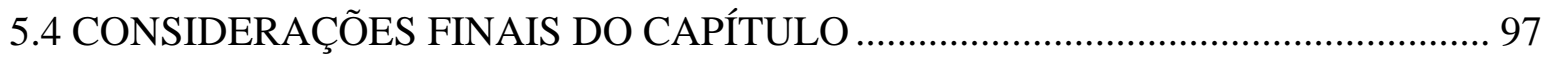

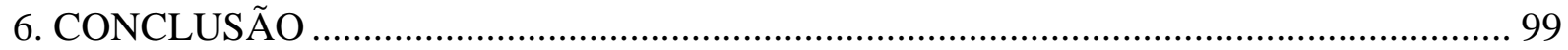




\section{Lista de figuras}

Figura 1 - Sistema distribuído organizado através de uma camada middleware ....................24

Figura 2 - Ilustração da arquitetura cliente-servidor......................................................... 25

Figura 3 - Ilustração da arquitetura peer-to-peer............................................................... 26

Figura 4 - Ilustração das camadas de um middleware com relação aos paradigmas de

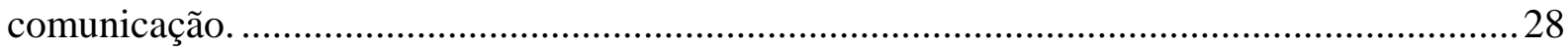

Figura 5 - Estrutura de camadas utilizada para endereçar os serviços proporcionados por um middleware.

Figura 6 - Fluxo e construção das mensagens de acordo com a estrutura de camadas para os

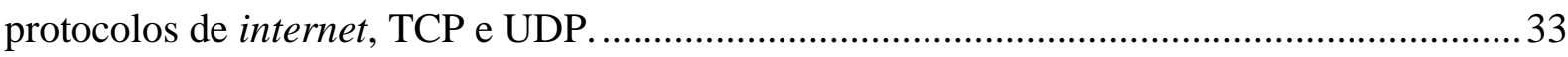

Figura 7 - Modelo de comunicação utilizado no Java RMI.................................................. 36

Figura 8 - Modelo de comunicação utilizado no CORBA. ..................................................... 38

Figura 9 - Representação do teste de tempo de resposta (RTT). ......................................... 45

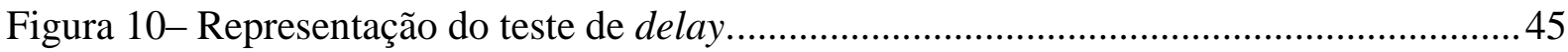

Figura 11- Camadas e diagrama de classe parcial da arquitetura proposta. ........................... 48

Figura 12 - Camadas e diagrama de classe parcial da arquitetura proposta. ..........................50

Figura 13 - Ilustração de um processo e suas threads. ........................................................52

Figura 14 - Diagrama ilustrando o mecanismo de criação de threads para o envio e

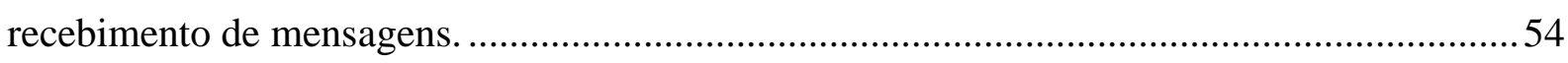

Figura 15 - Ilustração da estrutura dos objetos da classe Parameters. ...................................56

Figura 16 - Ilustração da estrutura dos objetos da classe Function . ........................................57

Figura 17 - Ilustração da estrutura dos objetos da classe Function_list. ................................58

Figura 18 - Diagrama ilustrando o mecanismo de criação de threads para o recebimento de

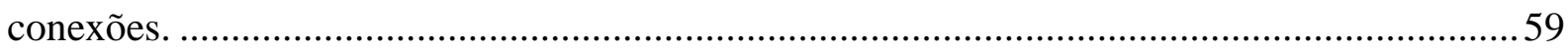

Figura 19 - Diagrama ilustrando o mecanismo de requisição de métodos ou funções entre processos.

Figura 20 - Possível configuração de nós formada pelos objetos das classes Unit e

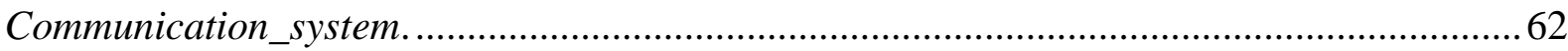

Figura 21- Formato de mensagem utilizado pela arquitetura proposta...................................62 Figura 22 - Diagrama ilustrando o mecanismo do serviço de descobrimento implementado pela arquitetura proposta.

Figura 23 - Diagrama ilustrando o mecanismo de timeout implementado no serviço de requisição síncrona. 
Figura 24 - Código exemplo do servidor: utilização da interface oferecida pelo middleware proposto para disponibilizar o serviço implementado pela classe Publish_subscribe.

Figura 25 - Código exemplo do cliente: utilização da interface oferecida pelo middleware proposto para acessar o serviço publish-subscribe disponível no servidor.

Figura 26 - Classes utilizadas e conexões estabelecidas entre as unidades do AGVS. 76 Figura 27 - Ilustração da interação entre os processos utilizados para o controle de uma empilhadeira robótica através de um celular com plataforma Android. 79

Figura 28 - Interface do aplicativo no celular para controlar a empilhadeira (esquerda) e a empilhadeira sendo controlada (direita)

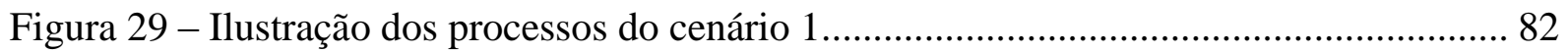

Figura 30 - Ilustração dos processos dos cenários 2, 3, 4 e 5. 85

Figura 31 - Tempos de respostas medidas em todos os cenários para o caso de tamanhos de mensagem de 20000 caracteres 89

Figura 32 - Teste de disponibilidade medida para o cenário 1 90

Figura 33 - Teste de disponibilidade medida para o cenário 2. 91

Figura 34 - Teste de disponibilidade medida para o cenário 3 92

Figura 35 - Teste de disponibilidade medida para o cenário 4. 93

Figura 36 - Teste de disponibilidade medida para o cenário 5. 94

Figura 37 - Teste de disponibilidade medido em todos os cenários para o tamanho de mensagem de 20000 caracteres. 95

Figura 38 - Interface proporcionada pelo WMS para acompanhar o deslocamento dos produtos (paletes) no armazém. As caixas coloridas presentes na figura indicam a presença de um palete. 96

Figura 39 - Ambiente simulado proporcionada pelo Player/Stage onde os AGVs executam as tarefas passadas pelo supervisor. 96 


\section{Lista de tabelas}

Tabela 1 - Medidas dos testes de geração e processamento das mensagens, tempo de resposta

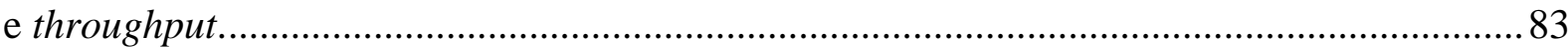

Tabela 2 - Diferença entre o tempo de resposta obtido através do protocolo ICMP e através

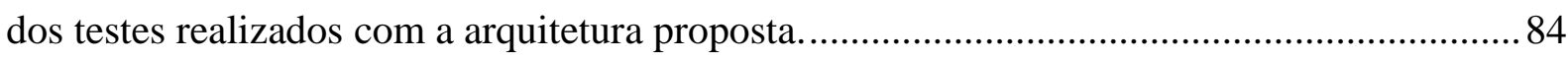

Tabela 3 - Diferença entre os tempos de resposta obtidos pelos cenários 1 e 2 ..................... 87

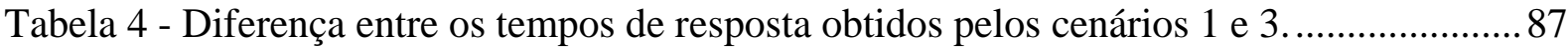

Tabela 5 - Diferença entre os tempos de resposta obtidos pelos cenários 1 e 4 ....................... 87

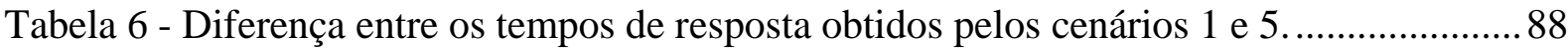

Tabela 7 - Dados coletados durante a operação do AGVS para um conjunto de tarefas

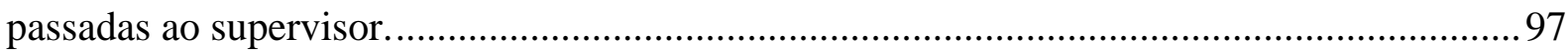





\section{INTRODUÇÃO}

Com o aumento crescente do número de dispositivos móveis e de suas respectivas capacidades de processamento, o desenvolvimento de aplicações distribuídas tem ganhado popularidade ao longo dos últimos anos, o que reflete no número de publicações relacionadas a este tema em diversas áreas como, por exemplo, robótica (1)-(2), computação (3)-(4), militar (5), segurança pública (6), entre outras. Por este motivo, o desenvolvimento de sistemas de comunicação que possam dar suporte às aplicações distribuídas é de interesse tanto do mercado quanto de pesquisadores relacionados à área, uma vez que estes sistemas podem acelerar o desenvolvimento de novas tecnologias. A arquitetura de comunicação em sistemas distribuídos possui um papel importante por estar diretamente ligada à topologia e escalabilidade da aplicação, e que além de garantir a troca de informações entre as unidades do sistema ela também proporciona uma infraestrutura adequada para implementar a coordenação e interação entre estas unidades.

Uma boa prática para se garantir a comunicação do sistema é por meio da adoção de um middleware de comunicação. Um middleware é uma camada de software que abstrai funcionalidades das camadas inferiores, relacionadas com o sistema operacional, protocolos de rede e hardware, e oferece um modelo de programação que alivia os desenvolvedores de se preocuparem com programação de baixo nível (7)-(8). O middleware permite aos desenvolvedores focarem principalmente na lógica intrínseca de suas aplicações, facilitando seu desenvolvimento e reduzindo o custo de manutenção. E é por esta razão que o desenvolvimento de middlewares de comunicação tem recebido grandes investimentos de várias instituições e empreses ao redor do mundo (9).

Com relação aos sistemas robóticos, sejam eles constituídos de um único ou múltiplos robôs, a comunicação é essencial. Ela permite tanto o controle dos robôs quanto a coleta de dados de seus sensores, provendo coordenação entre as unidades do sistema. Em geral, um sistema robótico é constituído de um conjunto de processos executados simultaneamente durante a operação do sistema. Estes processos podem tanto estarem associados ao sistema como um todo, quanto representarem um único robô individualmente. Cada processo é responsável por tratar um aspecto específico do sistema robótico, como coleta de dados dos sensores, detecção e desvio de obstáculos, gerenciamento de tarefas, entre outros. Desta 
forma, um sistema de comunicação adequado para permitir a interação e coordenação destes processos é fundamental e possui um papel importante no desempenho da aplicação.

\subsection{MOTIVAÇÃO E OBJETIVO}

Tendo em vista a importância do desenvolvimento de novas tecnologias na área de armazéns inteligentes para o Brasil, o LabRoM (Laboratório de Robótica Móvel) da Universidade de São Paulo tem desenvolvido um sistema autônomo para gerenciar um conjunto de AGVs (Automated Guided Vehicles) de um armazém inteligente (10). Este sistema, denominado AGVS (Automated Guided Vehicles System), controla o roteamento e agendamento das tarefas passadas aos AGVs, sendo estes responsáveis pelas operações de manuseio no armazém. Durante seu desenvolvimento, houve a necessidade de adotar uma arquitetura de comunicação que garantisse a troca de informações entre as unidades do sistema de forma eficiente e flexível.

Para preencher tal necessidade, existem diversos middlewares de comunicação e frameworks para desenvolvimento de aplicações robóticas (CORBA (11), Java RMI (12), ROS (13), YARP (14), entre outros) que oferecem uma arquitetura de comunicação. Estes variam bastante em complexidade, serviços oferecidos, linguagens de programação e sistemas operacionais, podendo conter inclusive algoritmos e drivers para solucionar problemas específicos de aplicações robóticas. No entanto, para o projeto de AGVs mencionado, boa parte destes middlewares e frameworks além de não suportar a linguagem de programação ou plataforma de desenvolvimento do projeto (e.g., Java RMI, que permite sua implementação somente em Java), C++ e Linux, respectivamente, estes acabariam adicionando complexidade desnecessária ao projeto por oferecer mais serviços do que o necessário, dificultando sua adoção ao requerer maior tempo para seu aprendizado (e.g., implementações CORBA, que em geral requerem a introdução de elementos adicionais no sistema para sua execução e implementação). Os frameworks ROS e YARP poderiam ser utilizados para o projeto e necessitariam apenas que o sistema fosse adaptado de acordo com os mecanismos de comunicação oferecidos por eles. No entanto, é desejável a utilização de uma arquitetura de comunicação que seja adaptado de acordo com as necessidades do sistema e, para isso, é necessária a implementação de alguns serviços adicionais (e.g., serviços para garantir a 
segurança da comunicação) que podem não estar presentes, ou serem difíceis de implementar, ao utilizar um framework robótico em particular.

Tendo em vista que o sistema de AGVs desenvolvido pelo grupo tem como finalidade oferecer uma solução viável para o mercado industrial brasileiro, houve a necessidade de utilizar uma arquitetura de comunicação acessível para agregar novas funcionalidades diretamente à comunicação. E foi este motivo que deu início a este trabalho, em desenvolver uma arquitetura de comunicação middleware que, além de garantir a troca de informações, pudesse ser implementada de forma fácil e eficiente, tonando-se assim, tanto uma ferramenta útil ao grupo no desenvolvimento de futuras aplicações quanto uma opção viável para a proposta do sistema de AGVs.

O middleware proposto, desenvolvido na linguagem de programação $\mathrm{C}++\mathrm{e}$ plataforma Linux, foi inspirado no paradigma de comunicação de invocação remota, tendo como foco prover uma infraestrutura adequada para que os desenvolvedores estabeleçam as relações entre as unidades de seu sistema. Durante seu desenvolvimento, observou-se que a arquitetura obtida poderia tornar-se não somente uma solução específica para o projeto de AGVs, mas também extensível para outras aplicações. Para garantir esta flexibilidade ao middleware, a arquitetura adotou o paradigma de programação orientada a objetos, facilitando então seu desenvolvimento. Embora agregar esta flexibilidade ao middleware pudesse aumentar os overheads das mensagens trocadas, o que diminui seu desempenho, a possibilidade de utilizar a arquitetura em outros projetos foi entendida como um ponto mais relevante do que esta diminuição de desempenho.

Para validar a arquitetura proposta, diversos testes foram realizados, medindo-se características como disponibilidade, tempo de resposta e throughput. Estes testes foram realizados sobre diversas configurações experimentais, permitindo a avaliação do desempenho da arquitetura e suas limitações. Além disso, o middleware foi utilizado no projeto de AGVs mencionado anteriormente, o que ajudou a melhorar e reavaliar as interfaces disponibilizadas pela arquitetura durante seu desenvolvimento. Por falta de tempo, o desempenho da arquitetura não foi comparado com outros frameworks ou middlewares de comunicação, sendo sugeridos como trabalhos futuros.

Outro tópico abordado por este trabalho, para amenizar a especificidade do middleware quanto à linguagem de programação e sistema operacional, foi o de integrá-lo com um framework de serviços web em $\mathrm{C}++$, fornecido gratuitamente pela WSO2 (15), para permitir que dispositivos operando em diferentes plataformas tivessem acesso aos serviços 
disponibilizados pelo middleware. Para demonstração, foram criados serviços que permitiram controlar remotamente uma empilhadeira, utilizando-se um celular com a plataforma Android.

\subsection{ORGANIZAÇÃO DO TRABALHO}

Este capítulo apresentou brevemente a contextualização e motivação relacionadas com este trabalho. Os capítulos seguintes são organizados da seguinte forma:

Capítulo 2 apresenta a revisão bibliográfica sobre os conceitos relacionados com as arquiteturas de comunicação baseadas em middlewares, descrevendo em seguida os mecanismos presentes em dois middlewares de comunicação comumente encontrados na literatura (Java RMI e CORBA). Também neste capítulo é feita uma descrição sobre as abordagens de comunicação adotadas tanto em aplicações robóticas de artigos publicados quanto nos frameworks robóticos.

Capítulo 3 descreve a arquitetura de comunicação desenvolvida, apresentando a organização de suas estruturas e funcionalidades implementadas.

Capítulo 4 apresenta a aplicação da arquitetura proposta e o uso de sua interface em uma demonstração de como implementar novos serviços por meio das funcionalidades básicas oferecidas. Neste capítulo também é descrito como a arquitetura proposta foi utilizada para implementar a interação entre as unidades do AGVS. Ao final do capítulo é demonstrado o uso de serviços web para permitir a integração do middleware proposto com outras aplicações desenvolvidas em outras linguagens de programação e sistemas operacionais.

Capítulo 5 apresenta os testes realizados para avaliar o desempenho da arquitetura proposta. Estes testes são realizados em diferentes condições experimentais, tanto em cenários onde somente dois processos interagem, quanto em cenários mais dinâmicos, onde vários processos interagem simultaneamente. Também por questões de completude deste trabalho, dados referentes à operação do AGVS (utilizando a arquitetura proposta) foram coletados e apresentados no final.

Capítulo 6 conclui o trabalho e apresenta as sugestões para trabalhos futuros. 


\section{REVISÃO BIBLIOGRÁFICA}

Este capítulo introduz o conceito de middleware e descreve algumas de suas principais características, tais como o tipo de arquitetura e o paradigma de comunicação. Em seguida é apresentado um diagrama de camadas presente na literatura no qual endereça as principais funcionalidades associadas aos middlewares de comunicação. Para demonstrar como estas funcionalidades são implementadas e disponibilizadas por um middleware, são apresentados e descritos os mecanismos envolvidos em dois middlewares de comunicação (Java RMI e CORBA). Também é apresentada uma breve descrição sobre o estado da arte referente aos sistemas de comunicação utilizados em aplicações robóticas. Visto que o uso de um framework para desenvolvimento de aplicações robóticas é uma opção viável e interessante, são apresentados e descritos dois frameworks robóticos utilizados na literatura (ROS e YARP), dando-se um enfoque maior no sistema de comunicação proporcionado por eles.

\subsection{MIDDLEWARE}

Segundo Tanenbaum e Steen (16), com a intenção de oferecer uma visão de sistema único aos sistemas distribuídos (construídos em cima de dispositivos e redes heterogêneas), estes costumam ser organizados por meio de uma camada de software situada logicamente entre uma camada de nível mais alto, composta por aplicações e usuários, e outra camada adjacente que representa os sistemas operacionais, rede e hardware (Fig. 1). Esta camada de software, denominada de middleware, minimiza a carga dos desenvolvedores de se preocuparem com a programação de baixo nível relacionada com as facilidades básicas de comunicação disponibilizadas pelos sistemas operacionais e hardware. Assim, os desenvolvedores podem se concentrar apenas na implementação da lógica intrínseca da aplicação.

Um middleware proporciona transparência às aplicações distribuídas ao ocultar delas, até certo ponto, a distribuição de dados, processamento e controle entre as unidades do sistema. 


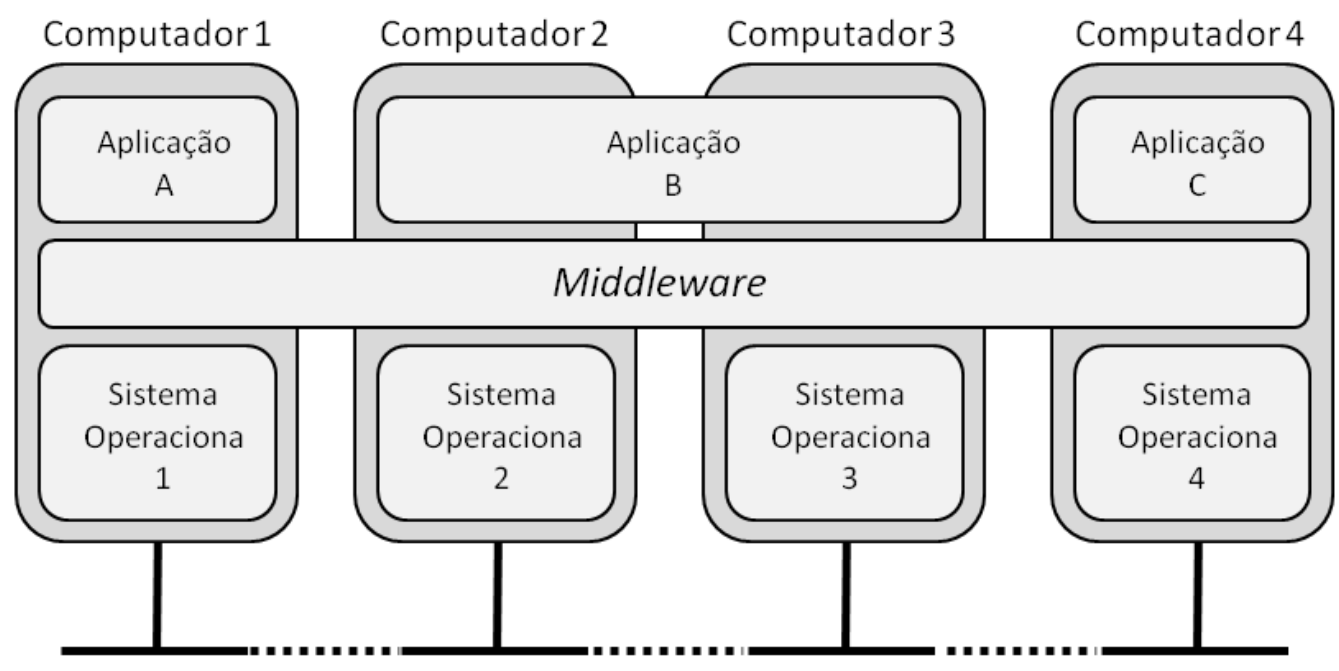

Figura 1 - Sistema distribuído organizado através de uma camada middleware. Adaptado: (16)

O fato de cada aplicação distribuída possuir seu próprio estilo arquitetônico e paradigma de comunicação reflete que o middleware que mais lhe beneficiaria seria aquele que também fosse construído em cima de suas características. Desta forma, um middleware ideal para determinada aplicação pode tornar-se bastante inconveniente para outra aplicação com necessidades distintas. Em contrapartida, acrescentar novas características e funcionalidades em um middleware para que este atenda um leque maior de aplicações pode torná-lo demasiadamente complexo para ser utilizado.

Segundo Tanenbaum e Steen (16), uma solução para este problema da especificidade dos sistemas middleware seria desenvolver diversas versões de um middleware cada uma projetada para uma classe específica de aplicação. Outra abordagem considerada é da desenvolver sistemas de middleware de forma que além de serem simples de configurar, sejam capazes de se adaptar e serem personalizados de acordo com as necessidades de uma dada aplicação.

Para cada configuração de arquitetura e paradigmas de comunicação adotados pelos middlewares, eles podem ser classificados em uma determinada categoria como, por exemplo, middleware orientado a objetos, middleware orientado a mensagens, middleware transacional, web services, entre outros. Cada categoria possui suas próprias características e conjunto de serviços disponibilizados, e são descritas em maiores detalhes tanto por Coulouris, Dollimore e Kindberg (8), quanto Costa (17). Emmerich, Aoyama e Sventek (9), apresentam os paradigmas de comunicação que foram surgindo ao longo da história, assim como o desenvolvimento do conceito de middleware e suas categorias. 


\subsection{TIPOS DE ARQUITETURAS}

Como mencionado anteriormente, uma das características que os middlewares possuem é o tipo de arquitetura adotado. O tipo de arquitetura influencia diretamente na maneira com que as unidades de um determinado sistema interagem e relacionam-se entre si. A seguir são apresentadas duas arquiteturas típicas na literatura e que são usadas de base em diversas aplicações: cliente-servidor e peer-to-peer $(p 2 p)$.

Cliente-Servidor: a arquitetura cliente-servidor é, historicamente, a mais importante e que ainda é uma das mais amplamente adotadas em diversas aplicações (Coulouris, Dollimore e Kindberg - (8)). Ela consiste basicamente de um processo cliente interagindo com um único processo servidor, possivelmente hospedado em uma máquina distinta, com a finalidade de obter acesso aos recursos gerenciados por ele. Por outro lado, processos servidores podem tornar-se clientes de outros processos servidores quando necessário. Na Fig. 2 é apresentada uma estrutura simples na qual os processos assumem o papel de cliente ou servidor ao interagirem com outros processos.

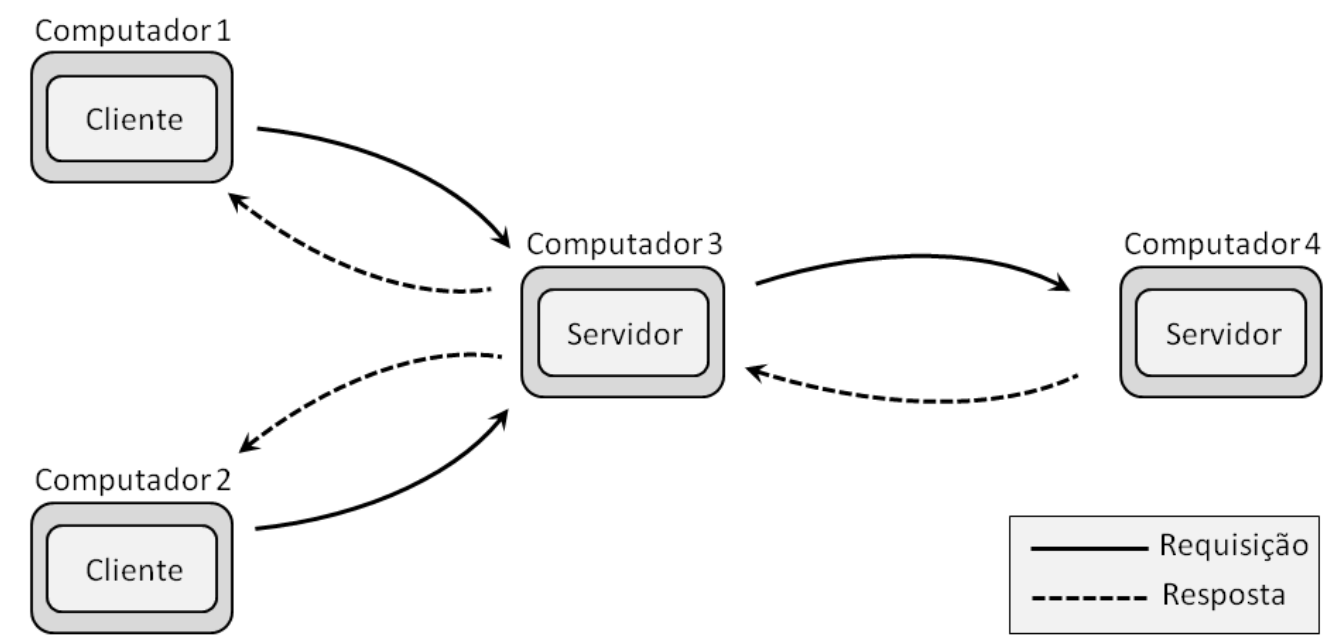

Figura 2 - Ilustração da arquitetura cliente-servidor.

Adaptado: (8)

Peer-to-peer (p2p): a arquitetura peer-to-peer é caracterizada pelo fato de que todos os processos possuem papéis similares no cumprimento de uma determinada tarefa ou atividade, trabalhando em pares e apresentando a mesma interface uns para com os outros (Coulouris, 
Dollimore e Kindberg - (8)). Isso permite distribuir o processamento necessário para executar dada atividade e utilizar mais eficientemente os recursos oferecidos por todos os dispositivos envolvidos, garantindo a escalabilidade do sistema. Esta abordagem é oposta à utilizada pela arquitetura cliente-servidor, onde grande parte do processamento feito é concentrada nos computadores dos processos servidores. Por outro lado, executar esta divisão de trabalho de forma eficiente requer maiores cuidados durante o desenvolvimento da aplicação, o que pode resultar em um aumento considerável na complexidade de um sistema baseado em $p 2 p$ com relação a um baseado na arquitetura cliente-servidor. Na Fig. 3 é ilustrada uma estrutura simples na qual a arquitetura peer-to-peer pode ser assumida, pois os processos atuam como pares e são indistintos entre si.

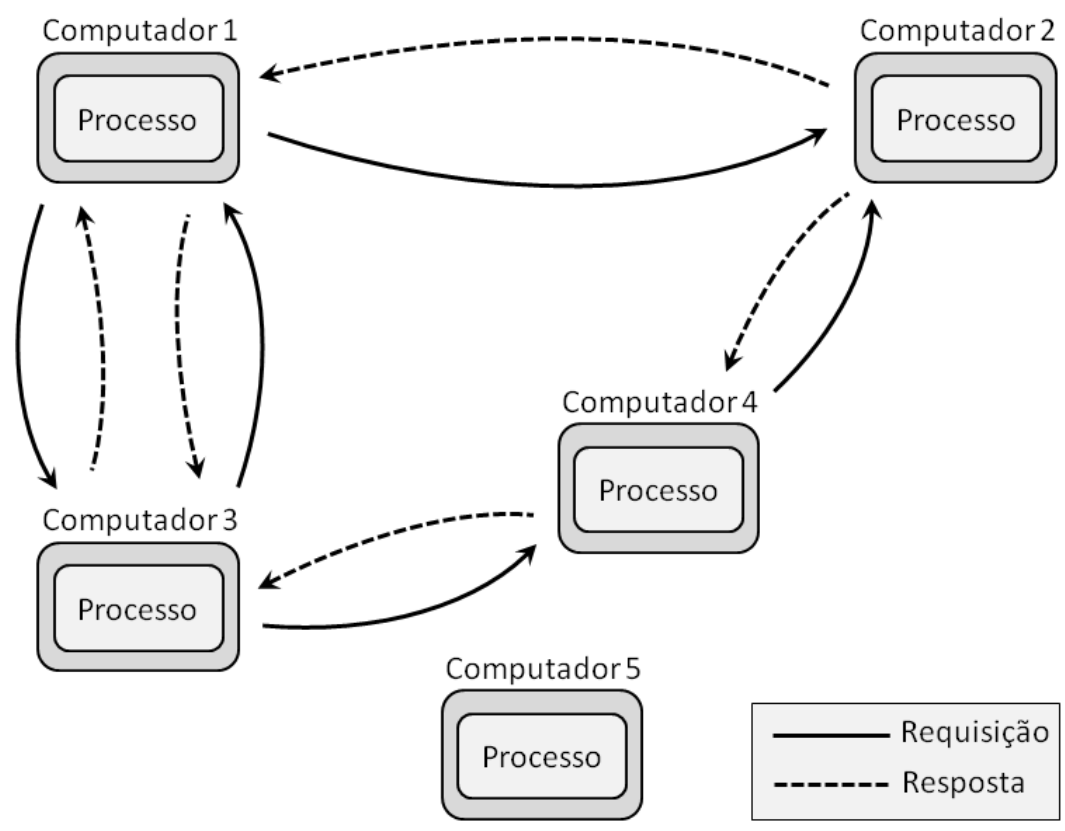

Figura 3 - Ilustração da arquitetura peer-to-peer.

Adaptado: (8)

Um ponto importante de ser mencionado é que o tipo de arquitetura é construído sobre uma topologia de rede, que em geral é classificada como uma rede estruturada ou não estruturada. Para o caso de uma rede estruturada, relacionada com a distribuição de nós na rede, o roteamento das mensagens trocadas e as funcionalidades de localização destes nós possuem uma política global preestabelecida. Entende-se por nó como um ponto de acesso para troca de informação com outros nós. Para as redes não estruturadas, a topologia da rede é reorganizada e criada à medida que o número de nós se modifica. Neste caso, a rede cresce em uma maneira denominada de ad hoc, na qual cada nó externo segue um conjunto de regras 
locais para se conectar a rede através de nós vizinhos. De forma geral, a principal diferença entre a rede estruturada e a não estruturada é que, para o caso da primeira, a infraestrutura da rede provida para um sistema não depende da distribuição de seus nós, enquanto que para o segundo caso, a infraestrutura da rede é dada de acordo com a distribuição dos nós.

Além destes tipos de arquitetura existem outros que não foram mencionados (superpares, arquiteturas híbridas, entre outros), e que, embora com abordagens diferentes, apresentam semelhanças com relação a estas duas arquiteturas apresentadas, podendo inclusive mesclar as propriedades de ambas, apresentando um caráter tanto centralizado quanto descentralizado.

Outra característica importante que os middlewares possuem, e que complementa o tipo de arquitetura no qual são baseados, é o paradigma de comunicação utilizado por eles. O paradigma de comunicação regra a maneira com que as unidades de um sistema interagem para alcançar seus objetivos. A seguir, são apresentados os paradigmas de comunicação comumente encontrados na literatura.

\subsection{PARADIGMAS DE COMUNICAÇÃO}

De acordo com Coulouris, Dollimore e Kindberg (8), boa parte dos paradigmas de comunicação pode ser dividida em três grupos: comunicação entre processos, invocação remota e comunicação indireta. Em um mesmo sistema mais de um paradigma de comunicação pode ser adotado.

\subsubsection{COMUNICAÇÃO ENTRE PROCESSOS}

O paradigma de comunicação entre processos consiste em prover suporte para a comunicação entre processos de um sistema distribuído ao oferecer mecanismos de troca de mensagens. Estes mecanismos estão relacionados em geral com a programação de baixo nível como, por exemplo, sockets (protocolos de internet). 
Como os mecanismos que permitem a troca de mensagens entre processos são essenciais em qualquer sistema distribuído, os middlewares costumam construir outros paradigmas de comunicação sobre os mecanismos presentes na comunicação entre processos (Fig. 4).

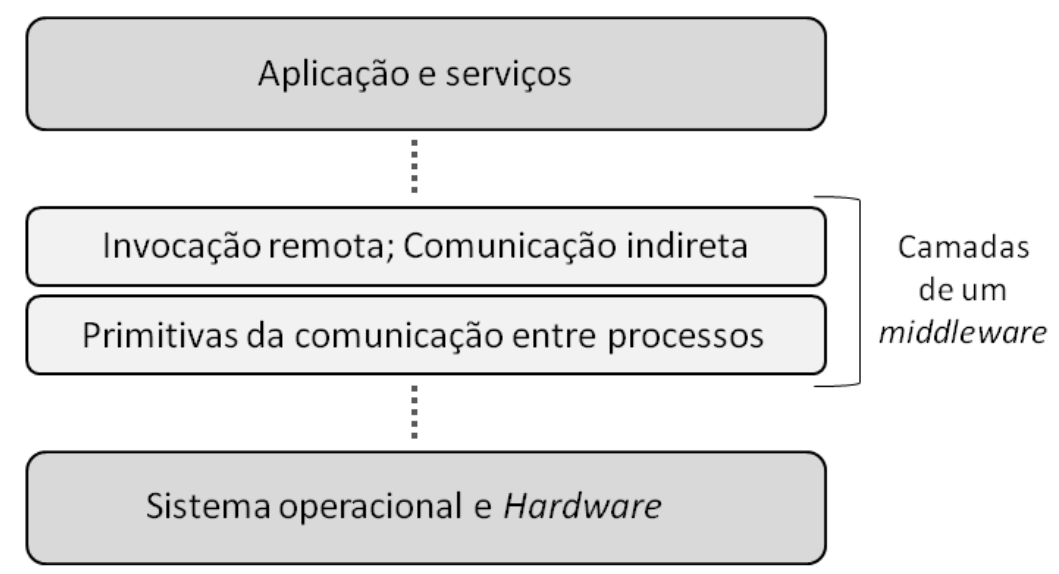

Figura 4 - Ilustração das camadas de um middleware com relação aos paradigmas de comunicação.

Adaptado: (8)

\subsubsection{INVOCAÇÃO REMOTA}

A invocação remota representa os paradigmas mais comuns utilizados pelas aplicações distribuídas. Ela consiste basicamente de técnicas que permitem um processo invocar remotamente uma operação, processo ou método de um objeto presente em outro processo.

Um dos paradigmas deste grupo é o conhecido como protocolo request-reply utilizado normalmente em arquiteturas cliente-servidor. Ele consiste em um processo cliente enviando uma mensagem para um processo servidor seguido do envio de uma mensagem de resposta do servidor para o cliente, contendo possivelmente o resultado de uma operação requisitada. Embora este paradigma seja relativamente primitivo, sua abordagem de troca de mensagens está presente em outros paradigmas populares que serão mencionados a seguir.

Um paradigma que teve grande influência na maneira de se desenvolver sistemas distribuídos foi o Remote Procedure Call (RPC). Este paradigma consiste em permitir que um processo invoque determinada rotina contida em um processo remoto como se esta rotina estivesse presente em seu espaço local. A implementação do RPC provê transparência ao 
usuário ao ocultar aspectos importantes da interação distribuída como, por exemplo, a passagem de mensagens, codificação e decodificação dos parâmetros e resultado associado à rotina, mantendo a mesma semântica de uma chamada de uma rotina local. Esta abordagem pode ser facilmente suportada por uma arquitetura cliente-servidor, onde processos servidores disponibilizam um conjunto de operações ou rotinas aos processos clientes, podendo então aliviar a carga de processamento dos clientes e distribuir melhor o papel das unidades do sistema.

A definição das operações que estarão disponíveis em determinado processo é feita por meio de uma interface, na qual também permite aos desenvolvedores definirem os parâmetros de entrada e saída destas operações. Para facilitar a implementação de um sistema utilizando RPC, as interfaces costumam ser realizadas por meio do que se chama de Interface Definition Language (IDL), oferecendo aos desenvolvedores um modelo de programação que simplifica a criação destas interfaces de acordo com a linguagem de programação utilizada.

Outro paradigma que ganhou grande popularidade nos últimos anos, e que se assemelha bastante com o RPC, é o Remote Method Invocation (RMI). A grande diferença entre o RPC e o RMI é que o RMI se situa no escopo de objetos distribuídos. Este paradigma consiste em permitir que objetos presentes em determinado processo possam invocar métodos contidos em objetos de outro processo, possivelmente remoto. Um objeto nada mais é do que um conjunto de dados (variáveis ou estruturas) e métodos (funções ou rotinas) associados a uma única entidade, e são utilizados no contexto de programação orientada a objetos (Objectoriented programming - OOP). A OOP é um paradigma de programação que possui forte apelo da percepção dos seres humanos com relação ao mundo real e, que por esta razão, ele oferece uma boa abordagem para o desenvolvimento de sistemas.

O RMI permite aos desenvolvedores de sistemas distribuídos se beneficiarem do poder expressivo e visão de projeto fornecidos pela OOP. Da mesma maneira que para o RPC, sistemas baseados em RMI costumam utilizar uma IDL para simplificar a definição dos métodos de objetos que serão disponibilizados para outros objetos possivelmente remotos.

Uma característica em comum dos paradigmas citados nesta seção é que estes são baseados em mecanismos de comunicação que envolvem sempre dois processos, um requisitante e outro recebedor e, para a maioria dos casos, ambos os processos devem existir ao mesmo tempo para que a comunicação ocorra. 


\subsubsection{COMUNICAÇÃO INDIRETA}

Diferentemente dos paradigmas citados, os paradigmas deste grupo consistem em permitir aos processos trocarem mensagens entre si de uma forma indireta, não necessitando que os processos saibam da existência uns dos outros. Os mecanismos de comunicação deste grupo envolvem uma terceira entidade na comunicação: um processo intermediário que permite um desacoplamento entre os processos requisitantes e recebedores, caracterizando a forma indireta da comunicação. Entre os paradigmas presentes neste grupo estão: comunicação em grupo, sistemas publish-subscribe, message queues e memória compartilhada distribuída, os quais são brevemente descritos a seguir.

O primeiro paradigma mencionado, comunicação em grupo, consiste em proporcionar mecanismos que permitam um processo entregar uma dada mensagem a um conjunto de processos pertencente a um grupo. Esse mecanismo permite a criação de grupos nos quais os processos podem se unir, e que quando um processo deseja transmitir uma mensagem, ele a transmite para um grupo desejado, não necessitando saber quais são os processos pertencentes ao mesmo.

O segundo paradigma, sistemas publish-subscribe, embora possua semelhança com o paradigma de comunicação em grupo, ele tem um foco maior na disseminação da informação entre os processos de um dado sistema. Sistemas publish-subscribe classificam os processos como produtores (publishers) de tópicos de informação, que são organizados e classificados em eventos, e processos consumidores (subscribers), que desejam saber da informação disponibilizada pelos produtores. São oferecidos mecanismos aos processos produtores para que estes possam criar e publicar seus eventos visíveis aos outros processos, da mesma maneira, são oferecidos mecanismos aos processos consumidores para que estes possam se inscrever a um conjunto de eventos relacionados com um tópico de seus interesses. Este mecanismo então é responsável por garantir que as mensagens geradas pelos produtores sejam encaminhadas para os consumidores que demonstraram interesse pela informação.

Message queues é um paradigma que, diferentemente dos outros dois paradigmas que oferecem uma comunicação de um para muitos, provê um serviço de passagem de mensagens de ponto a ponto utilizando o conceito de fileiras de mensagens para desacoplar a comunicação entre os processos remetentes e destinatários. Basicamente, o mecanismo consiste em permitir que processos enviem suas mensagens para uma fileira de mensagens. 
Esta fileira pode tanto repassar esta mensagem ou notificar a chegada de novas mensagens para outro determinado processo, uma vez que este esteja ativo. Embora seja uma comunicação ponto a ponto, este mecanismo pode necessitar de mais de um processo para realizar suas operações, sendo um processo remetente, um destinatário e outros possíveis processos que estejam encarregados pelas fileiras de mensagens.

Por último, o paradigma memória compartilhada distribuída consiste em oferecer mecanismos aos processos de um dado sistema para que estes, mesmo não compartilhando da mesma memória física, possam compartilhar estruturas de dados criadas a partir de comandos de escrita e leitura feitos como se estivessem em seu espaço local. Este paradigma consiste em um alto nível de transparência, ocultando suas operações dos processos e garantindo a consistência e a sincronização de acesso às estruturas de dados.

\subsection{CAMADAS MIDDLEWARE}

Segundo Schantz e Schmidt (7), com o crescimento da importância dada aos middlewares para o desenvolvimento de aplicações distribuídas, a implementação dos middlewares vêm crescendo em complexidade, deixando de abordar somente problemas relacionados à passagem de mensagens e de conectividade, mas também a oferecerem serviços que contribuam com a robustez e funcionalidade das aplicações. Desta forma, uma abordagem para simplificar o desenvolvimento de sistemas middleware é a de utilizar o desenvolvimento em camadas. Ao dividir um sistema middleware em camadas, cada camada fica responsável por implementar funcionalidades que lidam com determinados aspectos específicos da comunicação, interação entre os nós, serviços e interfaces disponíveis à aplicação.

Na Fig. 5 é apresentada uma estrutura de camadas endereçada por Schantz e Schmidt (7). Cada camada pode tanto ser um membro de um middleware que a engloba, quanto pode representar um middleware que proporciona serviços condizentes somente com aquela camada. 


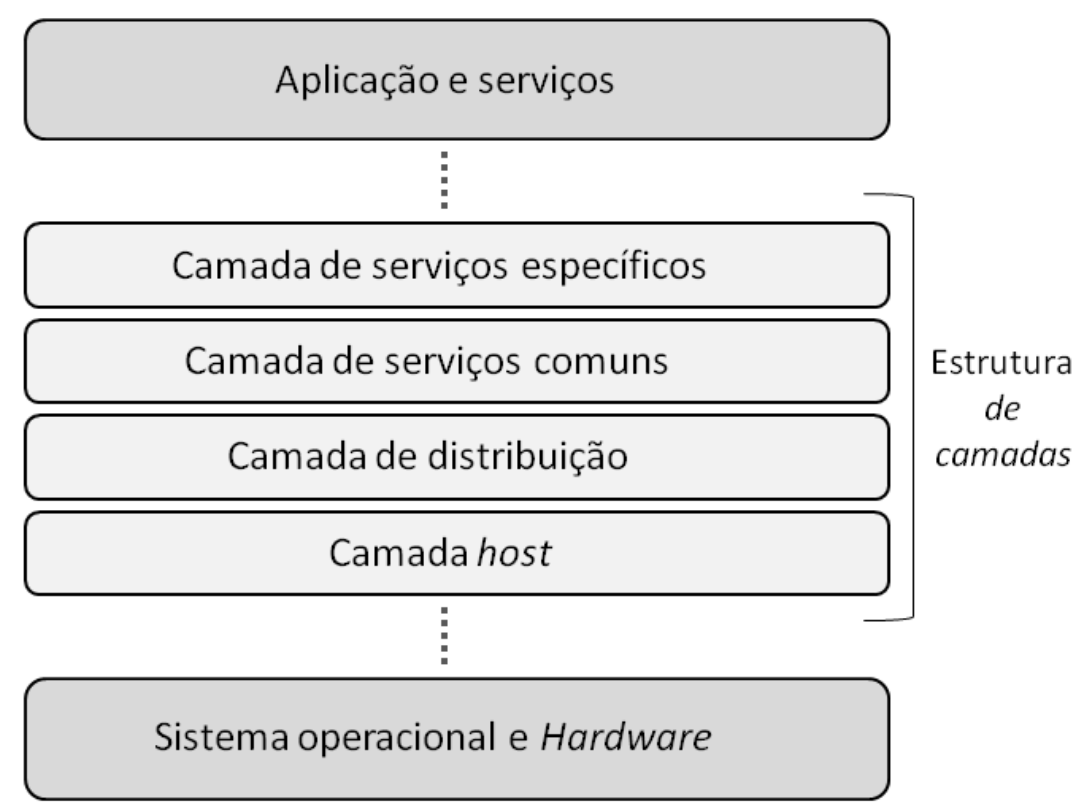

Figura 5 - Estrutura de camadas utilizada para endereçar os serviços proporcionados por um middleware.

Adaptado: (7)

Embora esta estrutura seja proposta no contexto de middleware orientado a objetos, os aspectos trados por cada camada podem ser facilmente mapeados para outras classes de middleware (e.g., orientados a mensagens ou serviços). Cada camada apresentada na estrutura é descrita a seguir.

Camada host: é a camada responsável por abstrair os mecanismos de comunicação e concorrência nativas do sistema operacional (OS). Ela lida com a programação de baixo nível utilizando as APIs (Application Programming Interface) disponibilizadas pelo OS, proporcionando ao sistema funcionalidades relacionadas com a troca, estrutura e monitoração de mensagens e o estabelecimento, manutenção e endereçamento de conexões.

A implementação dos mecanismos para a troca de mensagens e estabelecimento de conexões está diretamente relacionada com os protocolos de rede utilizados. Estes protocolos estabelecem todas as etapas envolvidas com a transmissão e recebimento de uma determinada mensagem de um processo a outro, controlando desde o empacotamento da mensagem em um aglomerado de bits, até o mapeamento destes bits em um sinal analógico gerado por um dispositivo para transmitir fisicamente a mensagem como, por exemplo, uma antena ou cabo.

Martins (18) apresenta uma descrição de diversos protocolos e tecnologias de rede encontrados na literatura e utilizados no ramo industrial, incluindo também uma descrição 
sobre o modelo de referência OSI (Open System Interconnection): uma proposta de relevância histórica para padronizar os protocolos de rede. Um dos protocolos de rede que ganhou grande relevância por sua adoção generalizada foi a internet, a qual se baseia em um conjunto de protocolos que podem ser organizados em camadas, de acordo com a Fig. 6, sendo os protocolos TCP (Transmission Control Protocol) ou UDP (User Datagram Protocol) na camada de transporte e o protocolo IP (Internet Protocol) na camada de rede. Somente estes protocolos não são suficientes para de fato transmitir as mensagens na rede e, portanto, é necessário o uso de outros protocolos relacionados com o meio físico da rede (camada de enlace) como, por exemplo, a Ethernet (Tanenbaum - (19)).

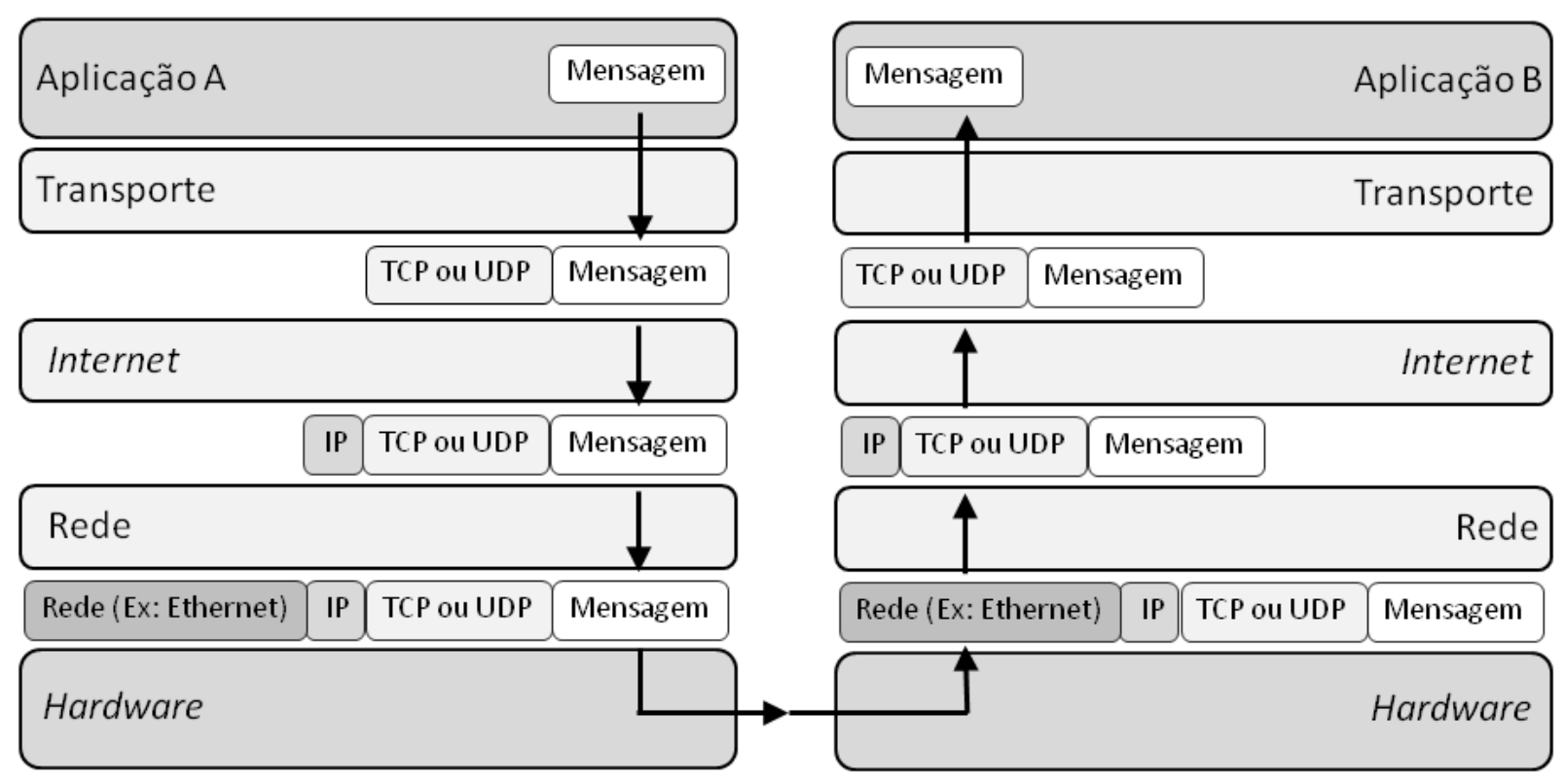

Figura 6 - Fluxo e construção das mensagens de acordo com a estrutura de camadas para os protocolos de internet, TCP e UDP.

Adaptado: (8)

Devido à natureza das aplicações distribuídas, que consistem da cooperação de múltiplos processos para o exercício de uma atividade, mecanismos que suportam programação concorrente são necessários para garantir a eficiência e flexibilidade destas aplicações. Da mesma forma, esses mecanismos são essenciais para os sistemas middleware proverem a flexibilidade e eficiência de suas operações, permitindo que determinado processo, ao mesmo tempo em que esteja executando suas operações, esteja monitorando e mantendo suas conexões com outros processos, atendendo ao recebimento de novas mensagens e executando outros possíveis serviços. 
O conceito de programação concorrente se baseia no fato de que um determinado processo pode estar associado a mais de uma rotina sendo executada simultaneamente para cumprir uma tarefa (Coulouris, Dollimore e Kindberg - (8)). E para garantir a coordenação entre estas rotinas, existem métodos de sincronização que são fundamentais para controlar, tanto a ordem de acesso à memória comum a rotinas, quanto assegurar a sincronia entre elas (20). Matloff (21) apresenta uma descrição e análise sobre a utilização de APIs para a implementação de mecanismos de concorrência.

Camada de distribuição: esta camada estende os serviços oferecidos pela camada inferior (camada host) para proporcionar ao sistema um modelo de programação distribuída de alto nível relacionado com a interação dos processos de uma aplicação. Para que um processo interaja com outro processo, requisitando serviços ou operações, é necessária a passagem de dados ou estruturas que estão normalmente relacionadas com, por exemplo, o OS e a linguagem de programação. Desta forma, esta camada está relacionada com a implementação de uma parte importante na maioria dos middlewares, o request broker. $\mathrm{O}$ request broker fornece as interfaces, e a IDL, se presente, que permitem os desenvolvedores implementar as interações entre os processos de forma transparente independentemente da heterogeneidade do sistema (i.e. localização dos processos, OS, linguagem de programação, protocolos de rede e hardware).

Camada de serviços comuns: utilizando-se das funcionalidades proporcionadas pelas camadas inferiores, esta camada propõe um conjunto de serviços de alto nível que são independentes do domínio da aplicação. Estes serviços estão relacionados com o gerenciamento (como alocação, agendamento e coordenação) dos recursos disponíveis pelo sistema distribuído, o que permite aos desenvolvedores se concentrarem mais na lógica intrínseca de suas aplicações do que na programação de mais baixo nível envolvendo a manipulação destes recursos. Como exemplo, estes serviços podem oferecer suporte com relação à segurança, conexão e interação com banco de dados, procura de recursos no sistema, comportamento de transações, notificação de eventos, logging, tolerância a falhas, controle de concorrência (programação concorrente), entre outros.

Camada de serviços específicos: como o próprio nome sugere, esta camada está relacionada com os serviços projetados de acordo com as necessidades de um domínio específicos de aplicações. Diferentemente dos serviços presentes na camada anterior, os quais 
suportam mecanismos que podem ser reutilizados por um leque abrangente de aplicações, os serviços desta camada incorporam o conhecimento de um determinado domínio (comércio eletrônico, área médica, computação, automação, entre outros) para melhorar consideravelmente a qualidade de serviço, desenvolvimento e custo de manutenção deste particular conjunto de aplicações. Segundo Schantz e Schmidt (7), para que esta camada atinja um maior nível de maturidade e para estabelecer um padrão para que os serviços se enquadrem nesta camada, é necessária uma regularização e definição adequadas dos serviços disponíveis nas camadas inferiores. Uma abordagem para esta regularização é vista nas especificações criadas pelo grupo OMG (Object Management Group) (22) para apontar serviços essenciais (camada de serviços comuns) que possam ser necessários aos desenvolvedores de aplicações distribuídas orientadas a objeto.

\subsection{MIDDLEWARES DE COMUNICAÇÃO}

A seguir são apresentados e descritos dois middlewares de comunicação baseados em objetos distribuídos que são comumente encontrados na literatura. Alguns mecanismos apresentados como, por exemplo, o serviço de nomeação e o uso de interfaces para a definição de serviços, foram utilizados como base para o desenvolvimento do middleware proposto neste trabalho.

Java RMI (12): é um middleware que estende o modelo de objetos da linguagem de programação Java para suportar o desenvolvimento de aplicações distribuídas baseadas em objetos distribuídos. Este middleware proporciona funcionalidades relacionadas com a camada de distribuição, e permite que objetos contidos em um determinado processo invoquem métodos de objetos remotos utilizando a mesma sintaxe de uma invocação local. Para que um objeto tenha acesso aos métodos de um objeto remoto, é necessário que ele conheça o que se chama de referência de objeto remoto do objeto de interesse. Esta referência pode ser encontrada em um servidor denominado de registry que armazena as referências de objetos remotos disponíveis. Por esta razão, para melhor visualização, um sistema baseado em Java RMI pode ser representado em uma arquitetura cliente-servidor durante uma determinada interação entre seus processos. Neste caso, processos servidores registram seus 
objetos remotos, onde remoto implica que o objeto estará disponível para que outros o invoquem, em um servidor registry, e então processos clientes procuram pelas referências de objetos de seu interesse. Esta estrutura é ilustrada na Fig. 7.

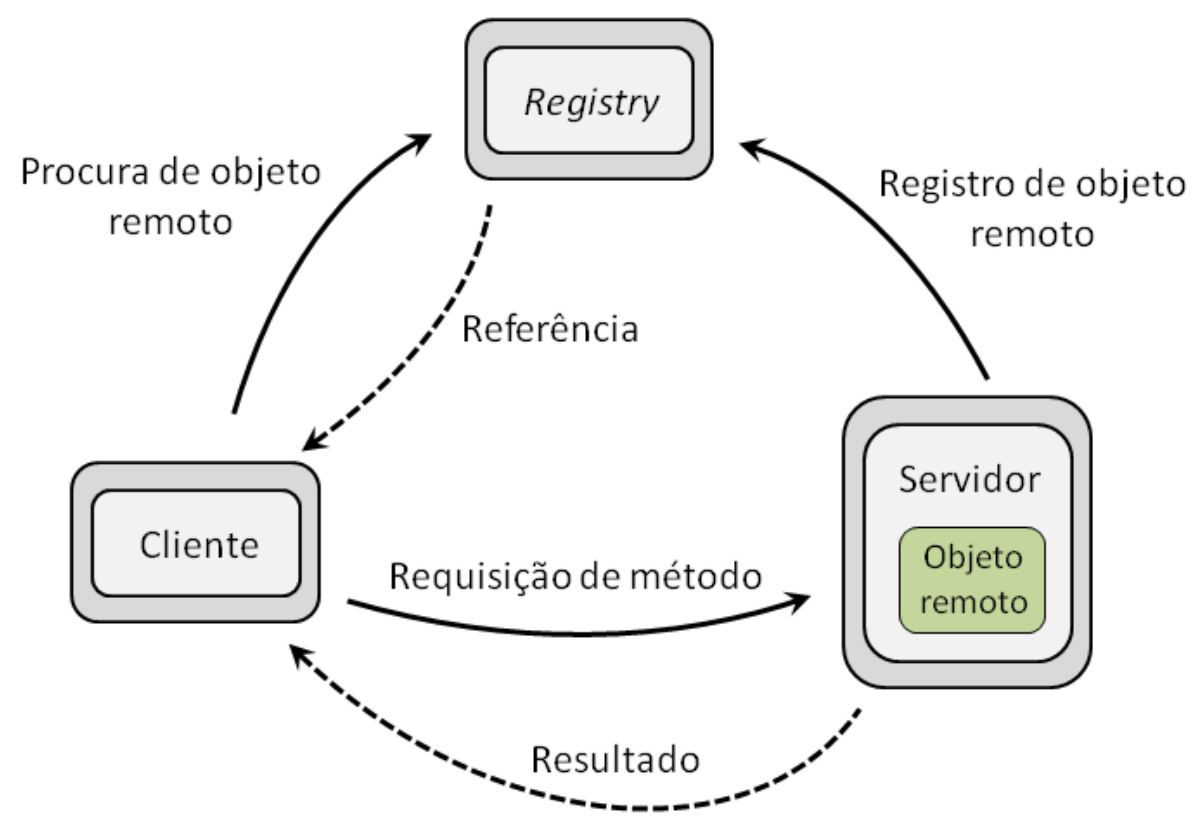

Figura 7 - Modelo de comunicação utilizado no Java RMI.

Adaptado: (17)

Durante a invocação de um método os parâmetros necessários para sua chamada passam por um processo chamado de marshalling, que consiste em converter estes argumentos em uma estrutura de dados que seja apropriada para o seu envio na rede. Ao alcançar o processo remoto desejado, a mensagem sofre o processo inverso denominado de unmarshalling, que consiste em retornar os parâmetros para sua estrutura de dados original. $\mathrm{O}$ resultado proveniente do método invocado passa pelo mesmo processo, mas nesta etapa a mensagem segue do processo remoto para o processo que iniciou a chamada.

O mecanismo utilizado pelo Java RMI permite que tanto os parâmetros de entrada destes métodos quanto seu resultado sejam passados como ou referências de outros objetos remotos, ou como cópia de um objeto, no qual inclui tanto suas estruturas de dados quanto seus métodos. Um fato importante de ser mencionado é que o Java RMI permite que um processo realize o download do código de uma classe, caso necessário, o que aumenta consideravelmente sua flexibilidade e rapidez para integrar novos serviços e funcionalidades em um sistema. Outro ponto importante para os sistemas baseados em Java RMI é que seus processos rodam no que se chama de máquina virtual Java (23). Segundo Schantz e Schmidt 
(7), ela é considerada como sendo um middleware que implementa as funcionalidades da camada Host para diversos OSs, permitindo que os processos sejam executados em diferentes plataformas.

O Java RMI também oferece aos desenvolvedores a liberdade de implementarem seus próprios canais de comunicação com as propriedades desejadas. Isso permite o desenvolvimento de um sistema baseado em Java RMI que possa suportar diversos ambientes de rede, como mostrado por Chen (24), que apresenta um estudo de caso para oferecer suporte do Java RMI sobre redes sem fio heterogêneas.

Common Object Request Broker Architecture (CORBA) (11): é uma especificação criada e mantida pelo grupo OMG de uma arquitetura middleware orientada a objetos. $\mathrm{O}$ OMG introduziu o conceito de Object Request Broker (ORB) que é o elemento principal de sua arquitetura. O ORB implementa as funcionalidades citadas na camada de distribuição e permite que processos presentes em um sistema heterogêneo possam interagir entre si de forma transparente. Essa interação consiste em um processo requisitando métodos de objetos contidos em outros processos. E, para tratar da questão da heterogeneidade do sistema, uma interface IDL é utilizada para a definição dos objetos usados na interação, oferecendo um modelo único aos desenvolvedores para diferentes linguagens de programação e OSs.

Para melhor visualização, um sistema utilizando a arquitetura proposta pelo OMG pode ser representado em uma estrutura cliente-servidor durante uma determinada interação entre seus processos. Nesta estrutura, processos clientes requisitam métodos de objetos remotos hospedados em processos servidores. Os elementos que constituem a arquitetura CORBA, assim como a representação de uma interação entre um processo cliente e um servidor, são ilustrados na Fig. 8. 


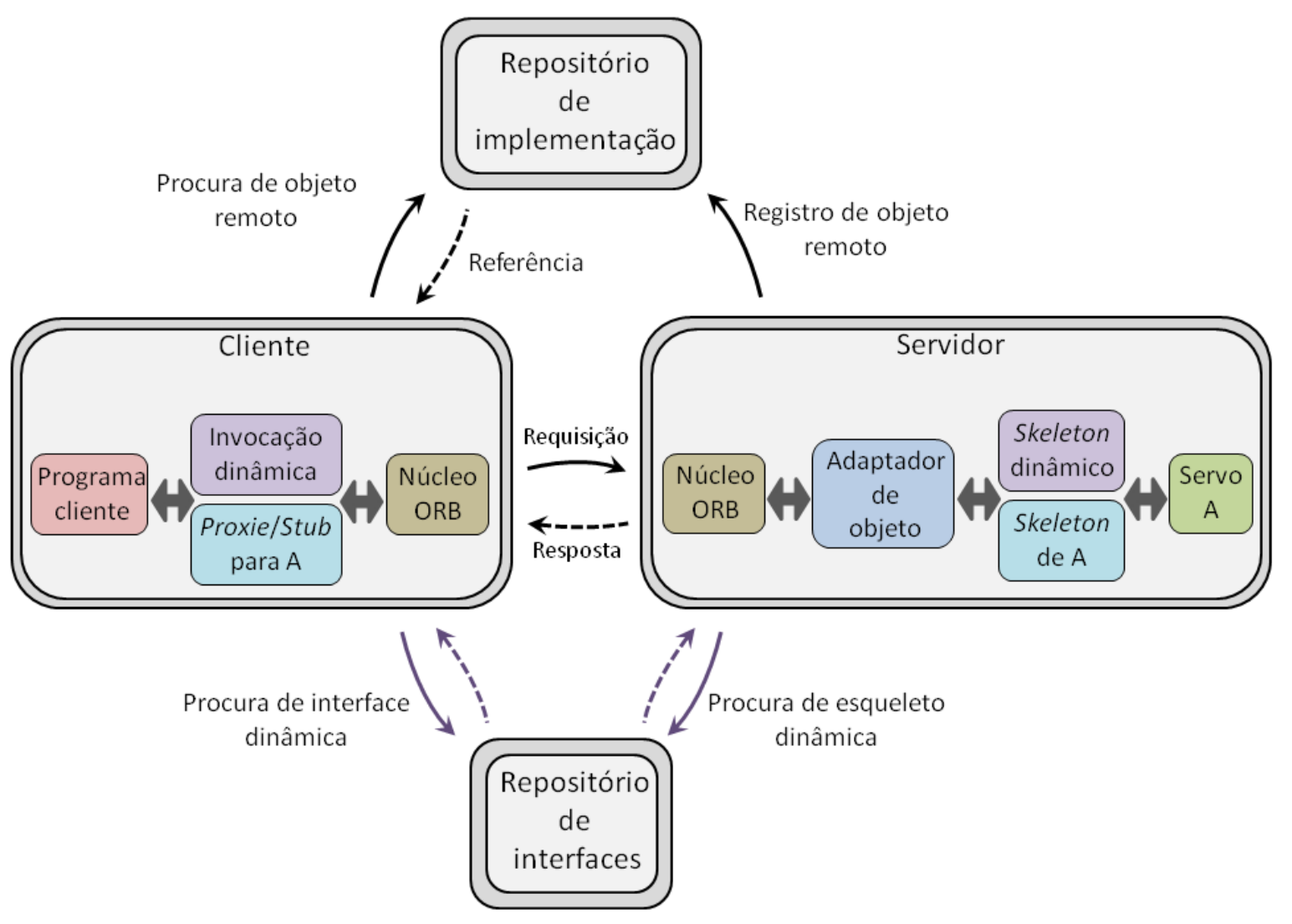

Figura 8 - Modelo de comunicação utilizado no CORBA.

Adaptado: (8)

A partir da definição de uma interface IDL para um determinado objeto, um compilador de IDL gera o que são chamados de proxie, ou stub, no lado do cliente, e o esqueleto no lado do servidor. O proxie, ou stub, é um código gerado na linguagem de programação do processo cliente que realiza tanto o marshalling de argumentos para uma mensagem de requisição, quanto o unmarshalling dos resultados ou exceções provenientes da requisição. Da mesma forma, o skeleton é o código gerado na linguagem de programação do processo servidor que realiza tanto unmarshalling dos argumentos de uma mensagem de requisição recebida, quanto o marshalling dos resultados ou exceções gerados para enviar a mensagem de resposta. Esse mecanismo implica que uma requisição de um método de um objeto poderá ocorrer somente se o cliente e o servidor possuírem, respectivamente, o proxie/stub e o esqueleto referentes ao objeto em questão. E então, para proporcionar maior flexibilidade ao sistema, os servidores e clientes podem utilizar o que são chamados de interface de invocação dinâmica, esqueleto dinâmico e repositório de interfaces. Na ausência do esqueleto ou proxie/stub de objeto específico para dar continuidade com uma requisição, o núcleo ORB pode procurar informações sobre o método desse objeto no repositório de 
interfaces e, a partir daí, a interface de invocação dinâmica ou esqueleto dinâmico são capazes de gerar as mensagens necessárias para a interação.

O adaptador de objeto, presente na Fig. 8, é o elemento responsável por, além de criar as referências de objetos remotos, que são usadas para endereçar o locar do objeto remoto, também por ativar e desativar o que são chamados de servos, instância de objetos que implementam os objetos remotos e seus métodos. Ao receber uma mensagem de requisição através do núcleo ORB, o adaptador de objeto repassa essa mensagem para o servo apropriado utilizando-se do esqueleto, ou esqueleto dinâmico, adequado.

Para que um cliente possa realizar uma requisição é necessário que ele possua a referência do objeto remoto desejado, podendo ser encontrada no que é chamado de repositório de implementação. Dependendo do tipo de referência de objeto remoto em posse do cliente, a requisição pode ser encaminhada diretamente ao processo servidor que possui o servo adequado para atender ao pedido, ou ser direcionada para o repositório de implementação. Neste segundo caso, o repositório procura em sua tabela de processos servidores registrados por um processo que possa atender a requisição. Encontrando um processo servidor adequado, ele envia um pedido a este processo para que ele ative um servo para atender ao pedido. Uma vez que o servo esteja ativo, o repositório envia de volta para o cliente o endereço do processo servidor para dar continuidade com a requisição.

Como mencionado anteriormente, na descrição da camada de serviços comuns, o CORBA também possui especificações para serviços de grande importância que podem facilitar consideravelmente o desenvolvimento de aplicações de objetos distribuídos. Dentre estes serviços estão, por exemplo, o serviço de nomeação, notificação de eventos (publish/subscribe), controle de concorrência, transação, entre outros.

Vale lembrar que o CORBA é apenas uma especificação, e que a sua implementação, chamada de ORB, é feita e disponibilizada por terceiros. Um exemplo de implementação CORBA que vem sendo utilizada em diversas aplicações é o projeto de código aberto TAO (The ACE ORB) (25). TAO utiliza as funcionalidades proporcionadas pelo framework ACE (Adaptive Communication Environment), que são relacionadas com a camada host, e oferece serviços aos desenvolvedores de aplicações distribuídas para gerenciar recursos como processamento, memória e comunicação. 


\subsection{TRABALHOS RELACIONADOS}

Como mencionado, a arquitetura de comunicação adotada tem grande influência sobre o desempenho de uma aplicação distribuída, podendo inclusive ser um fator limitante na implementação de novas funcionalidades para o sistema. A seguir, são apresentadas algumas abordagem de arquiteturas de comunicação utilizadas em trabalhos relacionados com a área de robótica.

López (26) propõe um framework, chamado RIDE (Robotic Integrated Development Environment), para o desenvolvimento de aplicações robóticas baseado na criação e interação de módulos (representados por processos) para prover as funcionalidades básicas do sistema. Para permitir a comunicação e interação entre estes módulos, o framework proposto utiliza dois mecanismos de comunicação que se baseiam no paradigma de sistemas publishsubscribe. O primeiro mecanismo, implementado por meio de um pacote de IPC (InterProcess Communication) desenvolvido pelo Instituto de Robótica Carnegie Mellon (27), permite a interação entre módulos envolvidos em uma única unidade robótica (i.e., módulos que envolvem os sensores, atuadores e tomada de decisão de um robô). O segundo mecanismo, implementado por meio da biblioteca Java Inter-Process Communication (JIPC), permite a interação entre os diversos módulos que constituem o sistema (i.e., um servidor central, robôs, interfaces gráficas, dispositivos externos, entre outros). Embora estes mecanismos de comunicação permitam a disseminação da informação no sistema de forma rápida e eficiente, eles apresentam algumas dificuldades quando se faz necessária a passagem direta de informação entre dois módulos em particular.

Witkowski (6) propõem uma arquitetura de comunicação $p 2 p$ não estruturada para um sistema robótico projetado para auxiliar em operações de resgate e procura em acidentes. Devido à incerteza das condições do ambiente do acidente, os robôs deste sistema, além de realizarem um reconhecimento do local, são responsáveis por estabelecer uma infraestrutura de rede dinâmica (ad hoc) para a comunicação no local. Cada robô representa um nó nesta rede e possui a infraestrutura adequada para se comunicar com os outros robôs. Nesse trabalho são apontados alguns serviços importantes para esse sistema de comunicação, como um serviço de descobrimento para a procura de recursos na rede e um serviço de roteamento de mensagens para otimizar o fluxo de informações. 
Vail (2) apresenta técnicas adotadas em um time robótico de futebol para melhor atribuir os papéis e tarefas às unidades durante o jogo, mostrando que a melhora da coordenação, embora não obtendo melhor desempenho, pode melhorar a resistência a falhas do sistema. Nesse trabalho, a comunicação utilizada para troca de informações consistia em um mecanismo de broadcast. Cada unidade gera e envia uma mensagem a todas as outras unidades com uma frequência determinada. Este mecanismo, embora suficiente para o cenário apresentado no trabalho, pode não se tornar viável com aumento no número de unidades do sistema, onde o número excessivo de mensagens geradas pode reduzir consideravelmente o desempenho da comunicação.

Suri (5) discute a importância para as aplicações distribuídas, o desenvolvimento e melhorias das interfaces oferecidas entre as camadas de aplicação e a comunicação, as quais podem ser implementadas por meio de um middleware. Embora o trabalho se contextualize em redes ambientadas em cenários de combate, as discussões apresentadas podem refletir também no desenvolvimento de aplicações distribuídas em outros contextos. $\mathrm{O}$ autor cita algumas funcionalidades importantes que um middleware de comunicação pode oferecer aos desenvolvedores, como: acesso ao estado das condições dos canais de comunicação, o que possibilita a adaptação da aplicação quanto ao uso destes canais para melhor utilização; possibilidade do uso de mais de um protocolo de comunicação em conjunto com o protocolo de rede, permitindo que o desenvolvedor tenha a flexibilidade para utilizar o formato de mensagem e mecanismo para a troca destas mensagens que mais se adequam; gerenciamento de recursos para priorização de um possível canal de comunicação de mais alta prioridade. Essas funcionalidades são absorvidas pelo middleware voltado para redes táticas denominado Mockets, proposto pelo autor.

Tavares (28) propõe uma interface implementada por meio da programação de sockets, baseada nos protocolos TCP/IP, para utilizar juntamente com o componente TinyWebDB proporcionado pelo MIT App inventor. O trabalho consiste em um robô construído utilizandose a plataforma disponibilizada no LEGO MINDSTORMS NXT kit, que permite a comunicação por meio de uma rede Bluetooth. O robô estabelece uma conexão com um celular, no qual possui uma aplicação desenvolvida utilizando-se o MIT App inventor, que por sua vez se conecta com um computador por meio de uma rede Wi-Fi. Para permitir o uso do componente TinyWebDB, que permite o compartilhamento de uma base dados (localizada em um servidor web) entre aplicativos, o trabalho propõe a interface (funcionalidades relacionadas com a camada host) que utiliza um protocolo de comunicação específico que é compatível com este componente. 


\subsubsection{FRAMEWORKS PARA APLICAÇÕES ROBÓTICAS}

Quando se trata de desenvolvimento de aplicações robóticas, o uso de um framework para tal tarefa torna-se uma abordagem bastante interessante. Um framework é uma tecnologia que oferece ferramentas para o desenvolvimento e reutilização de códigos (software) que proporcionam funcionalidades básicas para as aplicações de seu foco. Frameworks voltados para as aplicações robóticas, além de poderem disponibilizar algoritmos voltados para problemas específicos da área de robótica (i.e. desvio e detecção de obstáculos, controle, planejamento de trajetória, processamento de imagem, entre outros) costumam disponibilizar outros recursos e serviços como: drivers para o acesso de recursos de dispositivos; interfaces gráficas para visualização e simulação de aplicações; arquitetura de comunicação para oferecer suporte à interação entre processos. Iñigo-Blasco (29) apresenta uma discussão sobre diversos frameworks open source que têm surgido na literatura, fazendo uma análise sobre quais características um framework robótico deve possuir para atender adequadamente o desenvolvimento de sistemas multiagentes. A seguir, são apresentados alguns destes frameworks, dando-se um enfoque maior à arquitetura de comunicação disponibilizada por eles.

ROS (Robot Operating System) (13): de acordo com Iñigo-Blasco (29), este framework robótico é um dos mais completos e que possui grande contribuição da comunidade que o utiliza. Uma característica importante do ROS é que além de permitir a criação e interação de nós na execução de uma aplicação, ele também oferece um conjunto de serviços que podem ter um papel importante nas aplicações robóticas (drivers e algoritmos para resolver problemas específicos de aplicações robóticas). Cada nó criado representa um processo que desempenha um papel específico em uma dada aplicação. Os mecanismos de comunicação oferecidos pelo ROS permitem que os nós interajam tanto por meio de um sistema publish/subscribe, permitindo a disseminação de dados e informação de forma eficiente, quanto por meio de um mecanismo baseado em invocação remota, que permite que um nó invoque determinado serviço de outro. Ao invocar um serviço, um nó pode tanto enviar parâmetros junto da chamada, quanto receber o resultado desta invocação. Por não possuir um sistema de descobrimento, os nós precisam estar conectados a um nó mestre. Este nó mestre proporciona serviços de nomeação e procura (camada de serviços comuns) que, além de permitir a identificação de um nó para com o outro, realiza a localização e 
caracterização dos serviços disponibilizados por estes nós. Os mecanismos de comunicação do ROS são implementados sobre os protocolos TCP/IP (camada host) e utilizam um padrão próprio de formato de mensagens.

Outro ponto importante é que o ROS permite a passagem de um arquivo no formato XML (eXtensible Markup Language), que descreve um determinado sistema robótico, ao nó mestre. Tendo posse deste arquivo, o nó mestre se responsabiliza por criar e organizar os nós necessários para iniciar este sistema. O ROS também oferece uma IDL (camada de distribuição) para permitir que a aplicação seja desenvolvida em diversas linguagens de programação.

YARP (Yet Another Robot Platform) (14): este framework foi inicialmente proposto desenvolvido tendo como alvo o desenvolvimento de sistemas robóticos humanoides. Ele é constituído de uma biblioteca implementada em C++ que permite sua fácil adoção em um determinado sistema ao simplesmente instanciar classes apropriadas no código da aplicação. Ao utilizar as funcionalidades proporcionadas pelo framework ACE (camada host), ele oferece mecanismos de comunicação baseados em protocolos de internet (TCP e UDP), compartilhamento de memória (utilizado para conexões locais) e QNet (OS de tempo real QNX) para permitir seu uso em diversos sistemas operacionais. O mecanismo de comunicação se baseia em um conceito de portas (comunicação indireta), onde um processo pode criar portas associadas a uma determinada estrutura de dados, tanto para a entrada quanto para a saída. Cada porta, seja ela de entrada ou saída, é registrada em um processo servidor que permite o gerenciamento das conexões e roteamento das mensagens. Um processo contendo uma porta pode requisitar ao servidor para estabelecer uma conexão com outra porta, desde que seja uma conexão entre uma porta de saída com outra de entrada. Desta forma, a passagem de dados no sistema pode ser facilmente implementada uma vez que cada porta de saída pode estar conectada a diversas outras portas de entrada.

YARP também oferece funcionalidades para o trabalho com imagens, seja permitindo algumas operações sobre elas, como a manipulação de pixels, ou suportando sua transmissão pelas portas de comunicação. 


\subsection{TESTES UTILIZADOS NA ÁREA DE REDES PARA AVALIAR O DESEMPENHO DE ARQUITETURAS DE COMUNICAÇÃO}

A seguir, são descritos alguns testes comumente utilizados na área de redes para avaliar o desempenho de arquiteturas de comunicação. Estes testes são utilizados para avaliar o middleware proposto neste trabalho e, por questão de organização, são apresentados neste capítulo.

Disponibilidade: no contexto de um serviço, é a probabilidade de que um serviço estará operacional em uma requisição feita durante o período em que este serviço esteja ativo. Para exemplificação, para um conjunto de ' $n$ ' requisições feitas a determinado serviço, se metade destas requisições não forem executadas corretamente, então este serviço possui uma disponibilidade de $50 \%$, ou 0,5 .

Perda de pacotes: no contexto de redes, em um mecanismo que permite a troca de mensagens entre dois nós, o teste de perda de pacotes indica a probabilidade de que um pacote com determinado tamanho se perca ao ser enviado de um nó ao outro. Também para exemplificação, para um conjunto de ' $n$ ' pacotes de dados enviados de um nó ao outro, se metade destes pacotes não chegam ao seu destino final, então pode-se dizer que o sistema possui uma perda de pacotes de $50 \%$, ou 0,5 , para este cenário.

Tempo de resposta (RTT - Round Trip Time): no contexto de redes, para um mecanismo que permite a troca de mensagens, o tempo de resposta entre dois nós na rede, ou RTT, é definido como o tempo necessário para que um pacote de determinado tamanho seja enviado de um nó ao outro e em seguida, ao ser recebido pelo segundo nó, seja retornado ao seu nó de origem. Na Fig. 9 é ilustrado o tempo de resposta medido referente a um par de nós A e B. 


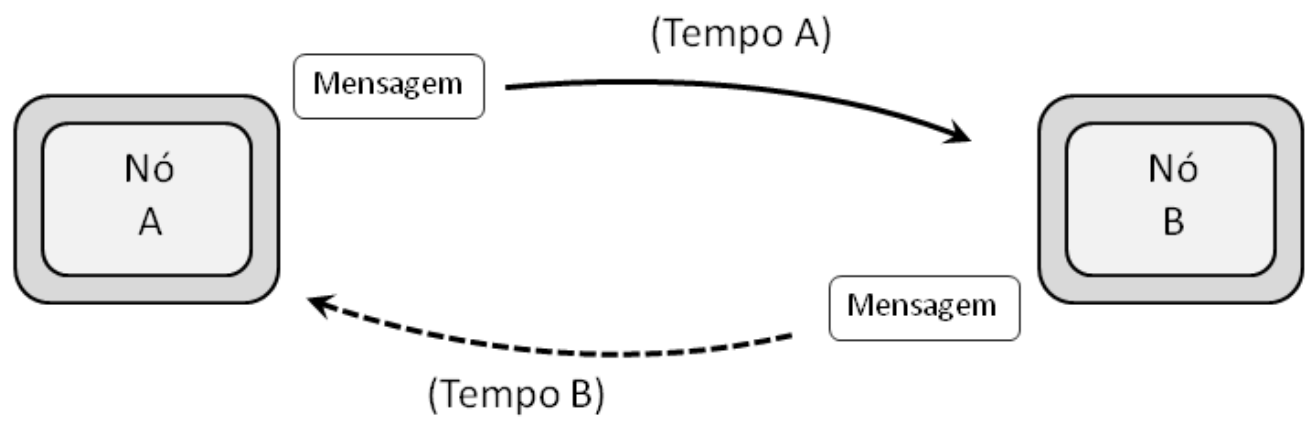

RTT = Tempo A + Tempo B

Figura 9 - Representação do teste de tempo de resposta (RTT).

Delay: é um teste semelhante ao RTT, mas com uma diferença sutil: o delay mede o tempo necessário para que um pacote de determinado tamanho saia de um nó e chegue ao outro. Desta forma, o delay pode ser aproximado como sendo metade do valor medido para o tempo de resposta para um determinado par de nós. Na Fig. 9 é ilustrado o delay medido referente a um par de nós A e B.

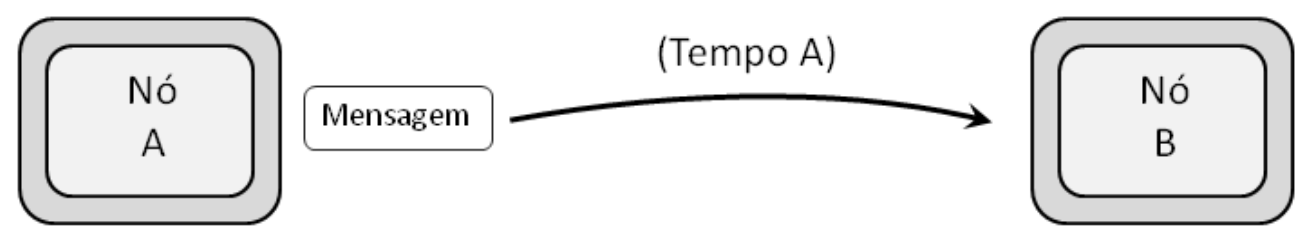

$$
\text { Delay }=\text { Tempo A }
$$

Figura 10- Representação do teste de delay.

Throughput (taxa de transferência): no contexto de redes em um mecanismo que permite a troca de mensagens entre dois nós, este teste fornece a quantidade de dados que podem ser passadas de um nó ao outro em um determinado período de tempo. 


\subsection{CONSIDERAÇÕES FINAIS}

Como descrito neste capítulo, o uso de um middleware no desenvolvimento de uma aplicação distribuída pode proporcionar diversas vantagens aos desenvolvedores, simplificando consideravelmente o processo de implementação e manutenção do sistema. Ao escolher um middleware adequado para domínio da aplicação, ele permite que os desenvolvedores se envolvam somente com a produção de códigos relacionados com a lógica intrínseca da aplicação, ocultando os detalhes das operações que lidam com a heterogeneidade do sistema.

Como mencionado no capítulo, a utilização de uma abordagem de objetos distribuídos oferece uma visão de projeto perceptível ao desenvolvedor, o que pode facilitar o desenvolvimento da aplicação ao permitir o uso do poder expressivo da programação orientada a objeto. Para o caso de aplicações robóticas distribuídas, pode-se notar que a arquitetura $p 2 p$ destaca-se em relação à arquitetura cliente-servidor com base nas relações possíveis entre os processos de uma aplicação. Como observado nos trabalhos de López e Vail, e nos frameworks robóticos ROS e YARP, percebe-se que há uma maior presença dos mecanismos baseados nos paradigmas de comunicação indireta. Embora estes mecanismos permitam a rápida disseminação da informação entre as unidades do sistema, ela dificulta o conhecimento individual entre seus processos, necessitando de um processo servidor adicional para realizar esta tarefa. Outro aspecto interessante notado no framework YARP é sua proposta de fácil adoção por instanciar classes adequadas provenientes da biblioteca que o constitui.

Baseando-se nos conceitos mencionados neste capítulo e nos mecanismos dos middlewares de comunicação apresentados, este trabalho propõe o desenvolvimento de uma arquitetura de comunicação baseada em middleware que oferece funcionalidades para simplificar a implementação da interação entre as unidades de um sistema robótico. A arquitetura de comunicação proposta foi desenvolvida baseando-se no paradigma de comunicação RMI, oferecendo suporte para o conceito de objetos distribuídos. Para tornar esta arquitetura uma ferramenta abrangente e útil no desenvolvimento de aplicações futuras, ela foi projetada com uma interface suficientemente genérica para permitir o acréscimo de novos serviços e funcionalidades de comunicação específicas, de acordo com as necessidades da aplicação. O capítulo a seguir apresenta a arquitetura do middleware proposto. 


\section{ARQUITETURA DE COMUNICAÇÃO PROPOSTA}

Este capítulo descreve a arquitetura de comunicação proposta e apresenta a abordagem de desenvolvimento adotada. Cada estrutura que compõe a arquitetura, assim como seus mecanismos que permitem a interação entre os processos de uma aplicação, são descritos em detalhe.

\subsection{ARQUITETURA}

A arquitetura de comunicação foi desenvolvida na mesma linguagem de programação e plataforma do projeto de AGVs mencionado no capítulo 1, sendo a C++ e Linux, respectivamente. A arquitetura foi projetada baseando-se nos conceitos de middlewares de comunicação que foram apresentados no capítulo anterior. Para poder usufruir do poder expressivo da linguagem de programação orientada a objetos, que é suportada naturalmente pela linguagem de programação $\mathrm{C}++$, o sistema de comunicação foi construído inspirando-se nos mecanismos baseados em RMI, suportando então o conceito de objetos distribuídos. Outro motivo que levou a escolha de um paradigma baseado em invocação remota em vez de, por exemplo, um paradigma baseado em comunicação indireta, foi porque os paradigmas de invocação remota não necessitam de um terceiro processo como, um processo servidor, para mediar a comunicação. Além disto, como a maioria das trocas de informações entre os processos do projeto AGVS era feita entre dois processos de cada vez, o paradigma de invocação remota era adequado ao sistema.

Durante seu desenvolvimento, a arquitetura passou por diversas modificações com relação ao seu funcionamento. A primeira abordagem implementada consistia em uma arquitetura específica para o projeto de AGVs. As funções ou métodos disponibilizados entre os processos, assim como o formato das mensagens para cada requisição eram definidos juntamente com o código da arquitetura. Esta primeira abordagem foi publicada no congresso 
Flexible Automation and Intelligent Manufacturing em 2013 (30). Um diagrama de classes parcial é apresentado na Fig. 11.

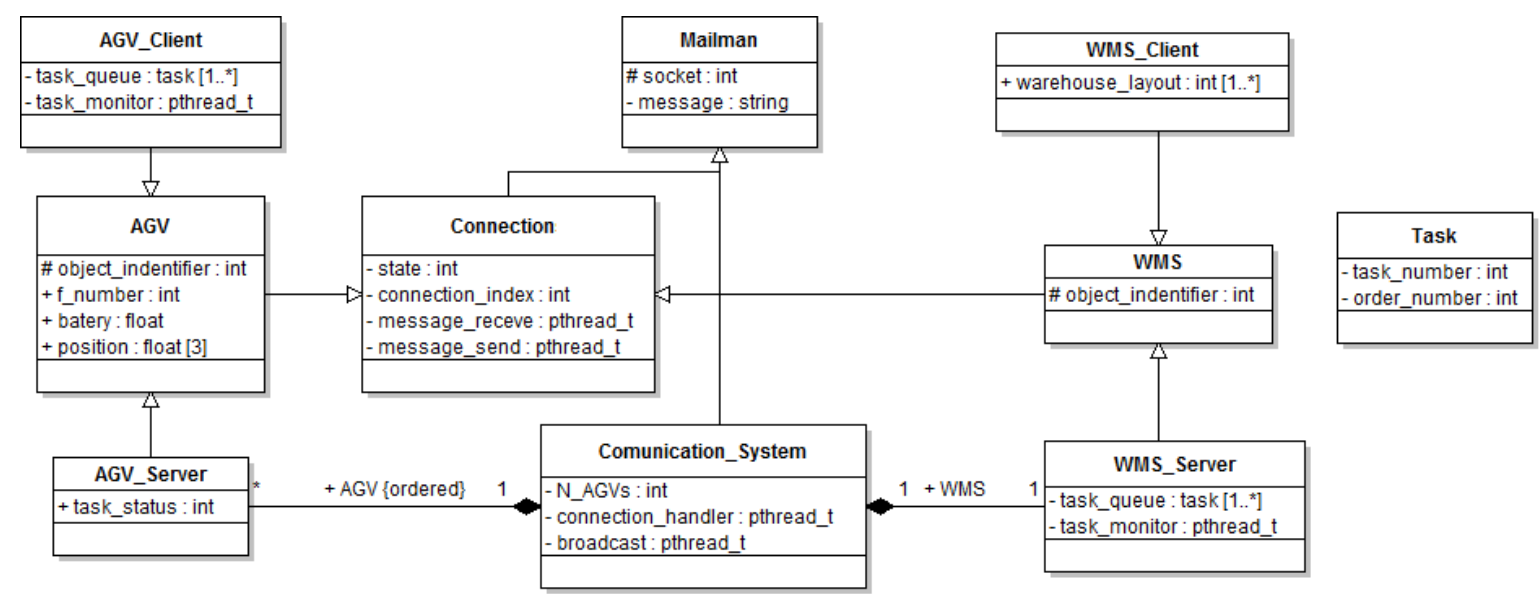

Figura 11- Camadas e diagrama de classe parcial da arquitetura proposta.

Fonte: (30)

Nesta primeira abordagem da arquitetura, as classes Mailman e Connection implementavam as funcionalidades básicas de comunicação, relacionadas com a camada host, para permitir a troca de mensagens entre os processos do sistema. Para cada tipo de unidade, eram necessárias as definições de uma classe cliente e outra servidor que implementavam as funções desejadas e seus respectivos formatos de mensagem para suas requisições. Os objetos das classes do tipo servidor (WMS_Server e $A G V \_S e r v e r$ ) eram utilizadas pela classe Communication_System para que este pudesse interagir com os objetos das classes do tipo cliente (WMS_Client e $A G V_{-}$Client). Sendo assim, a comunicação proporcionada se baseava em objetos das classes clientes se comunicando com um objeto da classe Communication_System. Esta primeira abordagem se assemelhava com a arquitetura proporcionada pelo ROS, onde os objetos da classe Communication_System podem ser vistos como os nós mestres presentes no ROS.

Embora esta primeira versão da arquitetura preenchesse a necessidade de comunicação do projeto AGVS, ela apresentava dificuldades caso fossem necessários adicionar novos tipos de unidades ou modificar as funções das unidades já implementadas. Estas dificuldades surgiam porque as modificações deveriam ser feitas diretamente no código que definia a arquitetura e, portanto, era necessário ter um conhecimento de como a arquitetura estava 
implementada. Ao buscar por soluções para estas dificuldades, foi notado que com algumas alterações a arquitetura em desenvolvimento poderia ser aplicada não somente ao projeto AGVS, mas também em outras aplicações com necessidades de comunicação semelhantes.

Com algumas modificações e o melhoramento dos serviços existentes na primeira versão da arquitetura como, os serviços de descobrimento e nomeação, e ao proporcionar uma IDL para a definição dos serviços utilizados pelas aplicações, esta nova abordagem da arquitetura adquiriu a flexibilidade necessária para atender a comunicação de outras aplicações, além do projeto AGVS. Em sua versão final, o middleware proposto foi planejado para oferecer os serviços fundamentais para implementar a interação entre os processos do sistema, oferecendo mecanismos para a construção de serviços mais específicos sobre as funcionalidades existentes. Ao utilizar o conceito de template, oferecido pela linguagem de programação $\mathrm{C}++$, estes novos serviços podem ser definidos em uma nova classe separada das classes que implementam as funcionalidades básicas do middleware, reduzindo o custo de manutenção. Desta forma, os desenvolvedores podem fazer a escolha das classes de acordo com os serviços necessários para a aplicação.

Para evitar o uso obrigatório de um processo servidor, como observado em alguns middlewares de comunicação e frameworks robóticos, o middleware proposto oferece serviços de descobrimento e nomeação (camada de serviços comuns) que permitem a procura e identificação de um processo para com os outros. Assim como no framework YARP, o middleware proposto neste trabalho também é implementado e oferecido por meio de uma biblioteca para facilitar sua adoção em uma determinada aplicação.

As estruturas presentes na arquitetura de comunicação em sua versão final são organizadas de acordo com suas funcionalidades oferecidas, seguindo a estrutura de camadas apresentada no capítulo anterior. Na Fig. 11 é apresentado um diagrama das classes principais que constituem a arquitetura proposta.

Nesta versão final, as classes Mailman e Connection, presentes na primeira abordagem, foram reutilizadas para prover as necessidades básicas de comunicação. A IDL introduzida é implementada pelas classes Parameters, Function e Function_list, sendo que, de forma geral, os objetos da classe Function_list são responsáveis por armazenar e gerenciar os serviços utilizados pelas aplicações. Os objetos da classe Unit, filha da classe Connection, permitem o estabelecimento de uma conexão com outro objeto também da classe Unit, possuindo, em geral, dois objetos da classe Function_list: um para armazenar seus próprios serviços, e outro para armazenar os serviços do outro objeto da classe Unit conectado. Os objetos da classe Communication_System, filha da classe Connection_handler, contém 
diversos objetos da classe Unit, os quais são gerenciados para permitir o estabelecimento de conexões, tanto com outros objetos da classe Unit, quanto da classe Communication_System. Os objetos da classe Unit contidos em um objeto da classe Communication_System, também possuem dois objetos da classe Function_list, sendo que a diferença é que o objeto referente aos seus próprios serviços aponta para o objeto da classe Function_list que está contido no objeto da classe Communication_System, o qual aponta para os próprios serviços deste objeto.

Desta forma, a comunicação proporcionada por esta versão final se baseia em objetos das classes Unit e Communication_System interagindo entre si. Esta configuração pode ser comparada a arquitetura ROS em um cenário onde diversos nós mestres estivessem interagindo entre si. Esta nova versão será publicada no congresso Flexible Automation and Intelligent Manufacturing de 2014 (31). A descrição dos mecanismos presentes em cada camada, assim como as classes que os implementam, são descritos nos tópicos a seguir.

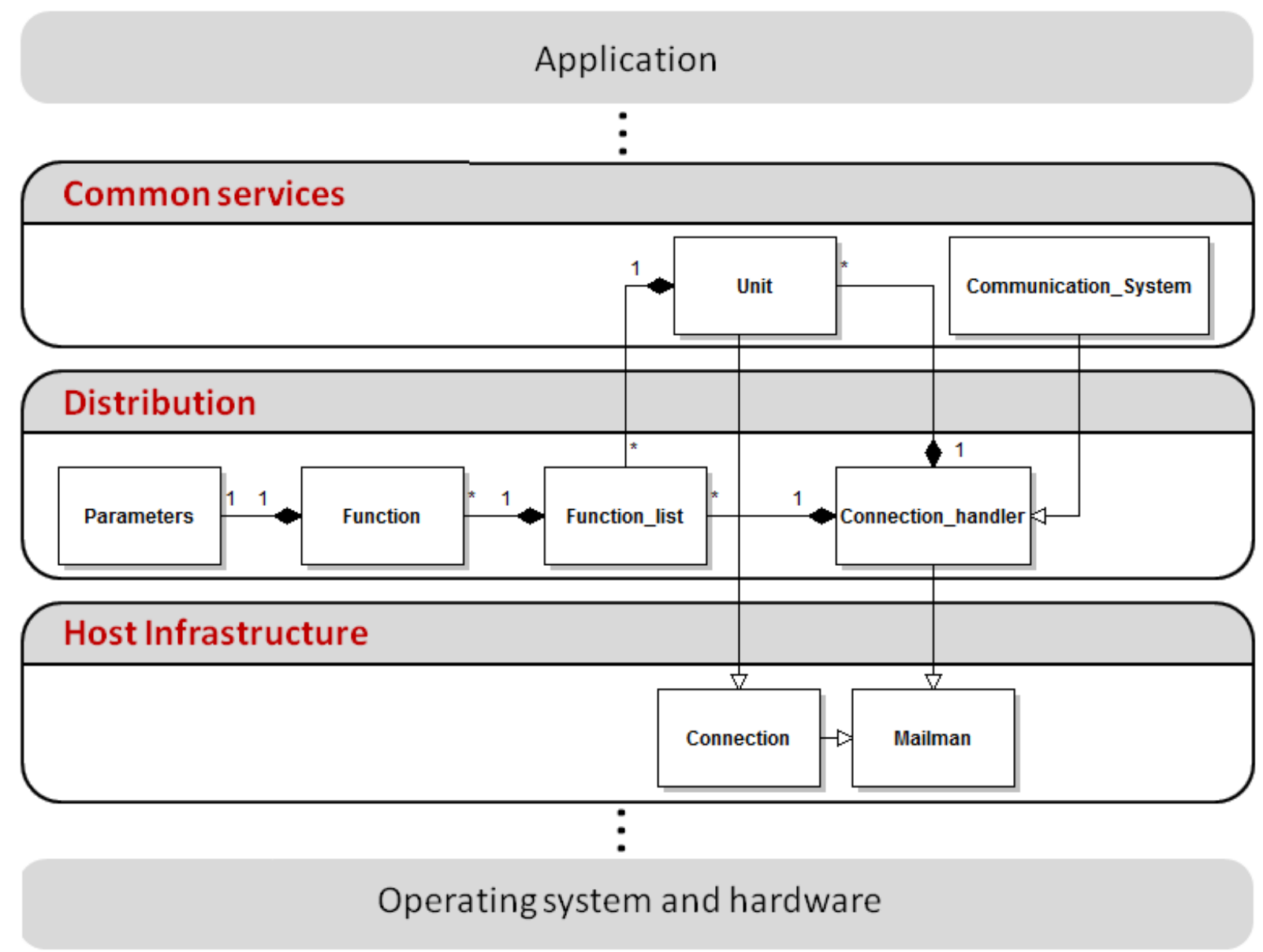

Figura 12 - Camadas e diagrama de classe parcial da arquitetura proposta. 


\subsubsection{CAMADA HOST}

Nesta camada foram implementadas as funcionalidades relacionadas com a troca, estrutura e monitoração de mensagens e o estabelecimento, manutenção e endereçamento de conexões. Como ilustradas na Fig. 11, as principais classes responsáveis por esta camada são as Connection e Mailman. A classe Connection é responsável por gerenciar, monitorar e manter as conexões estabelecidas, enquanto que a classe Mailman é responsável por prover os mecanismos relacionados com a troca (envio e recebimento) e estrutura das mensagens e estabelecimento de conexões.

A implementação destes mecanismos foi realizada por meio da programação de sockets, que se baseia no protocolo IP (camada de rede), TCP e UDP (camada de transporte). O protocolo TCP oferece mecanismos para estabelecer uma conexão e trocar mensagens com boa garantia e o UDP permite a rápida disseminação de informação no sistema ao oferecer mecanismos para o broadcast de mensagens.

A escolha destes protocolos para a arquitetura foi feita porque, além de serem uma opção de fácil acesso, possuindo uma boa quantidade de material na literatura para o seu aprendizado (e.g., Donahoo (32)), permitem a elaboração de mecanismos com um bom desempenho para diversas aplicações, sendo utilizados em diversos sistemas vistos no capítulo anterior. Em contrapartida, a desvantagem clara do uso de sockets é que não oferecem suporte para aplicações de tempo real. Essa desvantagem se dá pelo fato de que os mecanismos proporcionados pelos protocolos TCP/IP não estabelecem um limite de tempo para a entrega das mensagens enviadas.

Com relação aos mecanismos utilizados para dar suporte à programação concorrente, foram utilizadas as APIs proporcionadas pela biblioteca pthreads (POSIX threads). Esta biblioteca oferece as ferramentas necessárias para a criação de threads e o compartilhamento de memória entre elas (Matloff - (21)). Uma thread pode ser entendida como um processo "filho" associado a um processo "pai", mas o conjunto destes processos "filhos" e seu processo "pai" é identificado como um único processo (Fig. 12). A biblioteca pthreads também oferece ferramentas para implementar mecanismos de sincronização e coordenação de processos (ou threads), compartilhando uma memória em comum. Este mecanismo utiliza variáveis Mutex (mutual exclusion), que permitem o acesso alternado dos processos ou threads à memória compartilhada entre eles, criando para isso uma fila de espera. 


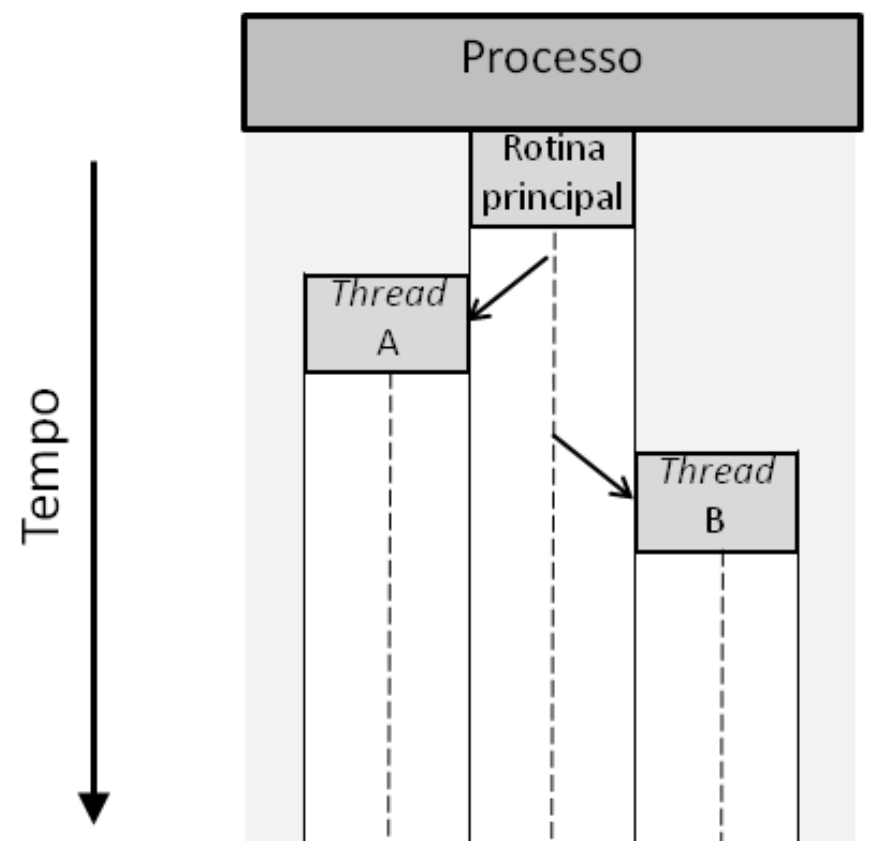

Figura 13 - Ilustração de um processo e suas threads.

As funcionalidades implementadas de acordo com as classes desta camada são descritas em maiores detalhes nos subtópicos a seguir.

\subsubsection{MAILMAN}

Estabelecimento de conexões: esta funcionalidade consiste em prover os mecanismos necessários para realizar uma conexão por meio dos protocolos TCP/IP. Para que uma conexão seja estabelecida é preciso que primeiro haja um processo aguardando por uma conexão e que, então, outro processo possa lhe requisitar o estabelecimento de uma conexão. Para que esta interação ocorra, é necessário que o processo requisitante saiba de dois parâmetros do processo em espera: o endereço deste processo na rede, sendo este dado pelo IP, e a porta na qual este processo espera receber o pedido, sendo esta caracterizada por um número inteiro entre 1 e 65.535 (16 bits). Cada conexão estabelecida é representada por um socket, possuindo um número inteiro que o identifica e, uma vez estabelecida permite que os processos troquem mensagens livremente entre si, não havendo um sentido preferencial.

Envio e recebimento de mensagens: esta funcionalidade permite o envio e recebimento de mensagens por meio do conjunto de protocolos TCP/IP. As mensagens 
trocadas consistem em strings, ou um array de variáveis do tipo char (caracteres), que são passados de um processo ao outro. Dependendo do tamanho da string a ser passada pode ser necessário quebrá-la em strings menores para realizar o seu envio. Isto é feito porque há um limite do tamanho máximo de string que pode ser enviado de uma única vez. Ao se estabelecer a conexão entre dois processos, o envio de mensagens pode ser feito a qualquer momento durante o período que a conexão estiver ativa. As mensagens enviadas a um processo são armazenadas em um buffer até que este requisite o seu recebimento.

Broadcast de mensagens: de forma semelhante ao caso anterior, estas funcionalidades permitem o envio e recebimento de mensagens através do mecanismo broadcast oferecido pelo protocolo UDP. O broadcast consiste no envio de uma determinada mensagem para todos os endereços presente em uma rede. Sendo assim, tanto para o envio quanto para o recebimento das mensagens trocadas por este mecanismo, é necessário apenas o conhecimento do parâmetro da porta destinada a estas mensagens. Embora o broadcast permite a rápida disseminação da informação para os outros processos, ele não garante que as mensagens enviadas cheguem até seu destino final, que é uma característica do protocolo UDP. Esta funcionalidade será utilizada para implementar o serviço de descobrimento que é oferecido pela camada de serviços comuns.

\subsubsection{CONNECTION}

Estado da conexão: consiste em monitorar o estado de uma determinada conexão através da modificação de uma estrutura de dados disponibilizada. Desta forma, é possível identificar e verificar informações como: disponibilidade da conexão para a troca de mensagens, fechamento da conexão pelo outro processo e queda da conexão por motivo desconhecido.

Criação de thread para o envio ou recebimento de mensagens: utiliza as ferramentas necessárias para a criação de threads que realizam o envio ou recebimento de mensagens passadas, tanto por meio de broadcasts, como de uma conexão em particular. Para o caso do envio, seja ele através do broadcast ou não, a mensagem a ser passada é copiada em um buffer disponibilizado para a thread criada, permitindo a execução de outras operações 
enquanto a mensagem é enviada. Para o caso do recebimento, uma thread é criada para ficar aguardando o recebimento de mensagens e, ao recebê-las, a mensagem é repassada para os objetos das classes definidas nas camadas superiores para ser processada e interpretada. $\mathrm{Na}$ Fig. 13 é apresentado um diagrama que ilustra os mecanismos mencionados.

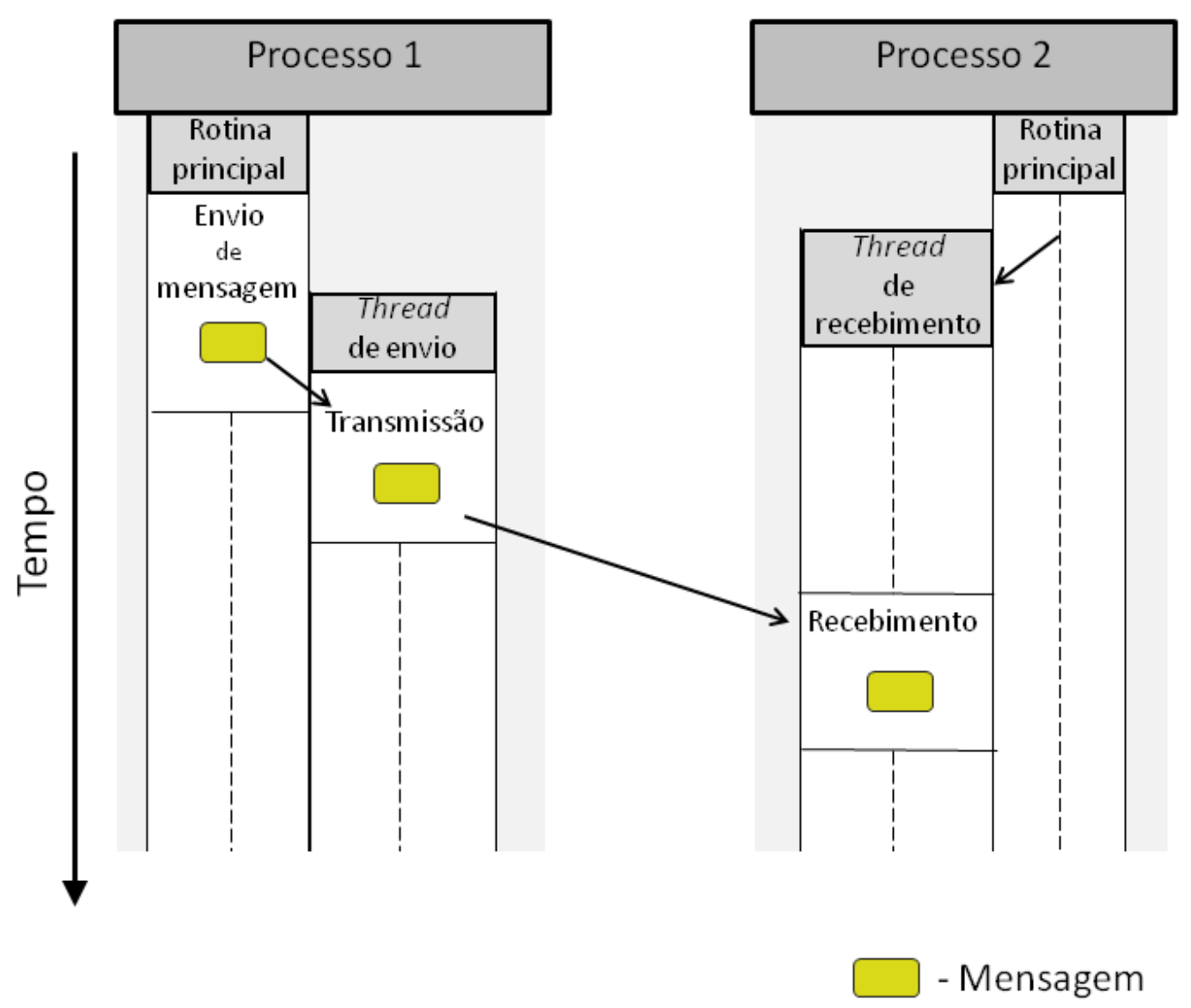

Figura 14 - Diagrama ilustrando o mecanismo de criação de threads para o envio e recebimento de mensagens.

\subsubsection{CAMADA DE DISTRIBUIÇÃO}

Esta camada é responsável por proporcionar ao sistema um modelo de programação distribuída de alto nível para promover a interação dos processos de uma aplicação. Para isso, esta camada oferece as funcionalidades relacionadas com o request broker e a IDL, que são implementadas principalmente pelas classes Parameters, Function, Function_list e Connection_handler. Enquanto que as classes Parameters e Function são responsáveis por implementar a IDL, a qual oferece as interfaces para a definição dos serviços e seus 
parâmetros de entrada e saída, as classes Function_list e Connection_handler são responsáveis por implementar as funcionalidades relacionadas ao request broker, disponibilizando as interfaces para a invocação de métodos entre os processos.

Para eliminar a necessidade de criar um código cliente (proxy) e outro servidor (skeleton) para cada serviço remoto definido, como no caso da arquitetura CORBA, as classes que implementam a IDL foram projetadas para possibilitar a geração e disseminação de todas as informações necessárias para dar procedimento com uma requisição. Embora esta abordagem possa aumentar ligeiramente o overhead associado às mensagens trocadas, ela facilita o uso da arquitetura ao remover a necessidade de manter um repositório de interfaces para transferir os proxies e skeletons para cada processo da aplicação.

Para simplificar o projeto da arquitetura proposta, foi adotado que a IDL disponibilizada permitiria a definição de três tipos de variáveis nos parâmetros de entrada e saída dos métodos remotos, sendo eles: string, integer e float. Caso sejam necessários outros tipos de variáveis, estas podem ser acrescentadas seguindo o mesmo procedimento de implementação feito para os três tipos iniciais.

A seguir, as funcionalidades implementadas pelas classes desta camada são descritas em maiores detalhes.

\subsubsection{PARAMETERS}

Definição dos parâmetros de entrada e saída de métodos: esta funcionalidade permite aos desenvolvedores realizarem a definição dos parâmetros, tanto de entrada dos métodos remotos (input), quanto dos parâmetros gerados como resultado da operação (output). As variáveis criadas são incorporadas em um objeto desta classe, e podem ser constituídas de uma combinação dos três tipos de dados mencionados (string, integer e float). Cada variável necessita de três parâmetros para sua definição, sendo eles o nome, tipo e tamanho. Na Fig. 14 são ilustrados os objetos desta classe contendo uma possível combinação de variáveis que podem ser utilizadas como parâmetros de um método ou função. 

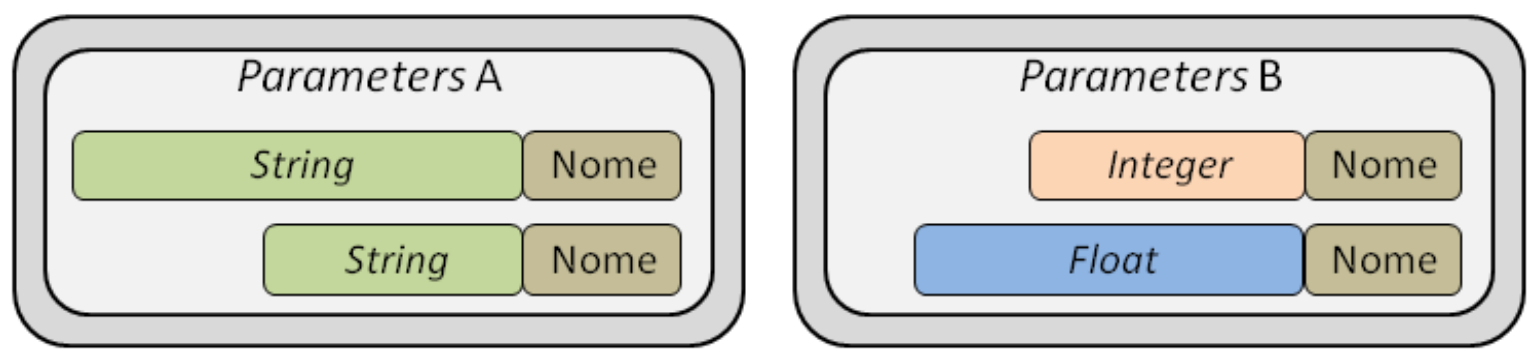

Figura 15 - Ilustração da estrutura dos objetos da classe Parameters.

Interação com os parâmetros definidos: consiste em proporcionar os mecanismos necessários para interagir com os parâmetros definidos. Basicamente, estes mecanismos oferecem funções para visualizar, extrair e modificar as variáveis contidas em um objeto desta classe.

Marshalling e unmarshalling das estruturas de dados dos parâmetros: permite a conversão dos parâmetros contidos em um objeto desta classe em uma estrutura de dados apropriada para o seu envio na rede. Ao ser transmitida, esta funcionalidade permite a conversão dos dados recebidos para replicar o objeto inicial, que poderá ser utilizado por outros processos.

\subsubsection{FUNCTION}

Modelo para definição de métodos ou funções: oferece o modelo para a definição dos métodos ou funções que serão disponibilizados aos outros processos. Este modelo consiste em funções que contêm um único parâmetro de entrada e um único parâmetro de saída, sendo estes objetos da classe Parameters. Estas funções podem tanto ser definidas como funções globais ou como métodos de um objeto.

Registro de métodos ou funções: oferece um mecanismo para realizar o registro de métodos ou funções que serão disponibilizados aos outros processos. Para o registro de cada função podem ser necessários até quatro parâmetros, sendo estes o nome, endereço da função ou método, possível endereço do objeto detentor do método e um objeto da classe Parameters, e são incorporados em um objeto desta classe. O objeto da classe Parameters é 
utilizado para informar aos outros processos quais são as variáveis que a função ou método utiliza, podendo inclusive ser utilizado para impedir uma requisição que não contenha as variáveis necessárias. Fig. 15 ilustra objetos desta classe contendo os parâmetros de um possível método registrado.
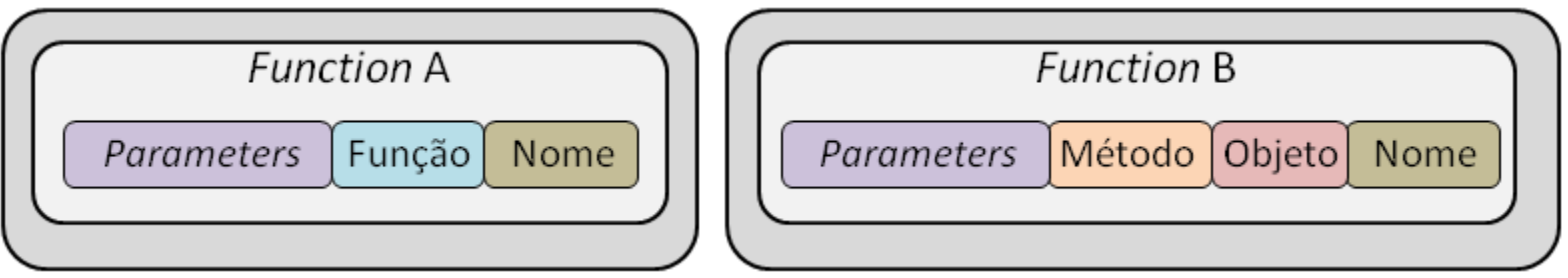

Figura 16 - Ilustração da estrutura dos objetos da classe Function.

Chamada de função ou método registrado: consiste em proporcionar os mecanismos necessários para realizar a chamada do método ou função registrada, permitindo a passagem do parâmetro de entrada e obtenção do resultado.

\subsubsection{FUNCTION_LIST}

Listagem dos métodos ou funções e seus parâmetros: consiste em oferecer uma interface para interagir com os objetos da classe Function, permitindo a criação e gerenciamento destes objetos. Desta forma, um objeto desta classe pode conter a lista com os diversos métodos ou funções disponibilizados aos outros processos. Uma condição que surge ao utilizar esta interface é de que ela não permite o registro de métodos ou funções com o mesmo nome, evitando assim casos de ambiguidade. Outra condição imposta é de que cada objeto desta classe permite o registro de métodos definidos em uma única classe. Fig. 16 ilustra objetos desta classe que contêm um conjunto de métodos ou funções registrados. 

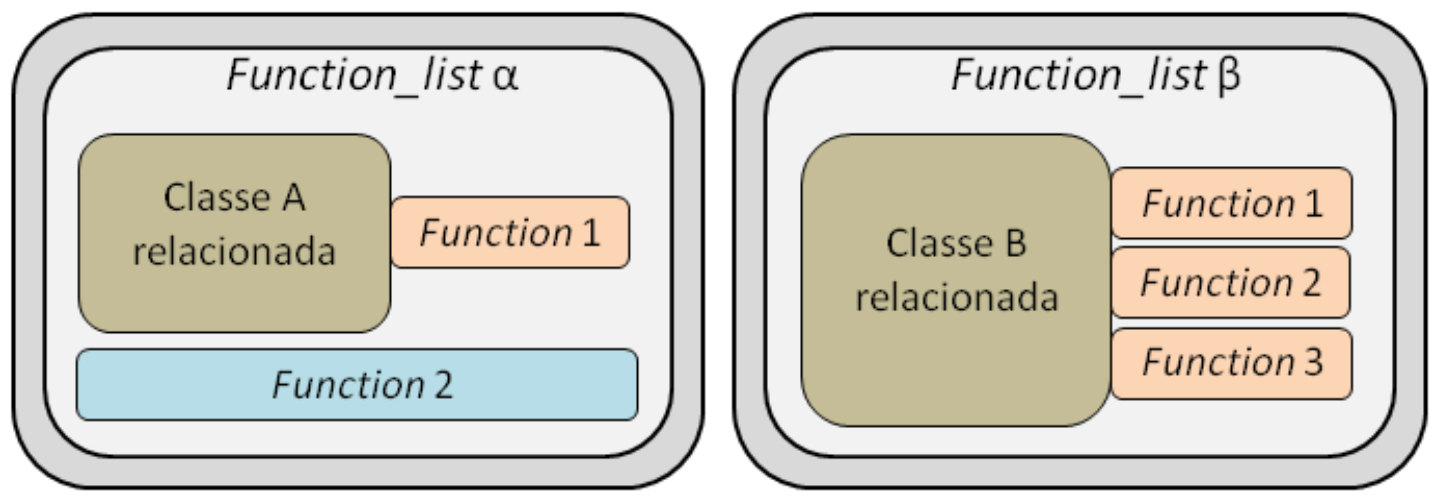

Figura 17 - Ilustração da estrutura dos objetos da classe Function_list.

Marshalling e unmarshalling de listas de funções: esta funcionalidade permite a conversão das informações contidas em um objeto desta classe para uma estrutura de dados adequada ao seu envio na rede. Da mesma forma, ela permite a conversão destes dados para replicar boa parte das informações em outro objeto desta classe. Isso permite a criação de mecanismos para que os processos passem adiante a informação sobre seus métodos ou funções disponíveis.

\section{Marshalling e unmarshalling de requisições de métodos ou funções remotas:}

oferece uma interface para realizar a requisição de um método ou função com base na lista contida em um objeto desta classe. Para realizar uma requisição pode ser necessária a passagem de até dois parâmetros, sendo eles o nome do método ou função desejada, e um objeto da classe Parameters (opcional). Ao receber a requisição, um objeto desta classe verifica em sua lista pela existência de um método ou função com o mesmo nome passado. Caso ela exista, ele verifica se o objeto da classe Parameters passado possui as variáveis necessárias para aquele método ou função. E então, em caso positivo, as informações necessárias para a requisição são convertidas em uma estrutura adequada para o seu envio na rede. Outro objeto desta classe recebe e processa estes dados para dar continuidade com a requisição. Para que este mecanismo funcione o objeto que gera a requisição deve possuir informações sobre o outro objeto alvo da requisição. Este mecanismo é utilizado nas funcionalidades proporcionadas pela classe a seguir, a qual permitirá um melhor entendimento de sua aplicação. 


\subsubsection{CONNECTION_HANDLER}

Criação de threads para o gerenciamento de conexões: proporciona os mecanismos necessários para a criação de uma thread que recebe (Mailman) as conexões de outros processos. Os objetos desta classe também oferecem uma interface para as funcionalidades disponibilizadas pela classe Mailman, permitindo a requisição de uma conexão com outros objetos. Para cada nova conexão estabelecida outra thread é criada (Connection) para receber futuras mensagens, e ela se mantém ativa pela mesma duração da conexão. Para exemplificar este processo a Fig. 17 ilustra o mecanismo, mostrando maiores detalhes para o processo que recebe a requisição para a conexão.

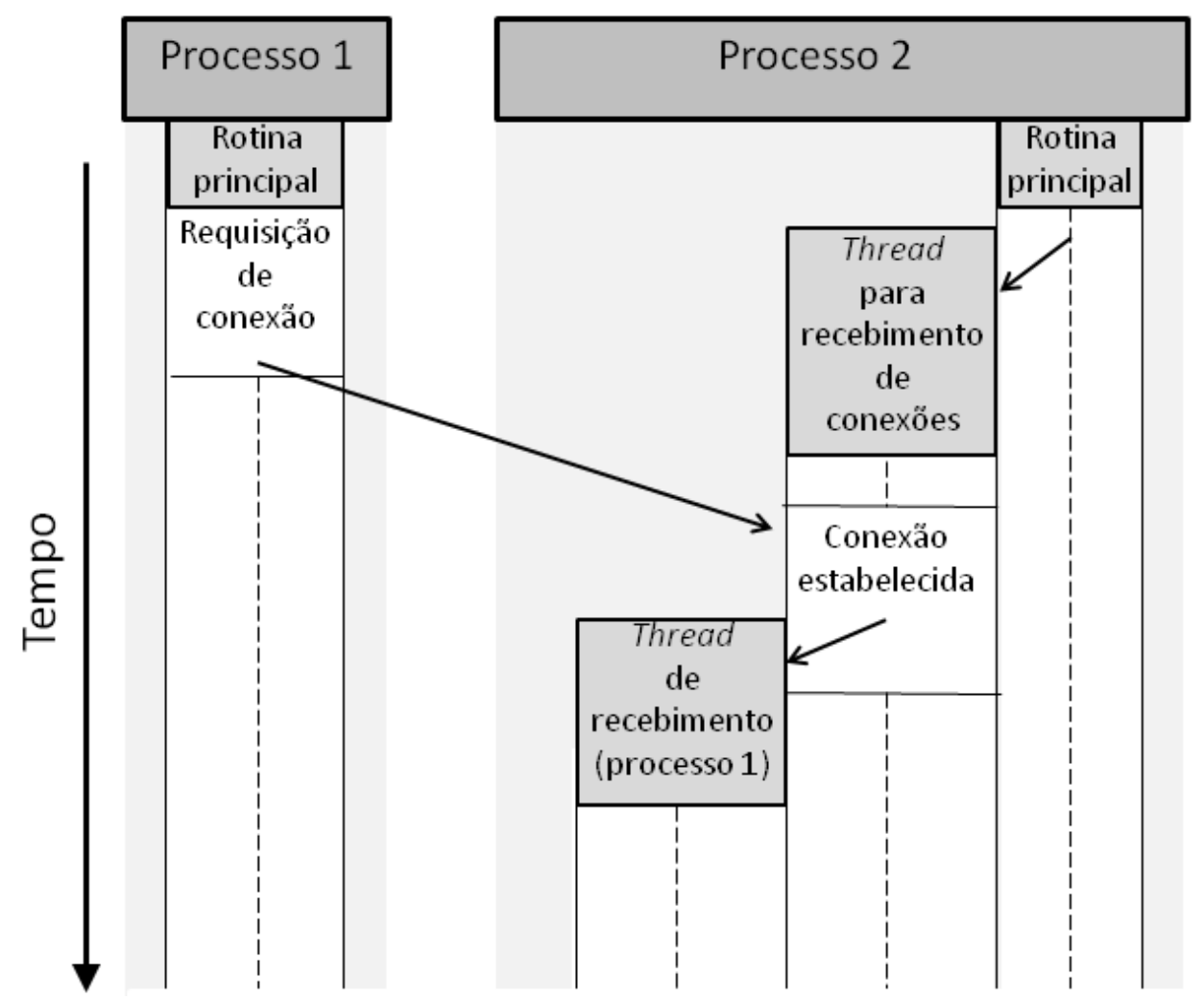

Figura 18 - Diagrama ilustrando o mecanismo de criação de threads para o recebimento de conexões.

Mecanismos para divulgação de métodos ou funções entre processos: oferece uma interface para trabalhar com objetos da classe Function_list, permitindo a criação e gerenciamento destes objetos. Para cada conexão estabelecida, um objeto da classe Function_list é criado para receber as informações sobre os métodos ou funções 
disponibilizadas pelo outro processo envolvido na conexão. Para simplificar o desenvolvimento da arquitetura proposta, cada objeto desta classe possui apenas um objeto da classe Function_list para armazenar os dados de seus próprios métodos ou funções. Os objetos desta classe também oferecem uma interface para divulgar as informações contidas em seu objeto Function_list (que contém seus métodos ou funções) para um processo conectado em particular.

Requisição de métodos ou funções de processos remotos: oferece uma interface para requisitar um método ou função oferecida por um processo remoto conectado. Esta requisição utiliza os mecanismos disponibilizados pela classe Function_list, e requer como entrada três possíveis parâmetros, sendo eles o nome do método ou função, um possível objeto da classe Parameters como parâmetro de entrada (input), e outro possível objeto, também da classe Parameters, para receber o resultado da operação (output). Fig. 18 ilustra este mecanismo em uma requisição feita por um processo denominado cliente, para outro processo denominado servidor. 


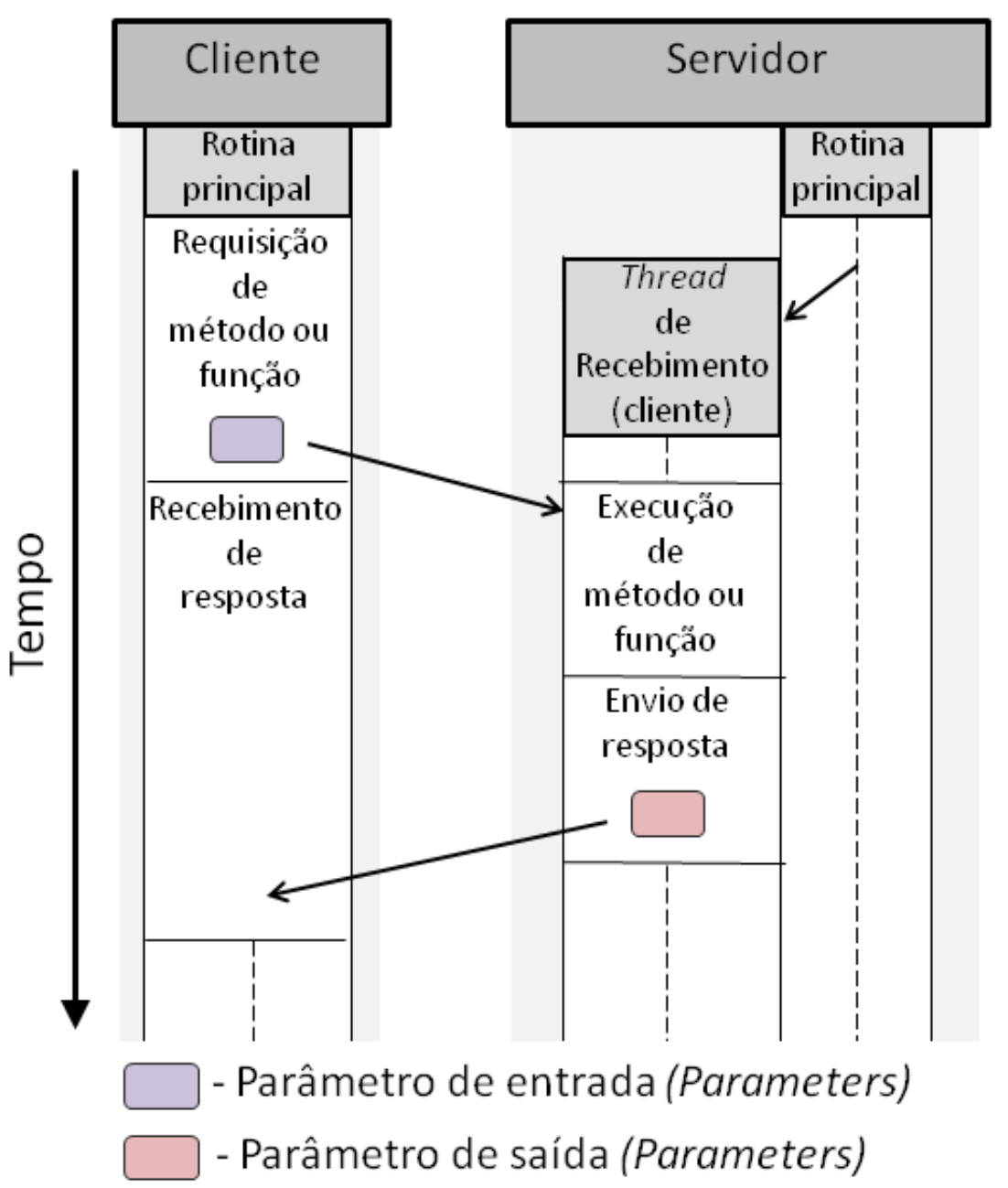

Figura 19 - Diagrama ilustrando o mecanismo de requisição de métodos ou funções entre processos.

\subsubsection{CAMADA DE SERVIÇOS COMUNS}

As funcionalidades proporcionadas por esta camada oferecem um conjunto de serviços de alto nível para permitir o gerenciamento dos recursos em uma aplicação. Estes serviços possuem um escopo abrangente e podem ser utilizados em diversos tipos de aplicações. Os serviços utilizados no middleware proposto oferecem funcionalidades relacionadas com o descobrimento de nós, nomeação, persistência de conexões e mecanismos de sincronização de requisições, e são implementados pelas classes Unit e Communication_system.

As classes presentes nesta camada agregam as funcionalidades das classes das camadas inferiores para oferecerem uma interface intuitiva aos desenvolvedores, e são então utilizadas para a criação dos nós nos processos da aplicação. A principal diferença entre as 
classes Unit e Communication_system se dá com relação ao número de conexões que seus objetos podem ter. Os objetos da classe Unit, denominados de s_unit (single connection), permitem a conexão com um único objeto (nó), sendo este obrigatoriamente um objeto da classe Communication_system. Os objetos da classe Communication_system, denominados de m_unit (multiple connections), permitem a conexão com múltiplos objetos (nós), nos quais podem ser tanto objetos da classe Communication_system quanto da classe Unit. Na Fig. 19 é ilustrada uma possível configuração de nós (objetos) e suas respectivas conexões.

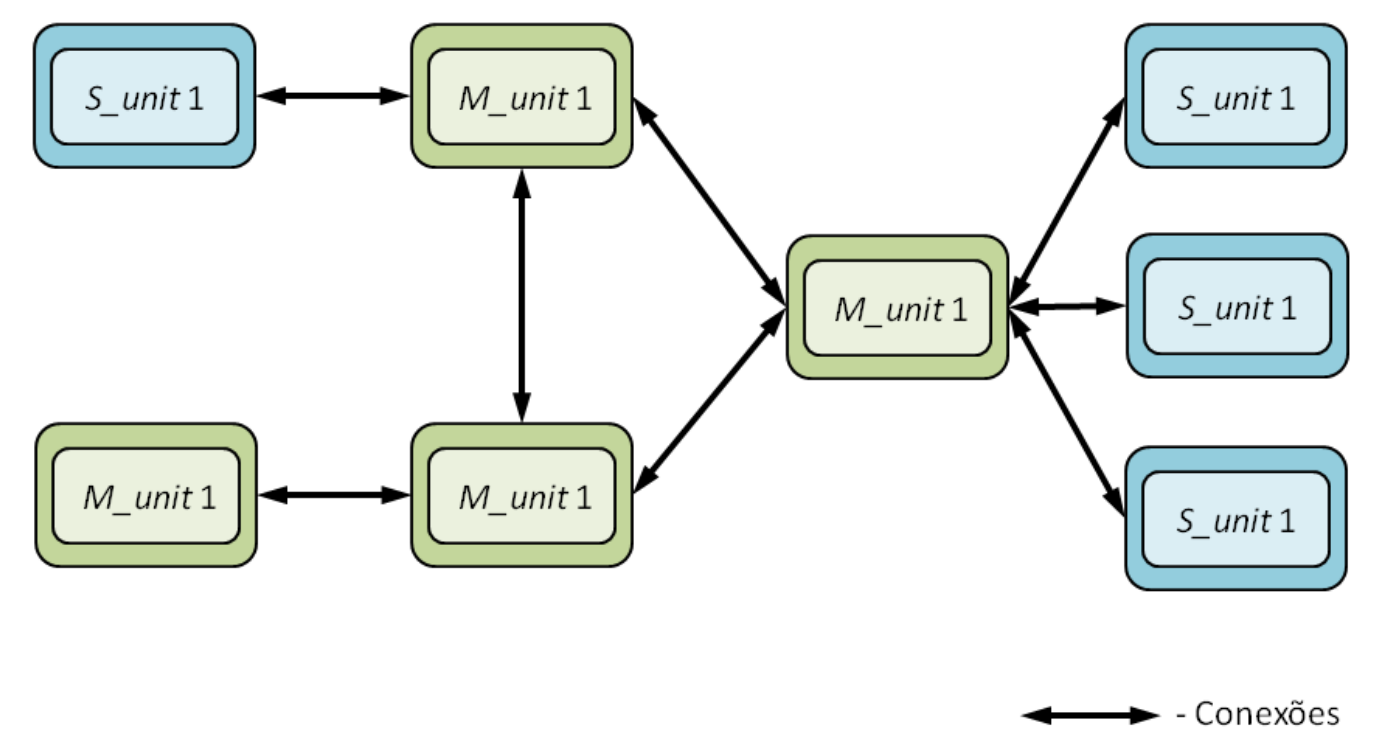

Figura 20 - Possível configuração de nós formada pelos objetos das classes Unit e Communication_system.

As mensagens trocadas entre estes objetos segue um formato definido que é apresentado na Fig. 21. Além do cabeçalho referente ao protocolo TCP/IP, existem outros quatro campos utilizados pela arquitetura, sendo eles: o tamanho total da mensagem, utilizado para garantir que toda a mensagem foi entregue (camada host); o código do serviço, utilizado para especificar se a chamada deve ser realizada de forma síncrona ou assíncrona (camada de serviços comuns); as informações do serviço, utilizadas para especificar qual o serviço que deve ser executado (camada de distribuição); os argumentos e outra possível mensagem necessários para realizar a chamada do serviço especificado (camada de distribuição).

\begin{tabular}{|c|c|c|c|c|}
\hline TCP/IP & $\begin{array}{c}\text { Tamanho da } \\
\text { mensagem }\end{array}$ & $\begin{array}{c}\text { Código do } \\
\text { serviço }\end{array}$ & $\begin{array}{c}\text { Informação do } \\
\text { serviço }\end{array}$ & Argumentos/Mensagem \\
\hline
\end{tabular}

Figura 21- Formato de mensagem utilizado pela arquitetura proposta. 
A seguir, as funcionalidades implementadas pelas classes para disponibilizar os serviços mencionados são descritas em maiores detalhes.

\subsubsection{SERVIÇO DE NOMEAÇÃO}

Este serviço permite que os nós que constituem determinada aplicação sejam identificados por um conjunto de características determinadas pelo desenvolvedor, como por exemplo, um nome e um identificador. Desta forma, é possível realizar o mapeamento dos serviços disponibilizados pelos nós (métodos ou funções) com as características definidas para cada nó. Isso implica que ao estabelecer uma conexão com determinado nó é possível saber quais são os serviços oferecidos por ele apenas conhecendo suas características (nome e identificador). Sendo assim, o serviço de nomeação torna-se uma ferramenta útil aos desenvolvedores por facilitar o gerenciamento dos serviços oferecidos pelos nós de sua aplicação. Para a arquitetura proposta as interfaces oferecidas para utilizar o serviço de nomeação são ligeiramente diferentes para cada tipo de objeto utilizado e, então, estas são descritas separadamente a seguir.

M_unit (classe Comunication_system): a classe Communication_system oferece uma interface para permitir que seus objetos (m_unit) sejam caracterizados por até dois parâmetros, sendo eles: o seu nome, e um possível identificador associado a ele (número inteiro). Durante o estabelecimento de uma conexão entre dois nós, esta conexão é efetivada somente depois que os nós tenham trocado entre si as informações sobre suas características.

S_unit (classe Unit): como os objetos do tipo $s \_u n i t$ se conectam somente com um único objeto, sendo este do tipo $m_{-}$unit, os objetos deste tipo são caracterizados por até três parâmetros, sendo eles: o seu nome, o nome do objeto $m \_$unit que ele deseja se conectar e um possível identificador (número inteiro) associado ao objeto m_unit. Desta forma, ao tentar realizar a conexão com outro nó, esta será efetivada somente se o objeto alvo da conexão possuir as mesmas características relacionadas com os dois últimos parâmetros mencionados. 


\subsubsection{SERVIÇO DE DESCOBRIMENTO}

Este serviço permite que os nós realizem a procura e descoberta de outros nós existentes na rede em que ele está inserido. Isto proporciona um mecanismo flexível para a criação de nós em determinado sistema sem que haja a necessidade de configurar manualmente as conexões estabelecidas. O serviço de descobrimento também oferece a possibilidade aos desenvolvedores de implementarem funcionalidades mais complexas para a procura de serviços na rede sem a necessidade de um servidor "central" como, por exemplo, o nó mestre presente na arquitetura ROS, permitindo que, caso haja a falha de um nó específico, o sistema possa procurar dinamicamente outros nós para suprirem os serviços necessários.

Para a arquitetura proposta, a implementação do serviço de descobrimento utiliza o mecanismo de broadcast oferecido pelo protocolo UDP, e consiste em um procedimento semelhante ao do protocolo de resolução de endereços (Tanenbaum e Steen - (16)). As interfaces oferecidas para utilizar este serviço diferem de acordo com o tipo de objeto utilizado, sendo então descritos separadamente a seguir.

M_unit (classe Comunication_system): ao ser requisitado o serviço de descobrimento de um objeto do tipo $m \_$unit, este cria uma thread para realizar o envio de uma mensagem via broadcast (camada host) contendo suas características por um determinado período de tempo. Os outros objetos, ao receberem o broadcast, podem enviar uma solicitação para estabelecer uma conexão com a fonte das mensagens caso seja de seu interesse. Para o caso dos objetos do tipo $m \_$unit, estes seguem o seguinte procedimento para decidir se devem ignorar o broadcast ou realizar a solicitação de conexão: eles procuram em suas conexões se existe um nó conectado com o mesmo nome e identificador da fonte do broadcast; se existir, é verificado se o endereço IP da fonte coincide com o do nó conectado; se coincidir, então o broadcast é ignorado, mas caso seja diferente então a solicitação de conexão é feita. Para que este mecanismo funcione é necessário que os objetos estejam preparados para receber uma mensagem via broadcast e, que por esta razão, os objetos podem criar uma thread adicional para escutar estas mensagens. Fig. 20 apresenta um diagrama que ilustra o mecanismo descrito para o serviço de descobrimento. 


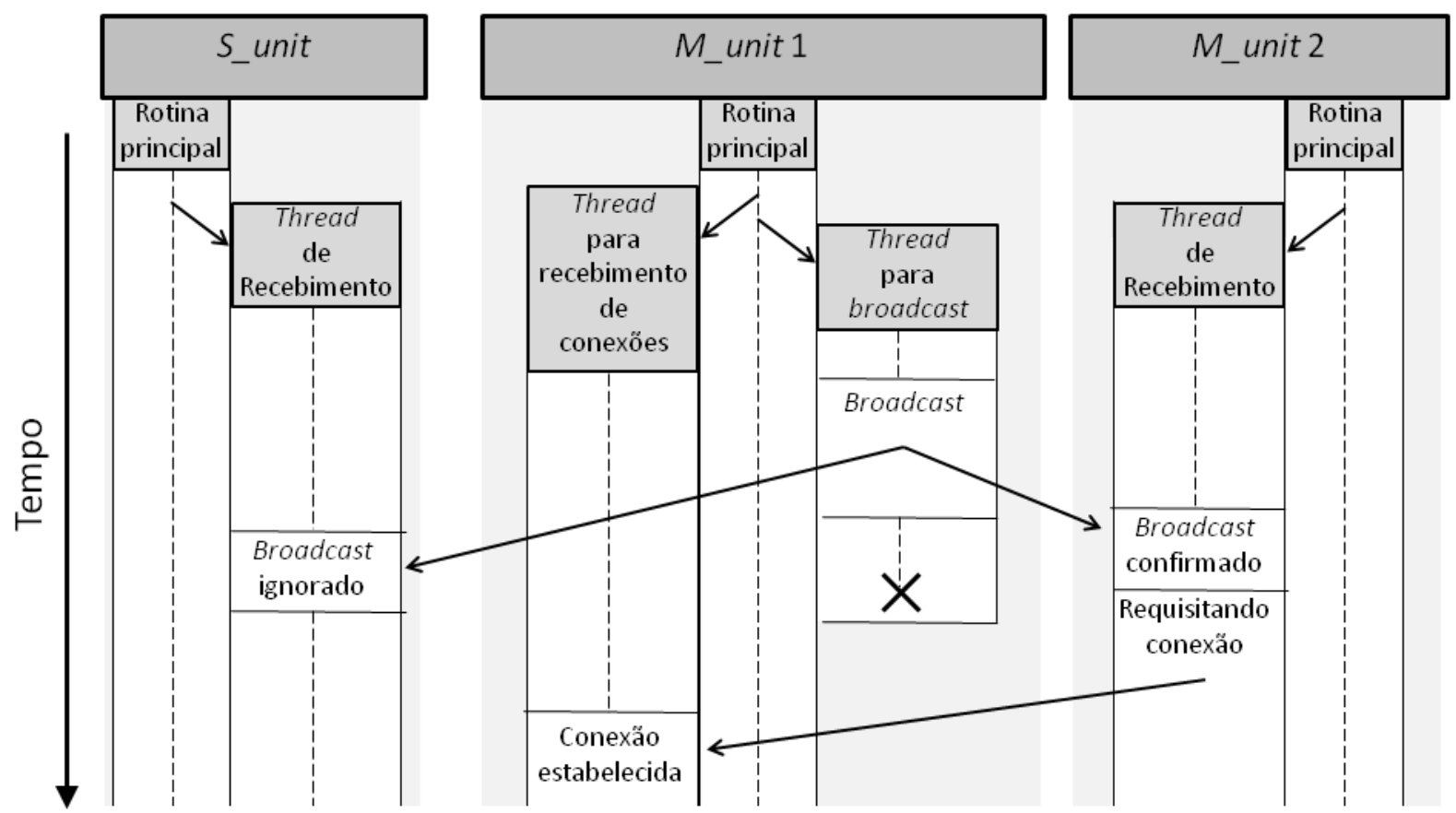

Figura 22 - Diagrama ilustrando o mecanismo do serviço de descobrimento implementado pela arquitetura proposta.

S_unit (classe Unit): para este tipo de objeto é utilizado o mesmo mecanismo dos objetos do tipo $m \_u n i t$, tendo como diferença a adoção de uma abordagem mais passiva da interface oferecida pelos objetos $s_{-}$unit. Como os objetos do tipo $s_{-}$unit possuem as características do objeto (m_unit) que desejam se conectar, a requisição do serviço de descobrimento consiste em criar uma thread para esperar uma mensagem broadcast do objeto com as características desejadas. Este comportamento foi adotado por simplificar o desenvolvimento da arquitetura de comunicação, definindo que somente os objetos do tipo m_unit é que deveriam esperar por uma solicitação de conexão.

\subsubsection{SINCRONIZAÇÃO DE REQUISIÇÕES}

Este serviço consiste em proporcionar funcionalidades aos desenvolvedores para facilitar a implementação da sincronização e coordenação durante a interação entre os processos. Basicamente, ele proporciona os mecanismos necessários para que um processo possa realizar a requisição de determinado método ou função de forma tanto síncrona quanto assíncrona. Uma requisição síncrona (Fig. 18) de um método ou função significa que o processo requisitante aguarda a finalização da operação desejada antes de continuar com sua 
rotina, podendo receber o resultado desta operação ou não. Caso haja uma falha durante a requisição, o processo requisitante aguarda um tempo máximo denominado de timeout e, que passado este tempo, o processo requisitante é informado de que algo ocorreu errado para que este possa continuar com sua rotina. Para o caso de uma requisição assíncrona, o processo requisitante espera somente o tempo necessário para que a mensagem de requisição seja enviada, e continua com sua rotina logo após o seu envio. Desta maneira, para o caso da requisição assíncrona, o processo não possuirá o conhecimento se algo ocorrer errado durante a requisição. Estes mecanismos proporcionam uma liberdade adicional para que os desenvolvedores implementem a interação entre seus processos de forma mais flexível para atender as necessidades da aplicação.

As interfaces proporcionadas para este serviço são as mesmas, tanto para a classe Unit, quanto Comunication_system. Na Fig. 21 é apresentado um diagrama que ilustra o mecanismo de timeout mencionado.
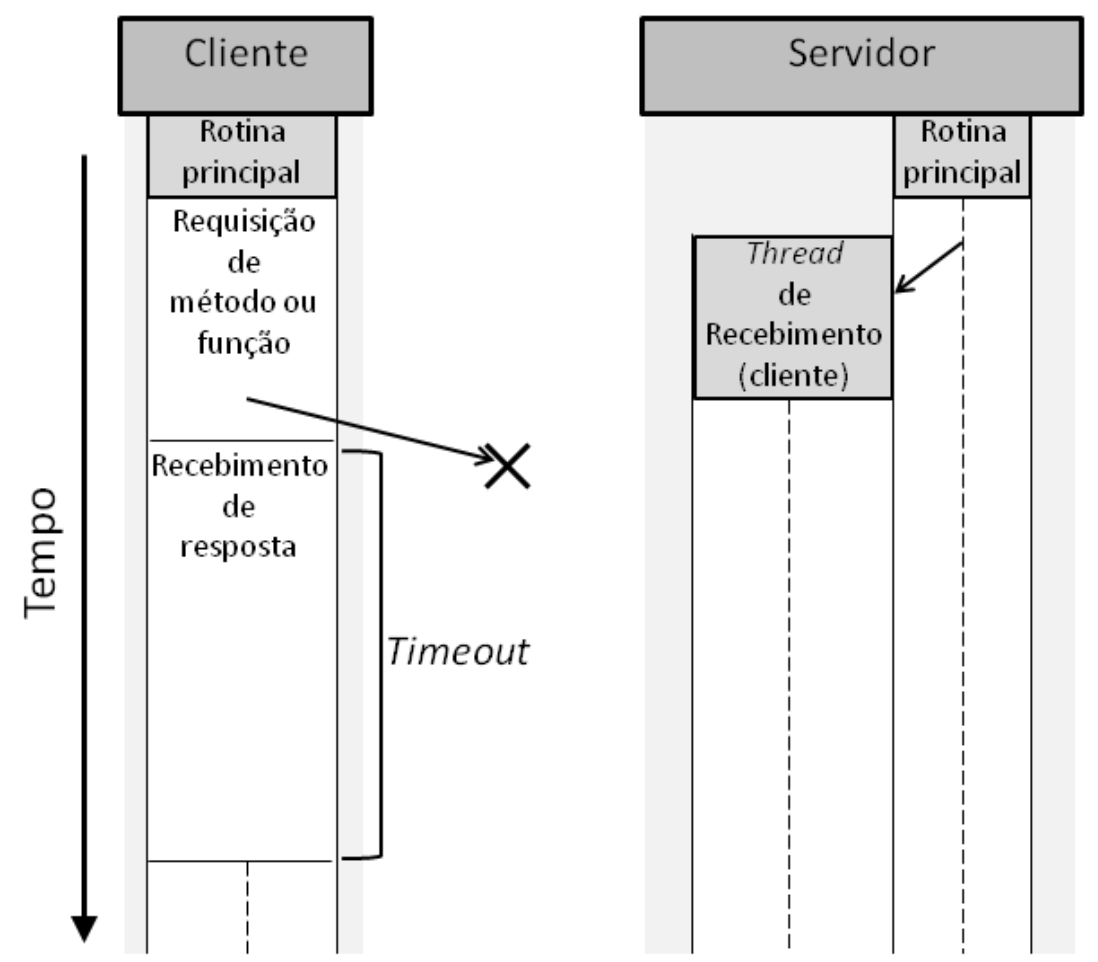

Figura 23 - Diagrama ilustrando o mecanismo de timeout implementado no serviço de requisição síncrona. 


\subsubsection{PERSISTÊNCIA DE CONEXÕES}

Este serviço oferece funcionalidades para manter as conexões entre os processos e, em caso de uma queda de conexão, ele oferece mecanismos para a tentativa de reestabelecimento. Este serviço, em conjunto com os serviços de descobrimento e nomeação, permite um melhor gerenciamento das conexões estabelecidas entre os processos ao armazenar os dados de cada conexão estabelecida. Mesmo que um processo encerre sua conexão, seus dados são mantidos e disponibilizados em um estado inativo e, caso o processo tente estabelecer novamente a conexão, a conexão antes inativa passa a ser ativa novamente. Este mecanismo é interessante para os sistemas constituídos de processos que são ativados e desativados várias vezes ao longo da aplicação, e permite que os desenvolvedores reconheçam facilmente quais os processos que estão disponíveis ou não.

Caso uma conexão desconecte-se por um motivo desconhecido, o serviço de persistência realiza uma tentativa para reestabelecer a conexão, seguindo um procedimento de acordo com o tipo de objeto. Para os objetos do tipo $s_{-} u n i t$, a queda inesperada da conexão faz com que estes criem novamente a thread para esperar por uma nova mensagem broadcast. Para os objetos do tipo $m \_u n i t$, ao cair uma conexão de forma inesperada tenta-se realizar o pedido para estabelecer a conexão novamente. Este pedido é realizado algumas vezes por um determinado período de tempo e, caso a conexão não seja reestabelecida, o objeto cria uma thread para emitir mensagens de broadcast periodicamente até que a conexão seja reestabelecida.

\subsection{CONSIDERAÇÕES FINAIS}

Como pode ser visto, as funcionalidades implementadas na arquitetura de comunicação proposta oferecem um conjunto de mecanismos e ferramentas para permitir a interação entre processos com um bom nível de flexibilidade. Por permitir que os processos ofereçam métodos contidos em outros objetos, é possível criar serviços contendo funcionalidades mais específicas a partir das funcionalidades básicas oferecidas pelo middleware. Desta forma, objetos podem ser desenvolvidos para conter estes novos serviços, 
e podem ser disponibilizados aos desenvolvedores de acordo com as necessidades da aplicação.

A arquitetura proposta permite mecanismos para organizar os serviços (métodos ou funções) nos objetos da classe Function_list, e esta contém informações suficientes para permitir que um processo requisite um serviço remoto sem que este possua a definição do mesmo. A arquitetura ainda não permite a seleção individual dos serviços disponíveis para cada processo de forma eficiente mas, com algumas modificações, é possível oferecer esta funcionalidade ao permitir que cada objeto da classe Connection_handler possua mais de um objeto da classe Function_list associado aos seus próprios serviços.

A presença dos serviços de descobrimento e nomeação na arquitetura permite que os nós possam localizar e identificar uns aos outros sem a necessidade de um processo intermediário para auxiliar no processo.

Para demonstrar a utilização da arquitetura proposta, o próximo capítulo apresenta a aplicação do modelo proposto em algumas aplicações específicas. Também é apresentado um exemplo de como implementar novos serviços utilizando-se a definição de novas classes. 


\section{APLICAÇÃO DA ARQUITETURA PROPOSTA}

Este capítulo apresenta o uso da arquitetura de comunicação proposta em algumas aplicações para validar sua interface disponibilizada. Em particular, é demonstrado o uso da interface proporcionada para a implementação de novos serviços à arquitetura. Como o middleware proposto foi utilizado no projeto de AGVS, mencionado na introdução, este sistema e a interação entre seus processos são brevemente descritos. Por fim, a integração de serviços web com a arquitetura proposta é apresentada como uma opção para permitir a interação com aplicações desenvolvidas em outras linguagens de programação e plataformas.

\subsection{IMPLEMENTAÇÃO DE UM SERVIÇO BASEADO EM SISTEMAS PUBLISH-SUBSCRIBE}

Para exemplificar o uso da arquitetura descrita no capítulo anterior, este tópico apresenta uma demonstração de como implementar um serviço baseado em sistemas publishsubscribe utilizando as funcionalidades proporcionadas pelo middleware proposto. Este serviço é incorporado na definição de uma classe que pode ser disponibilizada para o desenvolvimento de outras aplicações.

Para que este serviço seja implementado é necessária a criação de uma classe que contenha os métodos que serão disponibilizados entre os processos. Para este exemplo, a classe que implementa este serviço é chamada de Publish_subscribe, e os métodos que proporcionam os mecanismos necessários são descritos a seguir:

Registrar_tópico: este método contém os mecanismos necessários para realizar o registro de um tópico, e é disponibilizado em um processo servidor (o termo servidor indica o processo que contém o registro dos tópicos). Ao ser registrado um tópico em um processo servidor, outros processos clientes (o termo cliente indica que os processos requisitarão 
serviços de um processo servidor) podem requisitar os seus métodos para se subscreverem ao tópico ou publicar informações relacionadas a ele. Este método necessita como parâmetro uma string (incorporada em uma variável do tipo Parameters) contendo o nome do tópico a ser registrado.

Subscrever: este método é disponibilizado em um processo servidor e permite que outros processos clientes demonstrem interesse pelos tópicos registrados. Ao receber novas informações sobre um determinado tópico, o processo servidor encaminha estas informações a todos os processos clientes que se subscreveram para este tópico. Para enviar estes dados o servidor requisita a função Enviar_publicação disponibilizada pelos clientes. Este método necessita da passagem de uma string (incorporada em uma variável do tipo Parameters), contendo o nome do tópico de interesse como parâmetro.

Publicar: este método permite que os processos clientes publiquem novas informações relacionadas com um tópico registrado em um processo servidor. E como mencionado, estas informações são redirecionadas pelo servidor aos processos clientes que demonstraram interesse pelo tópico. Neste exemplo, para realizar a requisição deste método é necessária a passagem de quatro parâmetros (incorporados em uma variável do tipo Parameters), sendo eles: uma string, contendo o nome do tópico relacionado com a publicação; outra string, contendo possíveis informações na forma de texto; um vetor int e outro vetor float, ambos de tamanho dez, contendo possíveis informações numéricas relacionadas com o tópico.

Enviar_publicação: este método é disponibilizado pelos processos clientes para permitir que um determinado processo servidor repasse uma informação recebida para os clientes interessados. Embora a requisição deste método não seja feita explicitamente pela rotina principal do processo servidor, é subentendido que ao ser requisitado o método Publicar o servidor automaticamente requisite este método de todos os clientes interessados pelo tópico publicado. As informações enviadas aos clientes através deste método são armazenadas em estruturas internas de um objeto desta classe (Publish_subscribe), permitindo seu acesso através do método Ler_publicação. Os parâmetros de entrada, neste caso, são os mesmos utilizados no método Publicar. 
Ler_publicação: este método é utilizado pelos processos clientes para ter acesso às informações recebidas relacionadas com um determinado tópico de interesse. Para cada tópico subscrito é subentendido que existe uma estrutura para armazenar as informações enviadas pelo servidor, sendo acessadas então com a chamada deste método. Este método retorna um parâmetro do tipo Parameters que contém as informações desejadas.

Feita a definição dos métodos da classe Publish_subscribe, os códigos de exemplo mostrados a seguir apresentam a utilização da interface oferecida pela arquitetura proposta para estabelecer um servidor, responsável por disponibilizar o serviço publish-subscribe, e um cliente que utiliza este serviço.

\subsubsection{Código do servidor}

Neste exemplo, o processo servidor disponibiliza três métodos (Registrar_tópico, Subscrever e Publicar) da classe Publish_subscribe para oferecer o serviço desejado aos outros processos. O código exemplo do servidor que contém sua rotina principal é apresentado na Fig. 24 e descrito em detalhes a seguir.

Enquanto as linhas de 1 a 2 incluem as definições das classes necessárias para utilizar a arquitetura proposta, a linha 3 inclui a definição da classe Publish_subscribe que contém a implementação dos métodos descritos. A linha 5 cria um objeto da classe Communication_system (“servidor”) e utiliza seu template para permitir, posteriormente, a disponibilização dos métodos definidos na classe Publish_subscribe. Ainda na linha 5 é utilizado o serviço de nomeação para associar um nome ("servidor" novamente) e um identificador ("1") ao processo servidor. A linha 6 cria um objeto da classe Publish_subscribe ("serviço_pub_sub”) que executará os métodos necessários para oferecer o serviço Publish-subscribe. Ainda nesta linha é passada a referência do objeto "servidor" ao objeto "serviço_pub_sub" para permitir que este tenha acesso às conexões estabelecidas com o servidor, podendo então requisitar métodos de outros processos. As linhas 7 e 8 criam um objeto do tipo Parameters ("parâmetros_Reg_Subs") que contém uma string chamada "tópico" de tamanho 30. As linhas 9 e 10 utilizam a variável "parâmetros_Reg_Subs" como modelo para registrarem as funções Registrar_tópico e Subscrever, permitindo então a disponibilização destas funções. 
As linhas de 11 a 15 criam outro objeto do tipo Parameters ("parâmetros_Publicar") que contém quatro variáveis: uma string, chamada "tópicos", de tamanho 30; outra string, chamada "dados_s", de tamanho 100; um vetor int, chamado "dados_i”, de tamanho dez; um vetor float, chamado "dados_f", também de tamanho 10. A linha 16 utiliza a variável “parâmetros_Publicar” como modelo para registrar a função Publicar. Finalmente, a linha 17 requisita o serviço de descobrimento, que é acionada ao iniciar-se o servidor pela função start_thread, para procurar por outros processos na rede. Para simplificar o desenvolvimento da arquitetura proposta, o serviço de descobrimento se responsabiliza por divulgar os métodos registrados conforme novas conexões são estabelecidas.

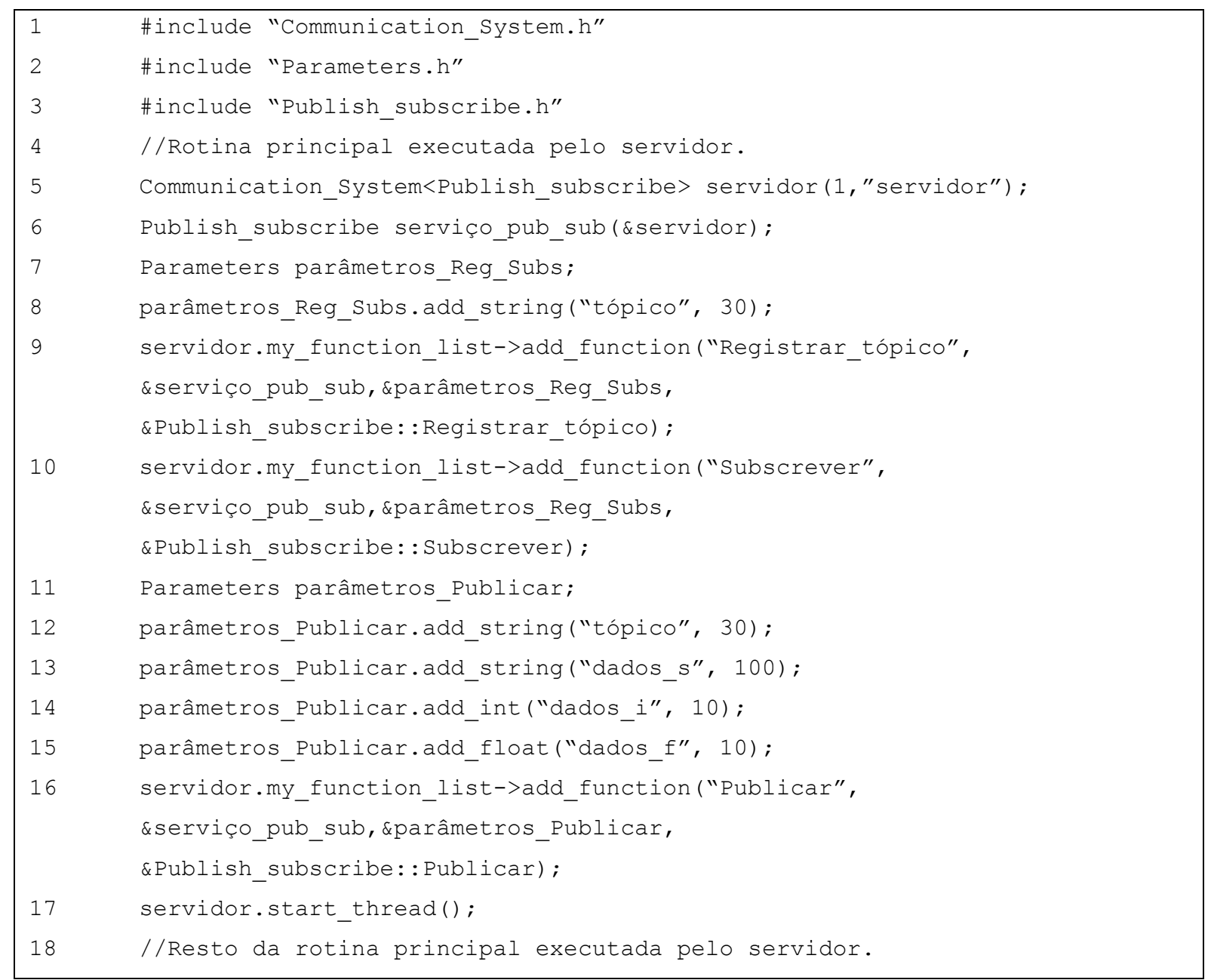

Figura 24 - Código exemplo do servidor: utilização da interface oferecida pelo middleware proposto para disponibilizar o serviço implementado pela classe Publish_subscribe. 


\subsubsection{Código do cliente}

Neste exemplo, o processo cliente utiliza o serviço proporcionado pelo servidor para registrar e subscrever tópicos de seu interesse, e publicar e receber informações sobre um determinado tópico. O cliente disponibiliza o método Enviar_publicação da classe Publish_subscribe para permitir o recebimento das informações (enviadas pelo servidor) relacionadas com os tópicos de seu interesse. O código exemplo do cliente que contém sua rotina principal é apresentado na Fig. 25 e descrito em detalhes a seguir.

Semelhantemente ao código do servidor, as linhas de 1 a 3 incluem as definições das classes necessárias para a implementação da rotina principal do cliente. Também de forma semelhante, a linha 5 cria um objeto da classe Unit ("cliente") e utiliza seu template para passar a definição da classe Publish_subscribe. É importante mencionar neste ponto que a classe Publish_subscribe é utilizada novamente para o cliente apenas por simplicidade, e que o cliente necessita apenas dos mecanismos associados ao método Enviar_publicação (não necessita da definição dos outros métodos) para sua execução. Ainda na linha 5 é utilizado o serviço de nomeação, tanto para associar um nome ao processo cliente (“cliente" novamente), quanto também passar o nome ("servidor") e identificador ("1") do processo servidor desejado para estabelecer uma conexão. Continuando com a descrição, a linha 6 cria um objeto da classe Publish-subscribe ("serviço_pub_sub") que vai proporcionar os mecanismos para armazenar as informações recebidas dos tópicos subscritos. As linhas de 7 a 11 criam um objeto do tipo Parameters ("parâmetros_Eviar_pub”) que contém as mesmas variáveis do objeto "parâmetros_Publicar" do código exemplo do servidor. A linha 12 utiliza o objeto "parâmetros_Eviar_pub” como modelo para registrar o método Enviar_publicação, permitindo então sua disponibilização para os outros processos (neste caso o servidor). A linha 13 requisita o serviço de descobrimento para aguardar o estabelecimento de uma conexão do servidor especificado pelo serviço de nomeação.

Ao estabelecer a conexão com o servidor desejado, o cliente inicia a utilização do serviço Publish-subscribe feita a partir da linha 13. Prosseguindo com o código exemplo, as linhas de 14 a 17 criam o objeto do tipo Parameters ("request") para requisitar o registro do tópico "comida" ao servidor (através da requisição do método Registrar_tópico). A requisição feita na linha 17 utiliza o serviço de sincronização para bloquear a rotina do cliente e esperar a confirmação do servidor de que o registro do tópico foi feito com sucesso. Após o 
recebimento da confirmação (chamada do método block_request_their_function retorna um número inteiro positivo), as linhas 18 e 19 fazem a subscrição ao tópico "comida" registrado no servidor. Em seguida, as linhas de 20 a 25 adicionam as variáveis necessárias no objeto "request" para publicar uma informação relacionada com tópico "tempero". Esta informação, que é constituída somente de uma mensagem no formato texto, será distribuída a todos os outros processos clientes que se subscreveram para o tópico "tempero". Feito isto, as linhas 26 e 27 criam um objeto da classe Parameters ("mensagem") para receber possíveis informações recebidas sobre os tópicos de seu interesse (neste caso somente o tópico “comida").

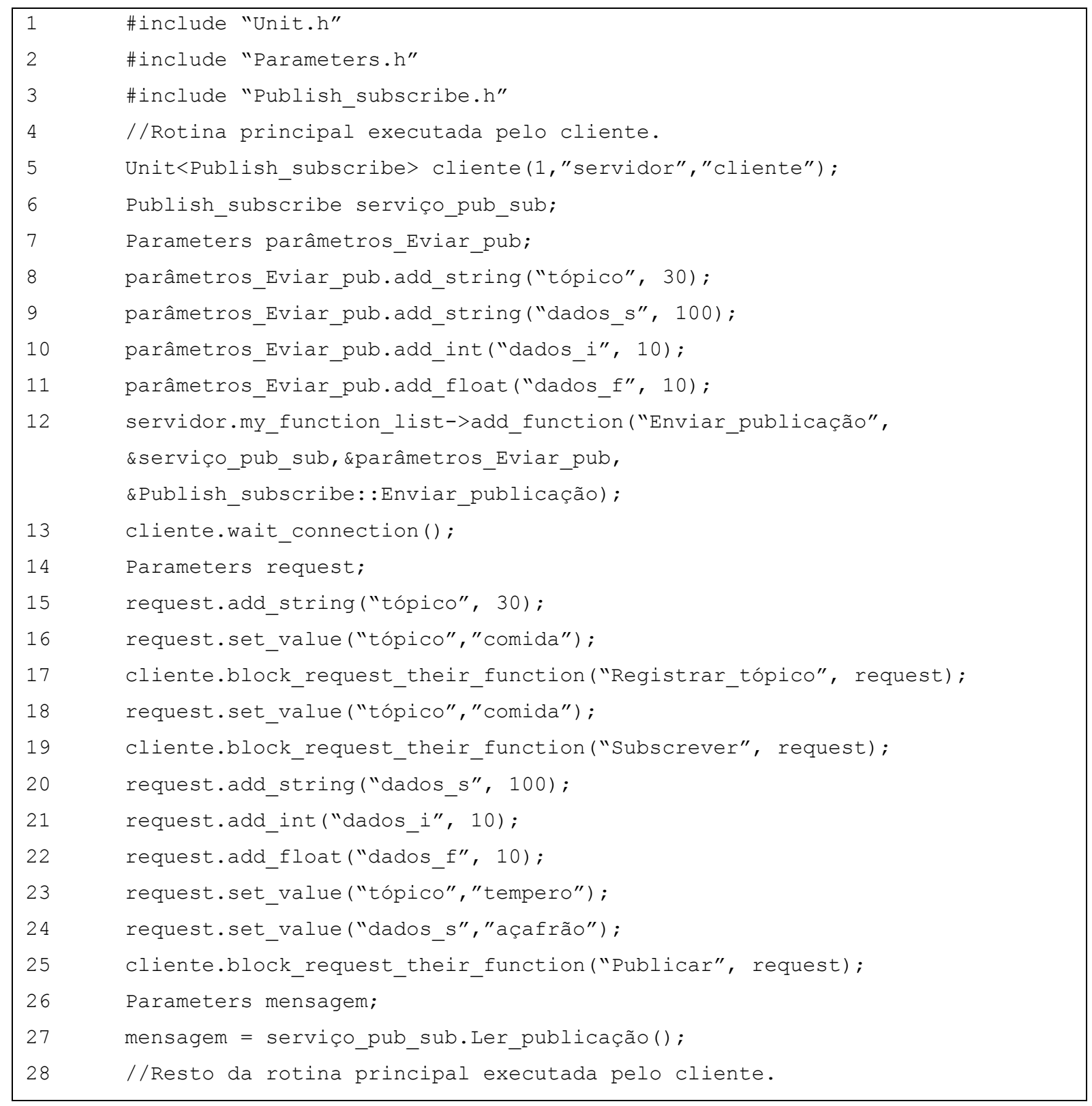

Figura 25 - Código exemplo do cliente: utilização da interface oferecida pelo middleware proposto para acessar o serviço publish-subscribe disponível no servidor. 


\subsection{APLICAÇÃO DA ARQUITETURA PARA O PROJETO DO AGVS}

Para testar os mecanismos disponibilizados pela arquitetura proposta e otimizar sua interface oferecida para o desenvolvimento de aplicações, este middleware foi utilizado para implementar as interações entre os processos do projeto do AGVS. Com isto, além de facilitar o reconhecimento dos mecanismos básicos essenciais para a arquitetura, permitiu um melhor ajuste de sua interface para oferecer uma visão intuitiva de seu uso. Uma breve descrição do funcionamento do sistema de AGVs, assim como as principais funcionalidades implementadas para permitir a interação entre as unidades que o compões, são apresentadas a seguir.

O projeto do AGVS (30) se baseia em um sistema inteligente projetado para gerenciar AGVs que realizam as operações de manuseio de materiais em um armazém industrial. Este sistema é constituído a partir da interação entre dois tipos de unidades (no qual cada unidade é associada a um processo): os AGVs, que são veículos autônomos capazes de realizar tarefas de carregamento e descarregamento de produtos (paletes) e o WMS (Warehouse Management System), que proporciona o acesso ao banco de dados do armazém e permite o agendamento das operações a serem realizadas.

O AGVS permite a distribuição das tarefas para os AGVs de forma eficiente (minimizando o custo em relação ao tempo de execução) e o monitoramento destas operações para garantir o funcionamento do armazém. Estes serviços são proporcionados por um supervisor (também associado a um processo). O AGVS possui uma arquitetura centralizada baseada em interações do tipo cliente-servidor, sendo o supervisor a unidade central do sistema. Desta forma, todas as interações que ocorrem entre as unidades são mediadas pelo supervisor, tornando-o uma peça fundamental para o funcionamento do sistema. A seguir, são apontadas as funcionalidades principais disponibilizadas por cada tipo de unidade do AGVS para implementar a interação necessária para sua operação. A Fig. 22 ilustra as conexões estabelecidas entre os tipos de unidades do AGVS durante sua operação, indicando também quais as classes da arquitetura proposta (Unit ou Communication_System) foram utilizadas em cada tipo. 


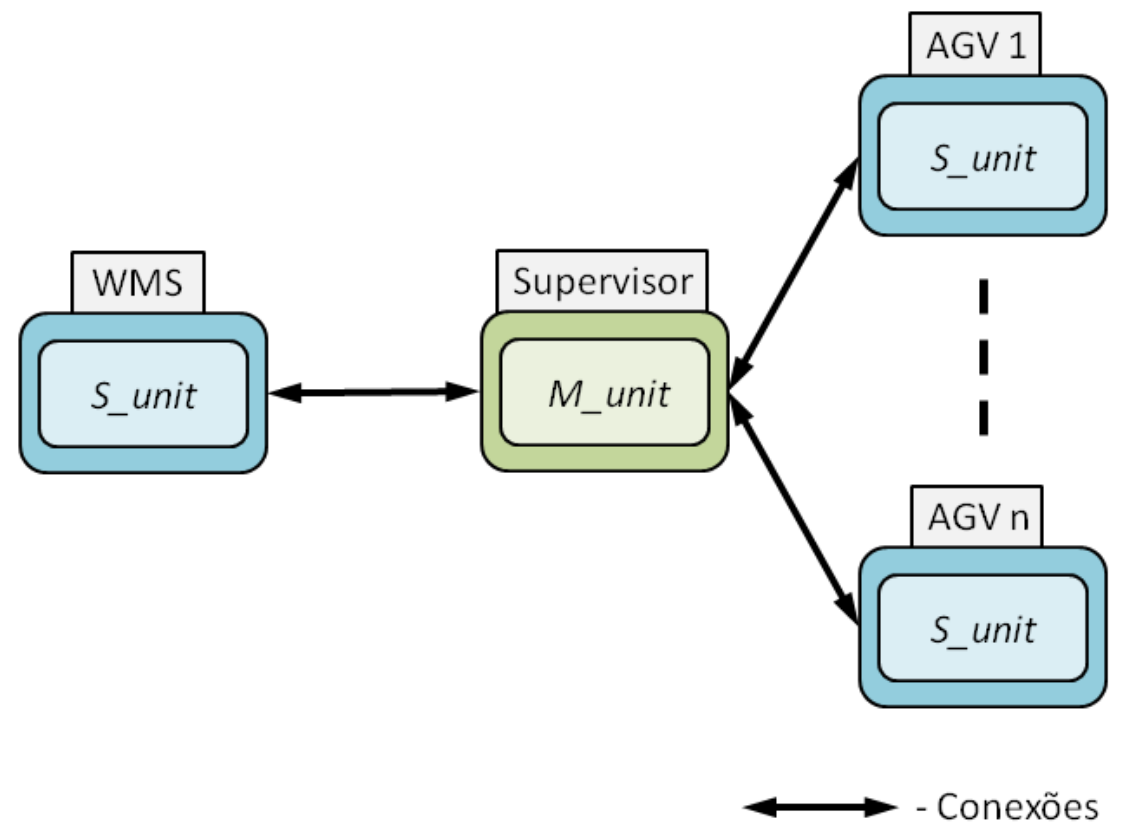

Figura 26 - Classes utilizadas e conexões estabelecidas entre as unidades do AGVS.

O WMS está relacionado com o agendamento das tarefas que devem ser realizadas no armazém em um determinado dia. Estas tarefas normalmente consistem em dois tipos de operação: coleta de produtos armazenados para o carregamento de um lote ou descarregamento de produtos de um lote para seu armazenamento. Para ambos os casos, o WMS gera um arquivo que contém a posição inicial e final para a movimentação de cada produto (palete) individualmente. Sendo assim, o middleware proposto foi utilizado para proporcionar basicamente duas funcionalidades envolvendo o WMS:

- Disponibilizar ao supervisor os arquivos das tarefas gerados de forma que este possa acessá-los sequencialmente a medida que são finalizadas;

- Oferecer um mecanismo para que o supervisor informe o WMS sobre cada movimentação individual realizada pelos produtos (paletes), permitindo então a atualização de seu banco de dados.

Os AGVs realizam as operações de manuseio (movimentação dos paletes) de forma autônoma no armazém. Este tipo de unidade possui a capacidade de se autolocalizar e se movimentar de forma autônoma dentro do armazém, podendo inclusive realizar a detecção e desvio de possíveis obstáculos. Eles são responsáveis por executar as tarefas de carregamento e descarregamento de paletes de acordo com o planejamento do supervisor inteligente. Desta forma, o middleware proposto foi utilizado para implementar basicamente dois tipos de funcionalidades associados aos AGVs: 
- Permitir a passagem de todas as informações necessárias (i.e., rotas, sequência de produtos e horário de operação) do supervisor aos AGVs para realizar a movimentação de um conjunto de produtos (paletes);

- Proporcionar mecanismos para que o supervisor realize a constante monitoração das operações dos AGVs para que possa realizar a intervenção, caso necessária.

O supervisor é responsável por processar as operações passadas pelo WMS e, a partir disto, gerar as tarefas para os AGVs de forma a maximizar a eficiência da execução destas operações. Para tanto, o supervisor pode decidir quais e quantos AGVs irão realizar estas operações, e também determinar quais as rotas que cada um deve executar para atender a tarefa. Para proporcionar a comunicação necessária, o middleware proposto, além de proporcionar as funcionalidades descritas para o WMS e AGVs, permite também que o supervisor tenha o conhecimento de quantos AGVs estão disponíveis para realizarem as tarefas (que estão devidamente conectados ao supervisor), e possibilita a interação individual com cada um segundo sua necessidade.

\subsection{EXEMPLO DE INTEGRAÇÃO DA ARQUITETURA DE COMUNICAÇÃO COM SERVIÇOS WEB}

Como mencionado no capítulo anterior, a arquitetura de comunicação proposta foi desenvolvida na linguagem de programação $\mathrm{C}++$ e na plataforma Linux. Desta forma, para poder permitir a interação das aplicações desenvolvidas, usando a arquitetura proposta, com outras aplicações desenvolvidas em outras linguagens de programação e plataformas, decidiuse optar pela utilização de serviços web (web services).

Os serviços web permitem a interação entre um servidor, que possui o serviço web, e um cliente que deseja utilizar o serviço disponibilizado. Segundo Coulouris, Dollimore e Kindberg (8), a interação entre um cliente e um servidor é geralmente realizada através da troca de mensagens no formato XML (eXtensible Markup Language), um modelo para representação textual, que são encapsuladas de acordo com o protocolo SOAP (Simple Object Access Protocol). 
Devido ao fato dos serviços web serem bem difundidos e amplamente utilizados em diversas áreas como, por exemplo, no comércio eletrônico (Amazon, Google, eBay, entre outras), existe um bom número de ferramentas que permitem a implementação destes serviços em várias linguagens de programação e plataformas. Sendo assim, o uso de serviços web para proporcionar a integração da arquitetura de comunicação proposta com outras aplicações desenvolvidas em outras linguagens de programação e plataformas é uma opção viável e interessante.

Para demonstrar que a integração dos serviços web com o middleware proposto é possível, foi implementado um sistema que permite o controle de uma miniatura de empilhadeira robótica por meio de um celular com plataforma Android. Os processos envolvidos, as funcionalidades e as ferramentas utilizadas para o desenvolvimento deste sistema são descritos a seguir.

O sistema exemplo consiste basicamente da interação de três processos, sendo um processo para controlar a empilhadeira robótica, um para hospedar os serviços web (servidor) e outro presente no celular para requisitar os serviços web disponibilizados. O processo referente à empilhadeira robótica foi desenvolvido utilizando-se o middleware proposto, o qual foi usado para disponibilizar os métodos de um objeto que permitiam o controle de movimento, tais como: movimentação das rodas e do garfo. Para o processo do servidor foi utilizado o framework disponibilizado gratuitamente pela empresa WSO2 (15) para a implementação dos serviços web em $\mathrm{C}++$. Cada um destes serviços utilizava a interface da arquitetura de comunicação proposta para interagir com o processo da empilhadeira robótica, e foram hospedados em um servidor Apache (33). Para o processo contido no celular foi utilizado o Android SKD (Software Development Kit) (34) para a sua implementação, e para permitir a requisição dos serviços web disponíveis no servidor foi utilizada a biblioteca ksoap2-android, que é licenciada pelo MIT (Massachusetts Institute of Technology) e disponibilizada gratuitamente em (35).

Nas Fig. 23 e 24 são apresentas, respectivamente, uma ilustração da interação entre os processos deste sistema exemplo e as fotos contendo a interface do aplicativo no celular para controlar a empilhadeira e a empilhadeira sendo controlada. 


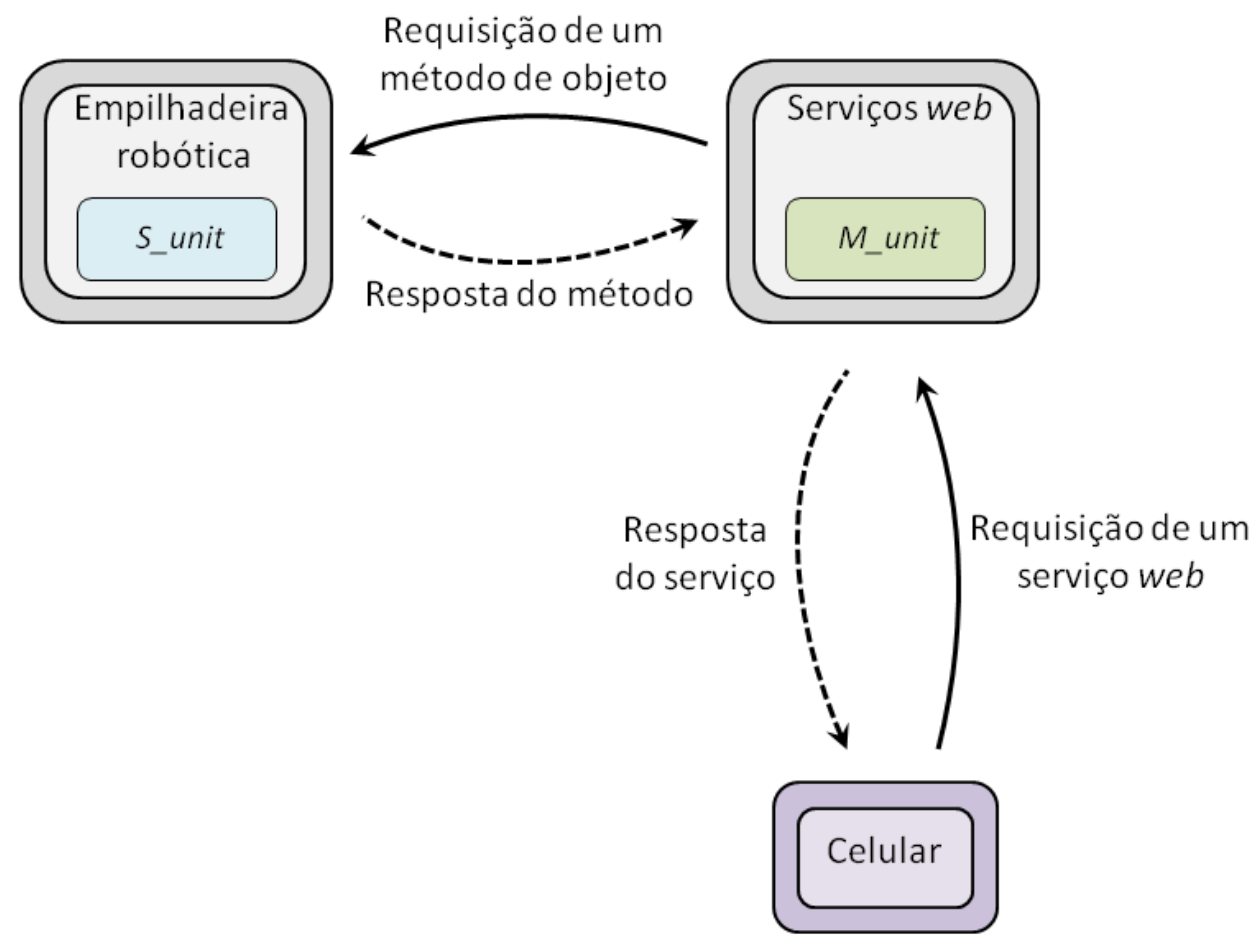

Figura 27 - Ilustração da interação entre os processos utilizados para o controle de uma empilhadeira robótica através de um celular com plataforma Android.

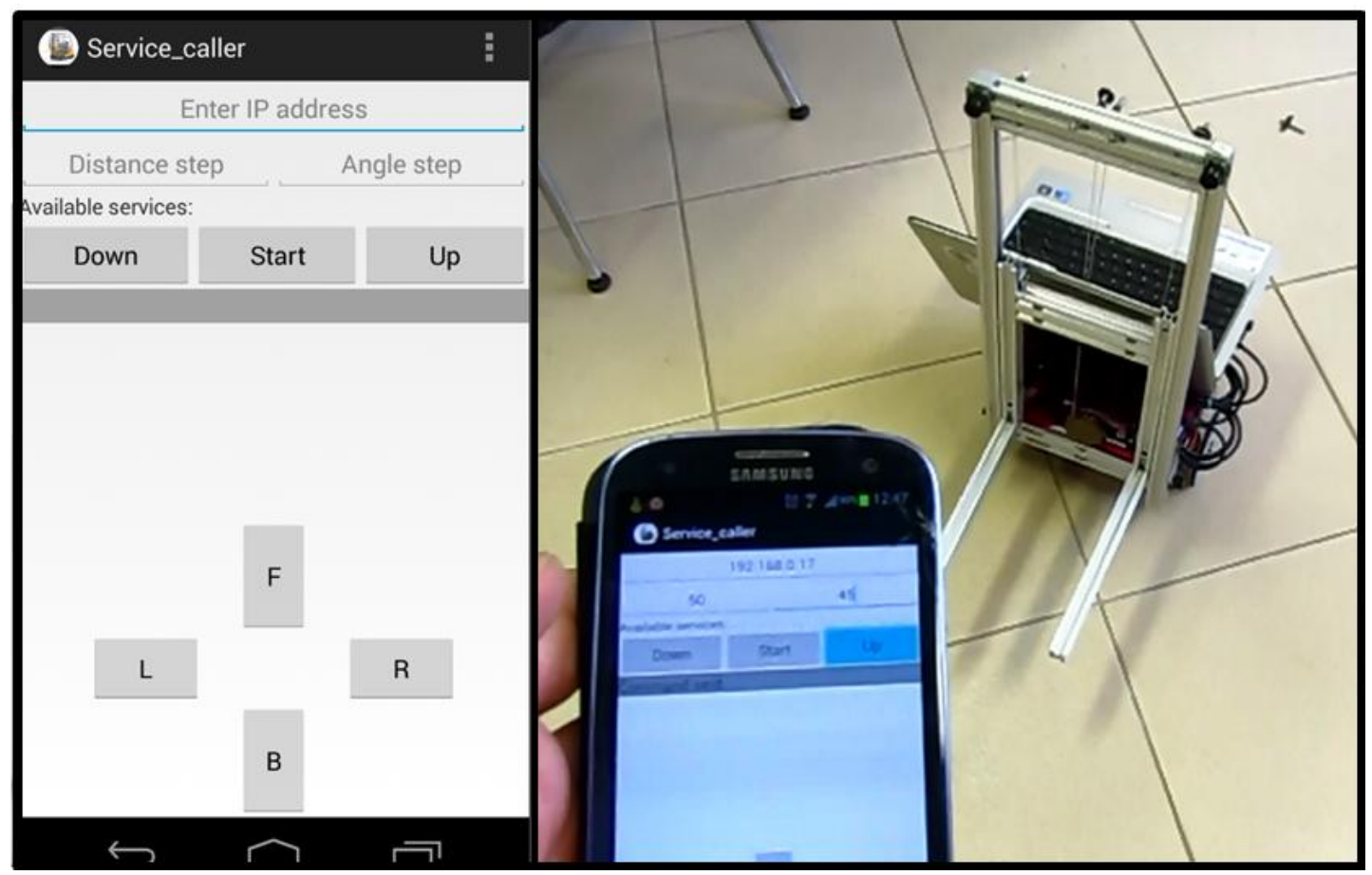

Figura 28 - Interface do aplicativo no celular para controlar a empilhadeira (esquerda) e a empilhadeira sendo controlada (direita). 


\subsection{CONSIDERAÇÕES FINAIS DO CAPÍTULO}

Para exemplificar o uso da interface da arquitetura e ao mesmo tempo explicar como novas funcionalidades podem ser agregadas a ela, foi demonstrado o uso de uma definição de classe para proporcionar um serviço publish-subscribe às aplicações. Como descrito neste capítulo, esta arquitetura foi utilizada para proporcionar a interação entre os processos presentes no projeto de AGVS, o que facilitou o reconhecimento dos mecanismos básicos necessários para o middleware proposto e auxiliou no desenvolvimento de sua interface. Por fim, foi demonstrado o uso de serviços web para proporcionar a interação da arquitetura proposta com outras aplicações desenvolvidas em outras linguagens de programação e plataformas.

Como pode ser observada, a interface proporcionada pelas classes Unit e Communication_system oferecem mecanismos intuitivos para a utilização da arquitetura proposta no desenvolvimento de aplicações. Como demonstrada, a implementação de novas funcionalidades na definição de classes oferece um mecanismo interessante para agregar serviços à arquitetura, o que permite aos desenvolvedores escolherem as classes de acordo com a necessidade de suas aplicações.

No próximo capítulo serão apresentados os testes realizados para avaliar o desempenho da arquitetura. Estes testes permitem avaliar os mecanismos utilizados durante a interação entre os processos de uma aplicação (troca de mensagens para requisitar métodos e receber seus resultados). 


\section{RESULTADOS}

Este capítulo apresenta os resultados dos testes realizados para avaliar o desempenho da arquitetura proposta. Desta forma, foram realizados testes de tempo de resposta, throughput, geração e processamento de mensagens e disponibilidade. Como a arquitetura foi utilizada para implementar a interação entre as unidades do projeto de AGVs, são apresentadas algumas medidas referentes a operação do sistema.

\subsection{TESTES DE TEMPO DE RESPOSTA, GERAÇÃO E PROCESSAMENTO DE MENSAGENS E THROUGHPUT}

Os testes de tempo de resposta e throughput (descritos no segundo capítulo) oferecem um conjunto de parâmetros temporais que permitem a avaliação do desempenho da arquitetura proposta. As características de uma arquitetura de comunicação que têm maior influência sobre estes testes, além dos protocolos de rede utilizados, são o formato das mensagens adotado, que afeta diretamente a quantidade de dados contida numa mensagem para descrevê-la (overhead), e a lógica interna da arquitetura para gerar e processar estas mensagens. Desta forma, para proporcionar uma visão do desempenho da arquitetura tanto de um ponto de vista externo, quanto de sua lógica interna, além dos testes de tempo de resposta e throughput, também foram medidos os tempos gastos para gerar e processar as mensagens trocadas nestes testes. Para evitar que um teste tivesse influência sobre o outro eles foram realizados individualmente, e o cenário em que foram feitos é descrito em maiores detalhes a seguir.

As medidas destes testes foram realizadas durante a interação entre dois processos, sendo que cada um foi executado em uma máquina diferente (ambas possuíam as mesmas configurações, tanto de hardware quanto de sistema operacional). Estas máquinas foram conectadas por meio de uma rede Wi-Fi disponibilizada por um roteador. Utilizando-se da 
arquitetura de comunicação proposta, um dos processos (denominado processo principal) requisitava um método contido no outro processo. Este método recebia como parâmetro de entrada um objeto da classe Parameters que continha uma ou mais variáveis do tipo string de tamanhos variados. A rotina chamada por este método era vazia e tinha como retorno o mesmo parâmetro recebido como parâmetro de entrada. Para o teste de throughput foi utilizado o serviço de requisição síncrona que fazia com que o processo requisitante bloqueasse sua chamada até receber uma confirmação de que o método desejado foi executado (um simples ACK). Para o teste de tempo de resposta foi utilizado o serviço de requisição síncrona que permitia que o processo requisitante recebesse o parâmetro retornado pelo método desejado. O cenário descrito é nomeado como cenário 1, e na Fig. 25 é ilustrada a interação entre estes dois processos para medir os testes mencionados.

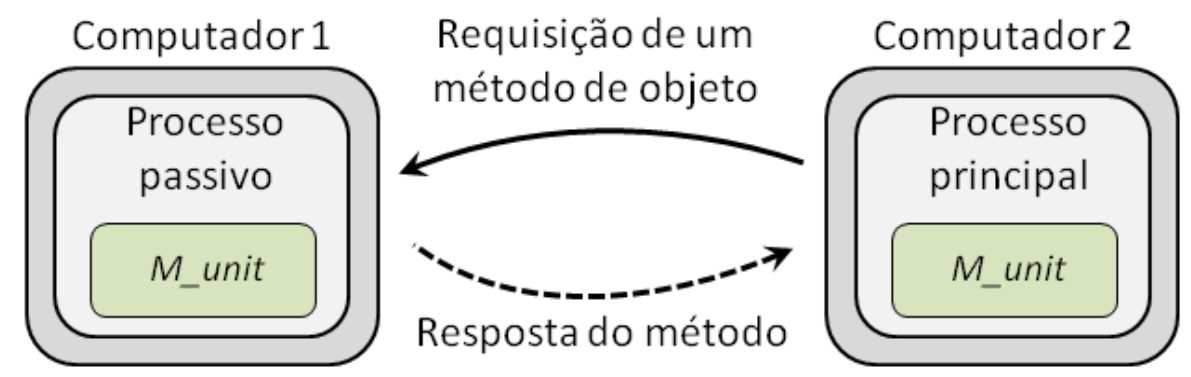

Figura 29 - Ilustração dos processos do cenário 1.

Para analisar o desempenho da arquitetura proposta sobre diferentes configurações, os testes mencionados foram realizados para diferentes tamanhos de variáveis do tipo string contidos no parâmetro de entrada do método requisitado (diferente número de caracteres contidos na mensagem). Também para poder analisar com maior precisão o tempo gasto pela arquitetura para gerar e processar as mensagens trocadas, com o mesmo número de caracteres enviados em uma requisição, foram realizados testes contendo números diferentes de variáveis do tipo string no parâmetro de entrada (i.e., uma variável contendo n caracteres ou dez variáveis contendo cada uma n/10 caracteres). Para cada configuração, foram realizadas cem medidas consecutivas para o teste de tempo de resposta, e 10000 medidas (100 grupos de 100 medidas consecutivas cada) para o teste de throughput. Os valores medidos pelos testes para os diferentes números de caracteres contidos nas mensagens trocadas, e diferentes números de variáveis, são apresentados na Tabela 1. 


\begin{tabular}{|c|c|c|c|c|c|}
\hline $\begin{array}{c}\text { Número } \\
\text { de } \\
\text { variáveis }\end{array}$ & $\begin{array}{c}\text { Tamanho da } \\
\text { mensagem } \\
\text { (caracteres) }\end{array}$ & $\begin{array}{c}\text { Geração da } \\
\text { mensagem } \\
(\boldsymbol{\mu s})\end{array}$ & $\begin{array}{c}\text { Processamento da } \\
\text { mensagem }(\boldsymbol{\mu s})\end{array}$ & $\begin{array}{c}\text { Tempo de } \\
\text { resposta } \\
(\mathbf{m s})\end{array}$ & $\begin{array}{c}\text { Throughput } \\
\text { (k.caracteres/s) }\end{array}$ \\
\hline 1 & 1 & $50 \pm 14$ & $21 \pm 1$ & $2 \pm 1$ & $0,52 \pm 0,04$ \\
\hline 1 & 10 & $59 \pm 9$ & $25 \pm 1$ & $2 \pm 1$ & $4 \pm 1$ \\
10 & 10 & $234 \pm 51$ & $61 \pm 3$ & $3 \pm 1$ & $3,7 \pm 0,4$ \\
\hline 1 & 100 & $119 \pm 28$ & $55 \pm 14$ & $3 \pm 2$ & $47 \pm 3$ \\
\hline 10 & 100 & $310 \pm 69$ & $121 \pm 23$ & $3 \pm 1$ & $35 \pm 4$ \\
\hline 1 & 1000 & $710 \pm 151$ & $585 \pm 111$ & $5 \pm 1$ & $225 \pm 14$ \\
\hline 10 & 1000 & $874 \pm 240$ & $889 \pm 104$ & $8 \pm 2$ & $183 \pm 8$ \\
\hline 1 & 10000 & $7,2 \mathrm{k} \pm 1,9 \mathrm{k}$ & $36 \mathrm{k} \pm 4 \mathrm{k}$ & $91 \pm 8$ & $186 \pm 4$ \\
\hline 1 & 10000 & $7,3 \mathrm{k} \pm 1,6 \mathrm{k}$ & $37 \mathrm{k} \pm 4 \mathrm{k}$ & $95 \pm 7$ & $185 \pm 4$ \\
\hline 10 & 20000 & $13 \mathrm{k} \pm 2 \mathrm{k}$ & $95 \mathrm{k} \pm 9 \mathrm{k}$ & $233 \pm 9$ & $158 \pm 3$ \\
\hline
\end{tabular}

Tabela 1 - Medidas dos testes de geração e processamento das mensagens, tempo de resposta e throughput.

De acordo com o esperado, o uso de um menor número de variáveis para transmitir uma mensagem de determinado tamanho (número de caracteres) requer um menor custo de processamento para gerar e processar estas informações, e pode ser facilmente observado quando o tamanho destas variáveis (número de caracteres contidos em cada variável) for da mesma ordem de grandeza que o número de variáveis utilizadas. Como pode ser visto na Tabela 1, para tamanhos de variáveis muito superiores ao número destas variáveis, a diferença do tempo necessário para gerar ou processar estas mensagens entre o caso de uma variável ou dez, passa a ser desprezível frente à incerteza associada a estas medidas. Isso ocorre porque o custo de processamento adicional necessário para gerenciar as variáveis na mensagem é desprezível frente ao custo necessário para processar o conteúdo em si de cada variável. Embora os valores médios do tempo de resposta entre os casos de uma variável ou dez sejam ligeiramente distintos, esta diferença permanece dentro da incerteza associada às medidas. Por outro lado, os testes de throughput confirmaram que, para um grande número de interações sucessivas entre processos, pode-se obter um melhor desempenho ao utilizar somente uma variável para transportar a informação. Nota-se também que o valor máximo permitido para o throughput é obtido para tamanhos de variáveis entre 1000 e 10000 caracteres. 
Para poder comparar o desempenho da arquitetura proposta e verificar o quanto sua lógica interna possui influência sobre as medidas realizadas, o tempo de resposta obtido é comparado com o tempo de resposta medido através do protocolo ICMP (Internet Control Message Protocol). O teste utilizando o protocolo ICMP é feito entre as mesmas máquinas que executam os processos utilizados para os testes da arquitetura, e proporciona os melhores resultados de acordo com a infraestrutura da rede utilizada. Tabela 2 apresenta a comparação entre o tempo de resposta obtido pela arquitetura e o tempo de resposta obtido pelo protocolo ICMP.

\begin{tabular}{|c|c|c|c|}
\hline & \multicolumn{2}{|c|}{ Tempo de resposta } & \\
\hline $\begin{array}{c}\text { Tamanho da mensagem } \\
\text { (caracteres) }\end{array}$ & $\begin{array}{l}\text { ICMP } \\
(\mathrm{ms})\end{array}$ & $\begin{array}{l}\text { Arquitetura proposta } \\
\qquad(\mathrm{ms})\end{array}$ & $\begin{array}{c}\text { Diferença das médias } \\
\qquad(\mathrm{ms})\end{array}$ \\
\hline 10 & $2 \pm 1$ & $2 \pm 1$ & 0 \\
\hline 100 & $3 \pm 1$ & $3 \pm 2$ & 0 \\
\hline 1000 & $5 \pm 1$ & $5 \pm 1$ & 0 \\
\hline 10000 & $19 \pm 6$ & $91 \pm 8$ & 70 \\
\hline 20000 & $32 \pm 5$ & $233 \pm 9$ & 203 \\
\hline
\end{tabular}

Tabela 2 - Diferença entre o tempo de resposta obtido através do protocolo ICMP e através dos testes realizados com a arquitetura proposta.

Como podem ser observados, os resultados obtidos pela arquitetura proposta são semelhantes aos obtidos pelo ICMP para mensagens com o tamanho da ordem de até 1000 caracteres. A partir deste ponto, o custo de processamento para gerar e processar as mensagens trocadas começa a se tornar relevante durante a interação entre os processos envolvidos no teste. Sendo assim, para melhorar o desempenho da arquitetura proposta e produzir resultados mais próximos do ideal, é necessário reavaliar os mecanismos utilizados para a geração e processamento das mensagens para torná-lo mais eficiente. Após a medida destes testes, foram identificados diversos pontos para reduzir o número de etapas utilizadas na duplicação dos objetos da classe Parameters, o que reduziu consideravelmente o tempo de processamento das mensagens, mas que não houve tempo de refazer os testes com estas modificações.

Um fato importante de ser notado é que, para os testes realizados com a arquitetura, os processos interagem de forma isolada e não possuem nenhuma outra influência. Para verificar como seria seu desempenho em ambientes mais dinâmicos, onde vários processos podem 
requisitar métodos de um mesmo processo simultaneamente, o teste de tempo de resposta foi realizado em outros quatro cenários diferentes. Nestes novos cenários, além de possuir os dois processos interagindo entre si para coletar as medidas, outros cinco processos foram acrescentados para aumentar a carga imposta sobre a rede. Estes processos adicionais são executados distribuidamente em duas outras máquinas também conectadas na rede Wi-Fi. Cada processo adicional requisita o mesmo método do processo envolvido na medida dos testes, e as requisições são feita repetidamente com um intervalo aleatório que varia de um cenário para o outro. Estes novos cenários são denominados de cenários 2, 3, 4 e 5 e possuem como período aleatório entre requisições, valores que variam, respectivamente, entre 1 e 500 ms (requisições contendo 10000 caracteres), 1 e 500 ms (requisições contendo 20000 caracteres), 1 e 50 ms (requisições contendo 1000 caracteres) e 1 e 20 ms (requisições contendo 1000 caracteres). A configuração dos processos presentes nestes novos cenários é ilustrada na Fig. 26.

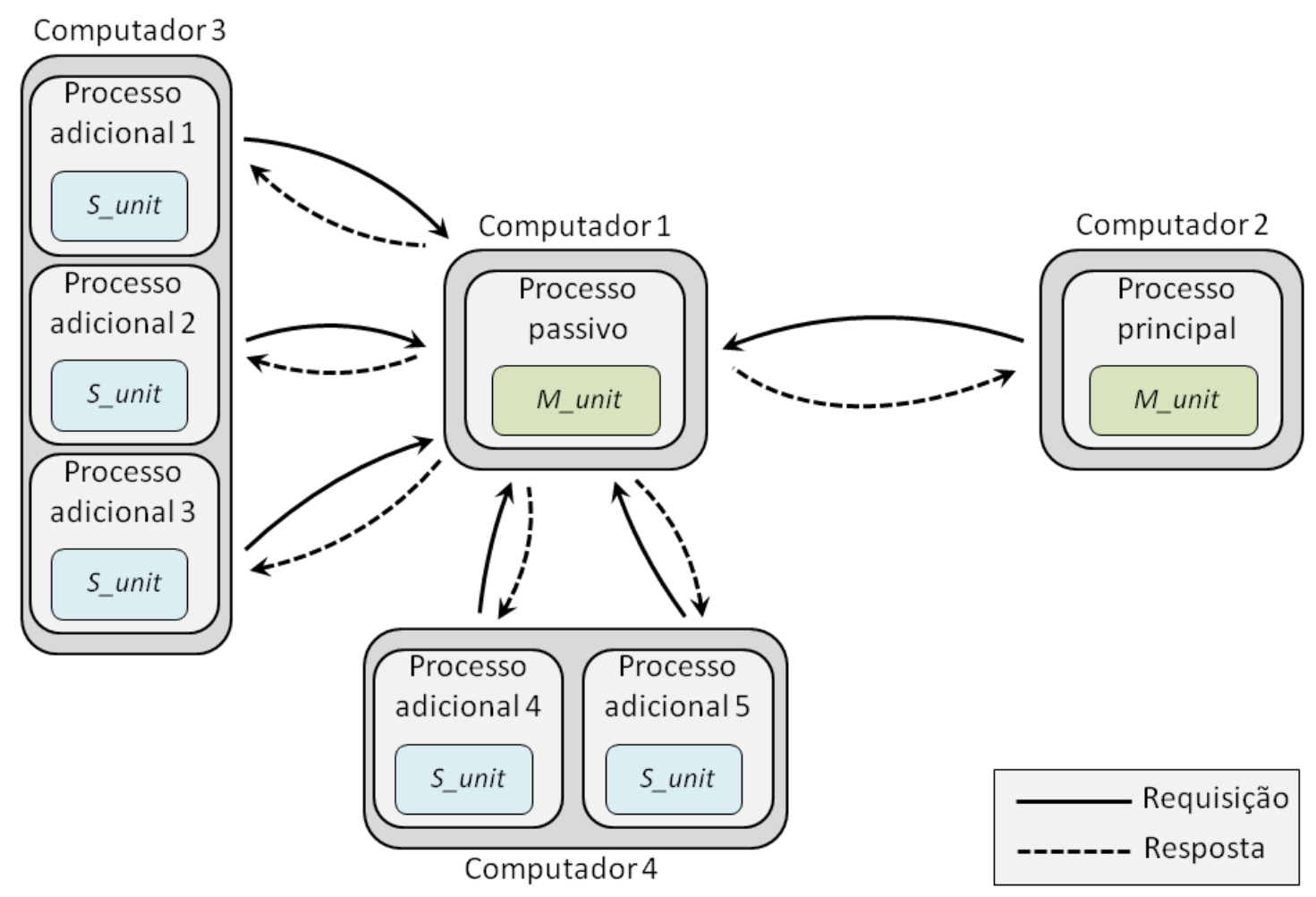

Figura 30 - Ilustração dos processos dos cenários 2, 3, 4 e 5.

Para estimar a carga na rede incrementada pelos processos adicionais, foi calculada a estimativa da probabilidade de que um dado processo adicional inicie o envio de sua requisição enquanto o processo principal (que realiza a medida) esteja trocando suas mensagens referentes a uma determinada requisição. Esta estimativa varia de acordo com o 
tamanho das mensagens trocadas pelo processo principal, e pode ser calculada de acordo com o conjunto de equações a seguir.

$$
\begin{aligned}
& \overline{f_{\text {requisição }}}=\frac{1}{\overline{T_{\text {requisição }}}}=\frac{1}{\left.\overline{(\Delta t}+\overline{t_{\text {retorno }}}\right)} \\
& \overline{P_{\text {envio }}}=\frac{\overline{t_{\text {retorno }}}-\overline{t_{\text {mensagem }}}}{\overline{T_{\text {requisição }}}} \\
& P_{\text {simultâneo }}=1-\left(1-\frac{P_{\text {envio }}^{\text {principal }}}{T_{\text {requisição }}^{\text {principal }}} \overline{f_{\text {requisição }}^{\text {adiciona }}}\right)
\end{aligned}
$$

Onde: $\mathrm{f}_{\text {requisição }}$ representa a frequência de requisição de um determinado processo; $\mathrm{T}_{\text {requisição }}$ representa o período entre requisições consecutivas realizadas por um dado processo; $\Delta t$ representa o intervalo de tempo aguardado para que um processo inicie outra requisição; $\mathrm{t}_{\text {retorno }}$ representa o tempo total tomado para realizar uma requisição; $\mathrm{P}_{\text {envio }}$ representa a probabilidade de que em um determinado instante de tempo um processo esteja enviando mensagens referentes a uma requisição; $\mathrm{t}_{\text {mensagem }}$ representa o tempo gasto para a geração e processamento das mensagens utilizadas numa requisição;

$\mathrm{P}_{\text {simultâneo }}$ representa a estimativa da probabilidade de que um determinado processo adicional inicie o envio de uma requisição enquanto o processo principal esteja trocando mensagens referentes a uma dada requisição;

$\mathrm{P}_{\text {envio }}{ }^{\text {principal }}$ representa a probabilidade $\mathrm{P}_{\text {envio }}$ referente ao processo principal;

$\mathrm{T}_{\text {requisição }}{ }^{\text {principal }}$ refere-se ao $\mathrm{T}_{\text {requisição }}$ do processo principal; $\mathrm{f}_{\text {requisição }}{ }^{\text {adicional }}$ refere-se a $\mathrm{f}_{\text {requisição }}$ de um determinado processo adicional.

As comparações dos tempos de resposta para diferentes números de caracteres utilizados nas requisições realizadas pelo processo principal, com somente uma variável do tipo string, entre o cenário 1 e os cenários 2, 3, 4 e 5, são apresentadas, respectivamente, nas tabelas $3,4,5$ e 6 . 


\begin{tabular}{|c|c|c|c|c|c|}
\cline { 2 - 5 } \multicolumn{1}{c|}{} & \multicolumn{2}{c|}{ Tempo de resposta } & \multicolumn{2}{c|}{} \\
\hline $\begin{array}{c}\text { Tamanho da } \\
\text { mensagem (caracteres) }\end{array}$ & $\begin{array}{c}\text { Cenário 1 } \\
(\mathbf{m s})\end{array}$ & $\begin{array}{c}\text { Cenário 2 } \\
(\mathbf{m s})\end{array}$ & $\begin{array}{c}\text { Diferença das } \\
\text { médias (ms) }\end{array}$ & $\mathbf{P}_{\text {simultâneo }}$ & $\mathbf{P}_{\text {envio }}^{\text {adicional }}$ \\
\hline $\mathbf{1}$ & $2 \pm 1$ & $3 \pm 2$ & 1 & $0,6 \%$ & $3,5 \%$ \\
\hline $\mathbf{1 0}$ & $2 \pm 1$ & $3 \pm 3$ & 1 & $0,6 \%$ & $3,5 \%$ \\
\hline $\mathbf{1 0 0}$ & $3 \pm 2$ & $4 \pm 3$ & 1 & $0,8 \%$ & $3,5 \%$ \\
\hline $\mathbf{1 0 0 0}$ & $5 \pm 1$ & $7 \pm 3$ & 2 & $0,9 \%$ & $3,5 \%$ \\
\hline $\mathbf{1 0 0 0 0}$ & $91 \pm 8$ & $97 \pm 14$ & 6 & $6,5 \%$ & $3,5 \%$ \\
\hline $\mathbf{2 0 0 0 0}$ & $233 \pm 9$ & $258 \pm 27$ & 25 & $18 \%$ & $3,5 \%$ \\
\hline
\end{tabular}

Tabela 3 - Diferença entre os tempos de resposta obtidos pelos cenários 1 e 2.

\begin{tabular}{|c|c|c|c|c|c|}
\cline { 2 - 3 } \multicolumn{1}{c|}{} & \multicolumn{2}{c|}{ Tempo de resposta } & \multicolumn{2}{c|}{} \\
\hline $\begin{array}{c}\text { Tamanho da } \\
\text { mensagem (caracteres) }\end{array}$ & $\begin{array}{c}\text { Cenário 1 } \\
(\mathbf{m s})\end{array}$ & $\begin{array}{c}\text { Cenário 3 } \\
(\mathbf{m s})\end{array}$ & $\begin{array}{c}\text { Diferença das } \\
\text { médias (ms) }\end{array}$ & $\mathbf{P}_{\text {simultâneo }}$ & $\mathbf{P}_{\text {envio }}^{\text {adicional }}$ \\
\hline $\mathbf{1}$ & $2 \pm 1$ & $5 \pm 5$ & 3 & $0,5 \%$ & $5,5 \%$ \\
\hline $\mathbf{1 0}$ & $2 \pm 1$ & $6 \pm 6$ & 4 & $0,5 \%$ & $5,5 \%$ \\
\hline $\mathbf{1 0 0}$ & $3 \pm 2$ & $6 \pm 5$ & 3 & $0,7 \%$ & $5,5 \%$ \\
\hline $\mathbf{1 0 0 0}$ & $5 \pm 1$ & $9 \pm 6$ & 4 & $0,8 \%$ & $5,5 \%$ \\
\hline $\mathbf{1 0 0 0 0}$ & $91 \pm 8$ & $104 \pm 28$ & 13 & $6 \%$ & $5,5 \%$ \\
\hline $\mathbf{2 0 0 0 0}$ & $233 \pm 9$ & $273 \pm 47$ & 40 & $16 \%$ & $5,5 \%$ \\
\hline
\end{tabular}

Tabela 4 - Diferença entre os tempos de resposta obtidos pelos cenários 1 e 3.

\begin{tabular}{|c|c|c|c|c|c|}
\cline { 2 - 3 } \multicolumn{1}{c|}{} & \multicolumn{2}{c|}{ Tempo de resposta } & \multicolumn{2}{c|}{} \\
\hline $\begin{array}{c}\text { Tamanho da } \\
\text { mensagem (caracteres) }\end{array}$ & $\begin{array}{c}\text { Cenário 1 } \\
(\mathbf{m s})\end{array}$ & $\begin{array}{c}\text { Cenário 4 } \\
(\mathbf{m s})\end{array}$ & $\begin{array}{c}\text { Diferença das } \\
\text { médias (ms) }\end{array}$ & $\mathbf{P}_{\text {simultâneo }}$ & $\mathbf{P}_{\text {envio }}{ }^{\text {adicional }}$ \\
\hline $\mathbf{1}$ & $2 \pm 1$ & $3 \pm 1$ & 1 & $6 \%$ & $9 \%$ \\
\hline $\mathbf{1 0}$ & $2 \pm 1$ & $3 \pm 2$ & 1 & $6 \%$ & $9 \%$ \\
\hline $\mathbf{1 0 0}$ & $3 \pm 2$ & $3 \pm 2$ & 0 & $9 \%$ & $9 \%$ \\
\hline $\mathbf{1 0 0 0}$ & $5 \pm 1$ & $6 \pm 2$ & 1 & $9,5 \%$ & $9 \%$ \\
\hline $\mathbf{1 0 0 0 0}$ & $91 \pm 8$ & $104 \pm 16$ & 13 & $53 \%$ & $9 \%$ \\
\hline $\mathbf{2 0 0 0 0}$ & $233 \pm 9$ & $257 \pm 23$ & 24 & $89 \%$ & $9 \%$ \\
\hline
\end{tabular}

Tabela 5 - Diferença entre os tempos de resposta obtidos pelos cenários 1 e 4 . 


\begin{tabular}{|c|c|c|c|c|c|}
\cline { 2 - 5 } \multicolumn{1}{c|}{} & \multicolumn{2}{c|}{ Tempo de resposta } & \multicolumn{2}{c|}{} \\
\hline $\begin{array}{c}\text { Tamanho da } \\
\text { mensagem (caracteres) }\end{array}$ & $\begin{array}{c}\text { Cenário 1 } \\
(\mathbf{m s})\end{array}$ & $\begin{array}{c}\text { Cenário 5 } \\
(\mathbf{m s})\end{array}$ & $\begin{array}{c}\text { Diferença das } \\
\text { médias (ms) }\end{array}$ & $\mathbf{P}_{\text {simultâneo }}$ & $\mathbf{P}_{\text {envio }}^{\text {adicional }}$ \\
\hline $\mathbf{1}$ & $2 \pm 1$ & $3 \pm 2$ & 1 & $12 \%$ & $19 \%$ \\
\hline $\mathbf{1 0}$ & $2 \pm 1$ & $3 \pm 2$ & 1 & $12 \%$ & $19 \%$ \\
\hline $\mathbf{1 0 0}$ & $3 \pm 2$ & $4 \pm 2$ & 1 & $17 \%$ & $19 \%$ \\
\hline $\mathbf{1 0 0 0}$ & $5 \pm 1$ & $7 \pm 3$ & 2 & $18 \%$ & $19 \%$ \\
\hline $\mathbf{1 0 0 0 0}$ & $91 \pm 8$ & $104 \pm 10$ & 13 & $78 \%$ & $19 \%$ \\
\hline $\mathbf{2 0 0 0 0}$ & $233 \pm 9$ & $265 \pm 17$ & 32 & $99 \%$ & $19 \%$ \\
\hline
\end{tabular}

Tabela 6 - Diferença entre os tempos de resposta obtidos pelos cenários 1 e 5.

De acordo com as tabelas 3 e 4, pode-se notar que mesmo aumentando o tamanho das mensagens utilizadas nas requisições dos processos adicionais, as probabilidades relacionadas com o envio simultâneo de requisições permanecem próximas. No entanto, foi observado que o aumento do tamanho das mensagens implicou em um aumento do tempo de resposta medido pelo processo principal. Isto é esperado porque embora as requisições simultâneas ocorram com frequências similares, para o caso das mensagens maiores (cenário 3, tabela 4) a duração dos "encontros" destas requisições é maior que para o caso do cenário 2. Sendo assim, tanto os tempos de respostas quanto a incerteza associada a estas medidas são maiores para o cenário 3 .

De acordo com as tabelas 5 e 6, pode-se notar que ao aumentar a frequência das requisições simultâneas implica também em um aumento nos tempos de resposta medidos pelo processo principal. No entanto, foi observado que o impacto causado nas medidas do tempo de resposta pelo aumento da frequência de requisições simultâneas (cenário 4 para cenário 5) é menor do que pelo aumento da duração destes "encontros" (cenário 2 para cenário 3). Esta diferença de impacto causado pelos processos adicionais pode ser facilmente observada pela diferença da incerteza associada às medidas, além do valor médio em si. $\mathrm{Na}$ Fig. 31 é ilustrado um gráfico com os tempos de respostas e suas respectivas incertezas, medidas em todos os cenários para o caso de tamanhos de mensagem de 20000 caracteres. 


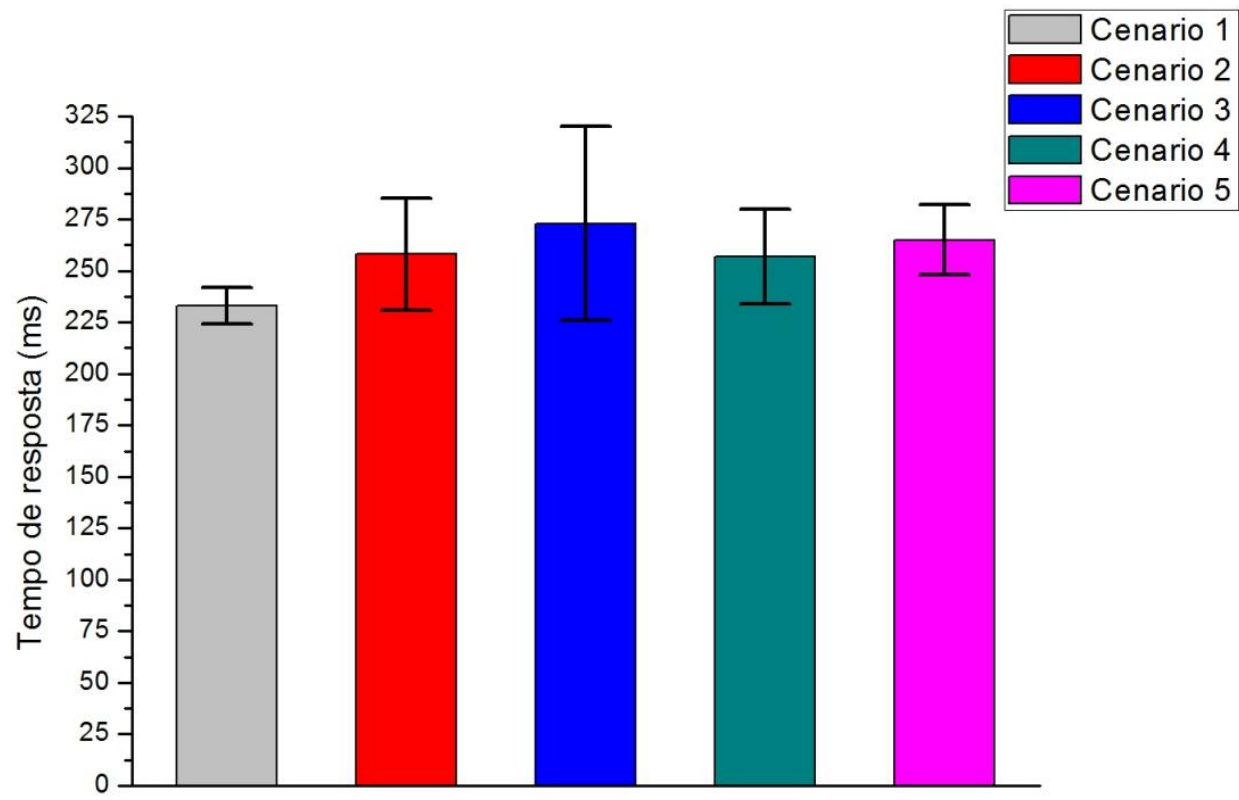

Figura 31 - Tempos de respostas medidas em todos os cenários para o caso de tamanhos de mensagem de 20000 caracteres.

Também foi observado que a presença dos processos adicionais teve maior influência sobre as medidas de tempo de resposta para mensagens maiores que 1000 caracteres. Isso é esperado porque para mensagens com tamanhos superiores a 1500 bytes, elas passam a ser fragmentadas em mensagens menores e são enviadas separadamente. Mesmo sobre as condições apresentadas pelos cenários 2, 3, 4 e 5, as variações dos tempos de resposta, para os tamanhos de mensagens utilizados, permaneceram na ordem de dezenas de milissegundos.

\subsection{TESTE DE DISPONIBILIDADE}

O teste de disponibilidade, descrito no capítulo 2, também é utilizado para avaliar o desempenho da arquitetura proposta. Este teste permite uma análise da consistência da arquitetura e é uma medida importante para aplicações que requerem a troca de um grande volume de informação entre seus processos. Para este teste, os processos requisitam os métodos de outros processos de forma assíncrona, não esperando para saber se o método desejado foi executado com sucesso. Desta forma, de acordo com a frequência das requisições, as mensagens podem acabar se acumulando, e a partir de certo ponto acabam se perdendo. 
Para poder verificar o desempenho da arquitetura proposta em diversas condições, as medidas para o teste de disponibilidade foram realizadas nos mesmos cenários 1, 2, 3, 4 e 5 dos testes anteriores. A única diferença para este caso, como mencionado, é que neste teste a interação entre os dois processos principais (que realizam as medidas) é feita de forma assíncrona. Para cada tamanho de mensagem utilizada pelo processo principal, as medidas foram feitas com diferentes valores para o intervalo entre requisições. Para cada configuração foi realizado um total de 1000 requisições (10 grupos de 100 requisições consecutivas). As Fig. 27, 28, 29, 30 e 31 apresentam, respectivamente, os gráficos referentes aos cenários 1, 2, 3,4 e 5 .

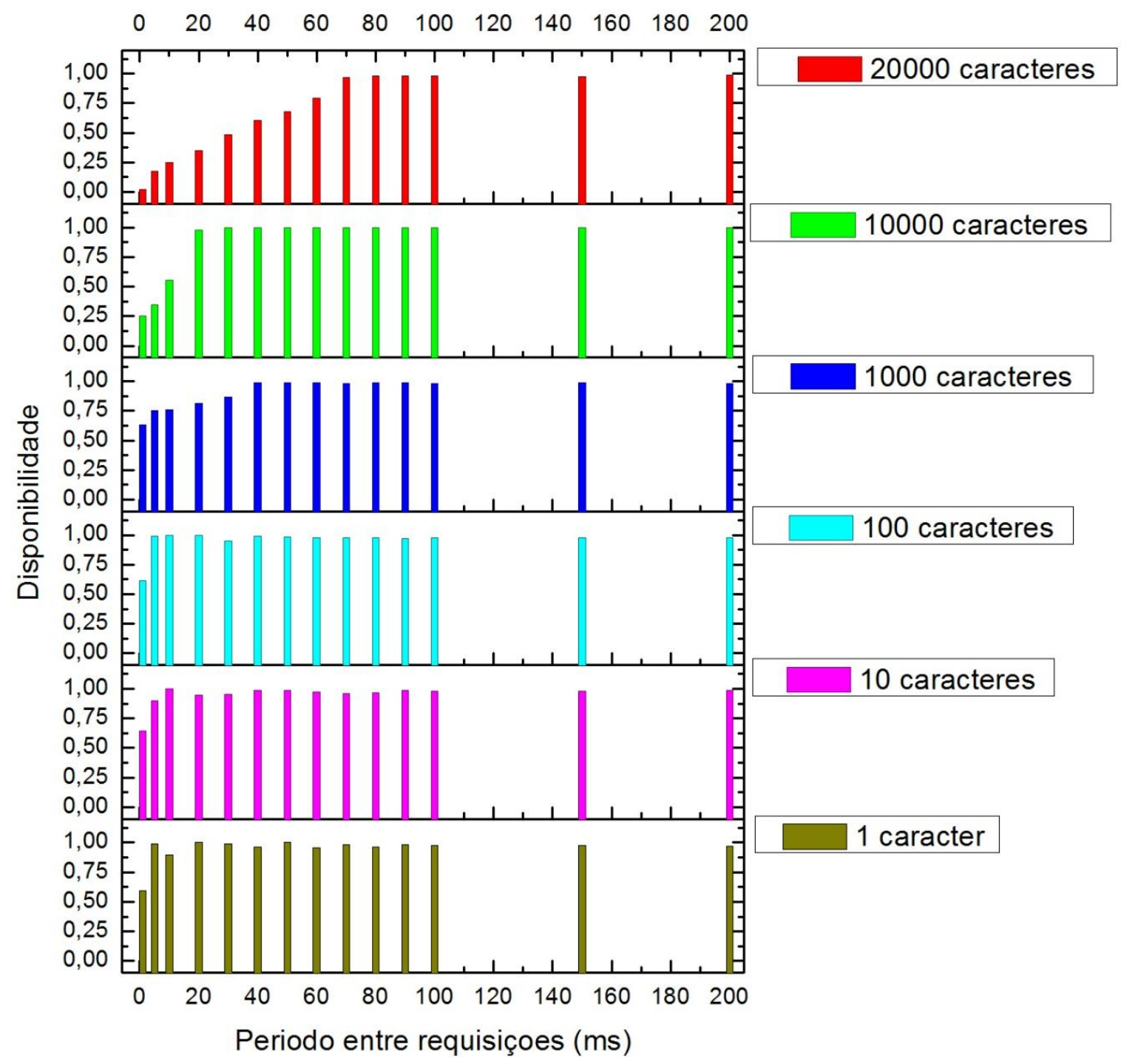

Figura 32 - Teste de disponibilidade medida para o cenário 1. 
Como pode ser observado na figura 27, para tamanhos de mensagens até da ordem de 10000 caracteres, é possível obter uma disponibilidade em torno de 1 para períodos de requisição até da ordem de 20 ms. A partir de 10000 caracteres, as mensagens enviadas nas requisições começam a se acumular mais rapidamente, causando sua perda total ou parcial para períodos de requisições menores (para o caso de 20000 caracteres, períodos menores que $70 \mathrm{~ms})$.

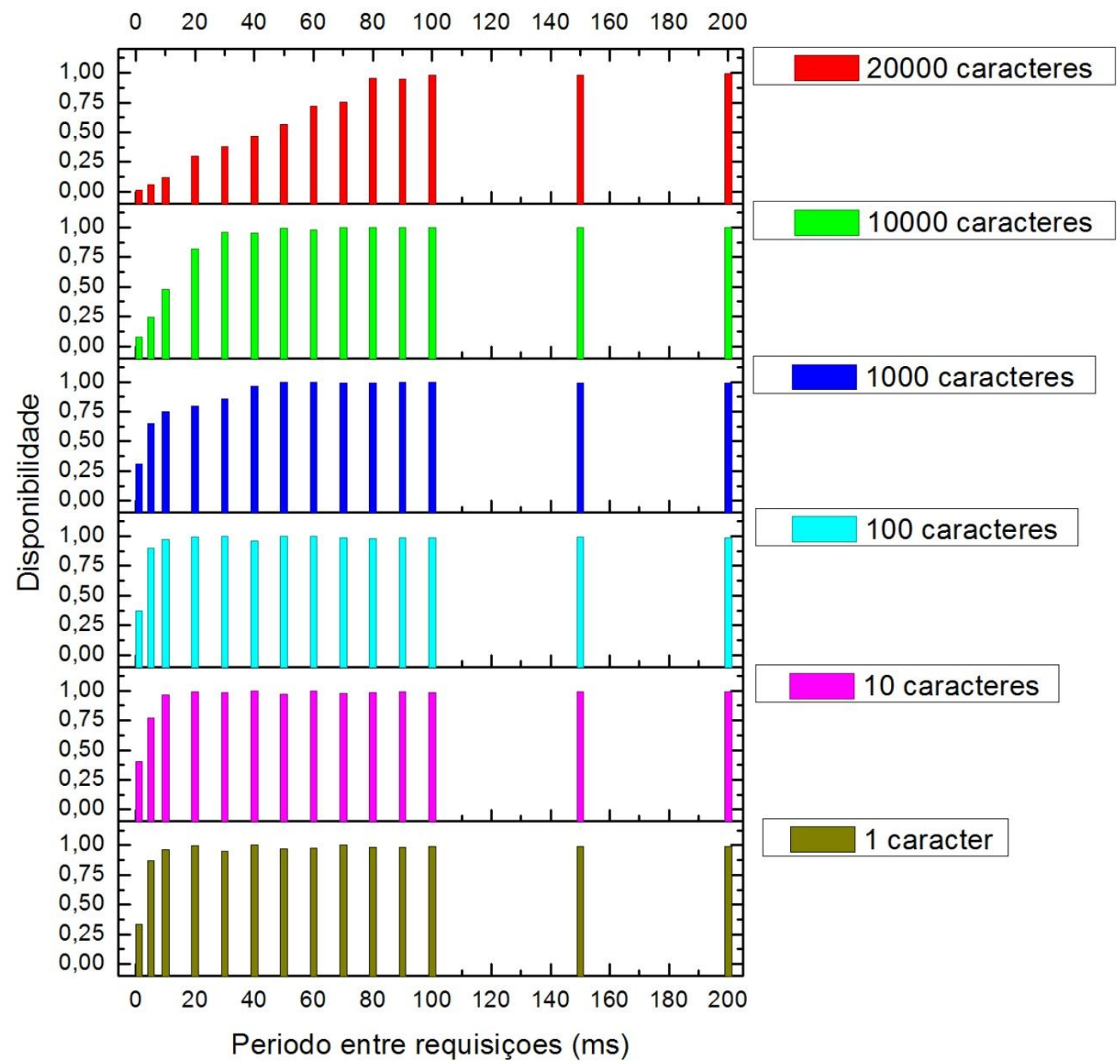

Figura 33 - Teste de disponibilidade medida para o cenário 2.

Como pode ser observada pelas figuras 27 e 28, a introdução dos processos adicionais teve como consequências a diminuição da disponibilidade medida pelo processo principal. Ao aumentar o tempo de resposta e sua incerteza, as requisições feitas pelo processo principal tendem a se acumularem mais rapidamente, facilitando a passagem do limite de mensagens acumuladas (ponto onde as mensagens passam a ser descartadas ou perde-se parte de seu 
conteúdo). Para tamanhos de mensagens entre 1 e 1000 caracteres, a diminuição da disponibilidade pode ser notada nas requisições de períodos menores que $20 \mathrm{~ms}$, e para os tamanhos de mensagens com 10000 e 20000, a diminuição pode ser observada para os períodos de requisição menores que $80 \mathrm{~ms}$.

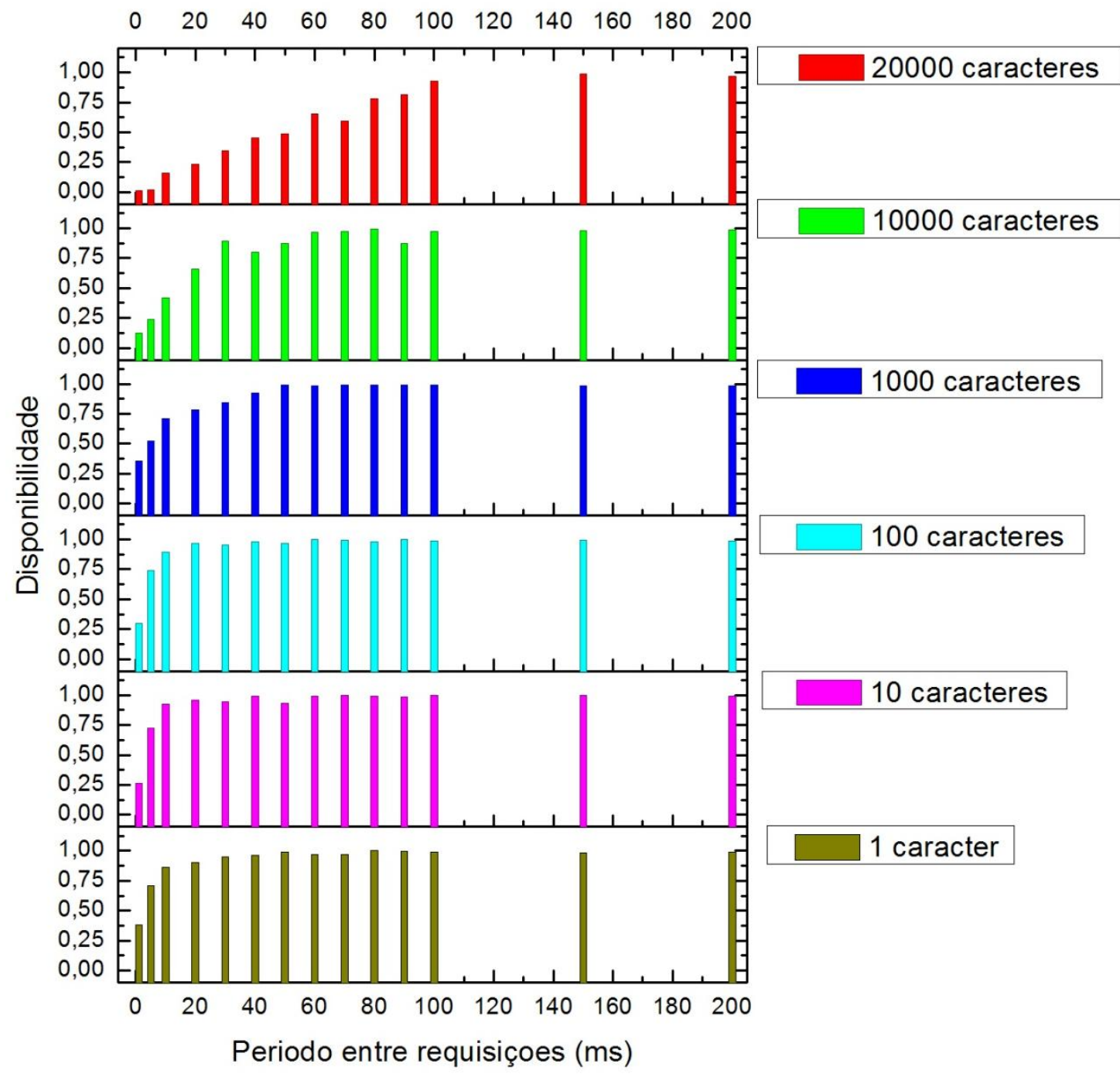

Figura 34 - Teste de disponibilidade medida para o cenário 3.

Como esperado, ao aumentar o tamanho das mensagens utilizadas pelos processos adicionais houve uma diminuição da disponibilidade medida pelo processo principal com relação ao cenário 2. Esta diminuição pode ser facilmente vista para tamanhos de mensagens maiores que 1000 caracteres como, por exemplo, para o caso de 20000 caracteres, há uma diminuição da disponibilidade para períodos de requisição menores que $100 \mathrm{~ms}$. 


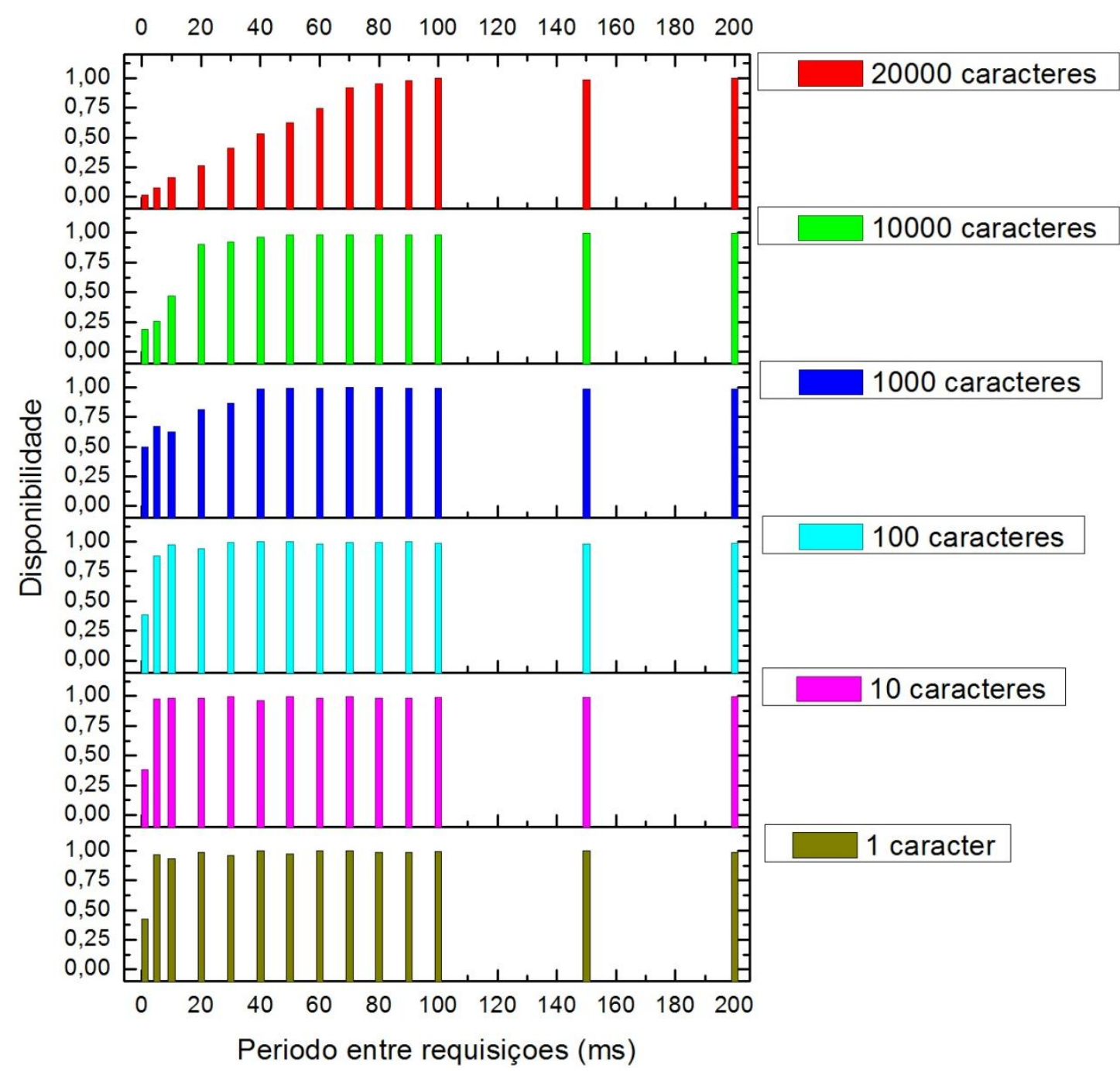

Figura 35 - Teste de disponibilidade medida para o cenário 4.

Ao aumentar a frequência das requisições simultâneas, houve uma diminuição com relação ao cenário 1 na disponibilidade medida pelo processo principal. Isto é visível em todos os tamanhos de mensagens utilizados para os períodos de requisição da ordem de alguns milissegundos. Também pode ser facilmente observada pela menor disponibilidade obtida para o tamanho de mensagem de 20000 caracteres (períodos de requisição menores que 70 $\mathrm{ms})$. 


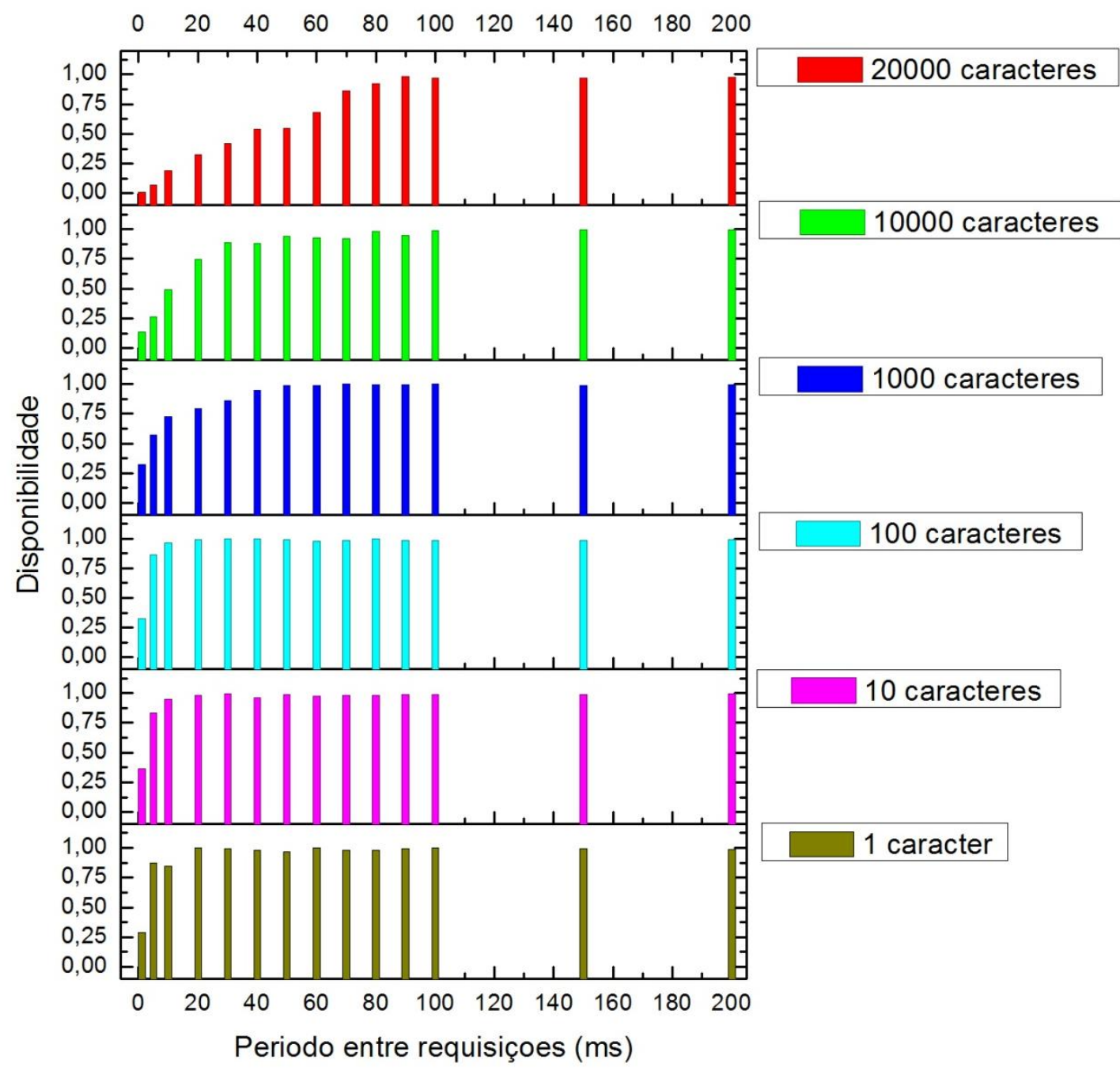

Figura 36 - Teste de disponibilidade medida para o cenário 5.

Semelhantemente ao observado para o teste de tempo de resposta, ao aumentar a frequência de requisições simultâneas, houve uma diminuição da disponibilidade medida pelo processo principal com relação ao cenário 4. E da mesma forma, embora a frequência de requisições simultâneas seja muito superior que do cenário 3, observou-se que a duração destes "encontros" tem maior impacto no teste de disponibilidade. Esta diferença pode ser facilmente vista para o caso de 20000 caracteres, que neste caso apresenta uma diminuição da disponibilidade para períodos de requisição menores que $90 \mathrm{~ms}$, enquanto que no cenário 3, a diminuição é visível para períodos de requisição menores que 100 ms.

Para permitir uma melhor comparação entre os gráficos apresentados neste tópico, Fig. 32 apresenta a disponibilidade medida em todos os cenários para o tamanho de mensagens de 20000 caracteres e períodos de requisição entre 10 e 100 ms. 


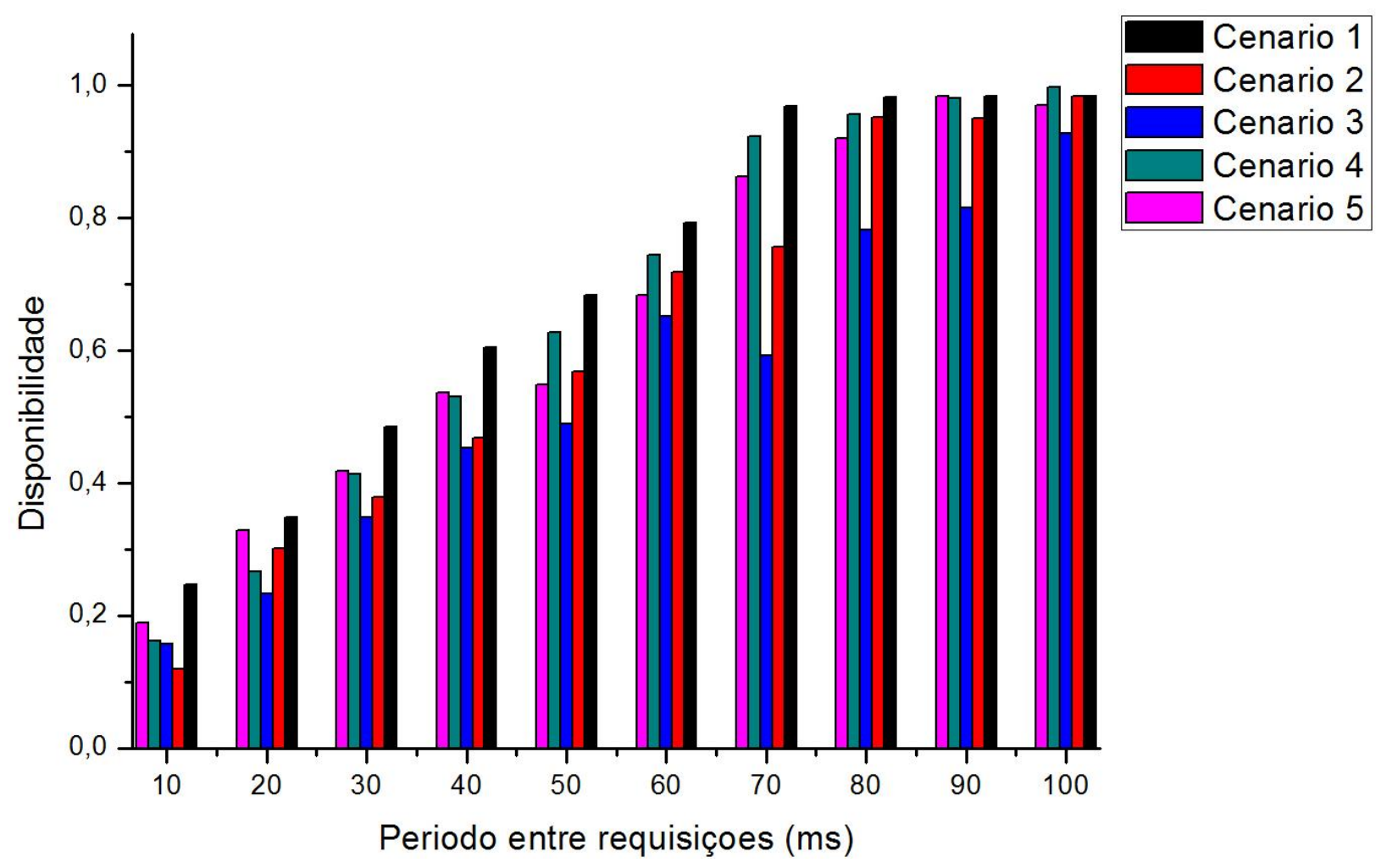

Figura 37 - Teste de disponibilidade medido em todos os cenários para o tamanho de mensagem de 20000 caracteres.

\subsection{PROJETO DO AGVS}

Como mencionado no capítulo anterior a arquitetura proposta foi utilizada para implementar as interações entre as unidades do sistema de AGVs. Por questões de completude deste trabalho são apresentados neste tópico alguns dados medidos referentes à operação do AGVS. Para esta operação, cada processo referente aos AGVs, WMS e supervisor foi executado em máquinas distintas conectadas em uma rede Wi-Fi. Para simular o ambiente de um armazém industrial, os AGVs são executados em um ambiente simulado proporcionado pelo Player/Stage. Fig. 33 e 34 apresentam, respectivamente, a interface utilizada pelo WMS, que permite observar o deslocamento dos produtos no armazém (conforme os AGVs retiram ou depositam os produtos nas prateleiras), e a interface proporcionada pelo simulador, onde os AGVs executam suas tarefas. 


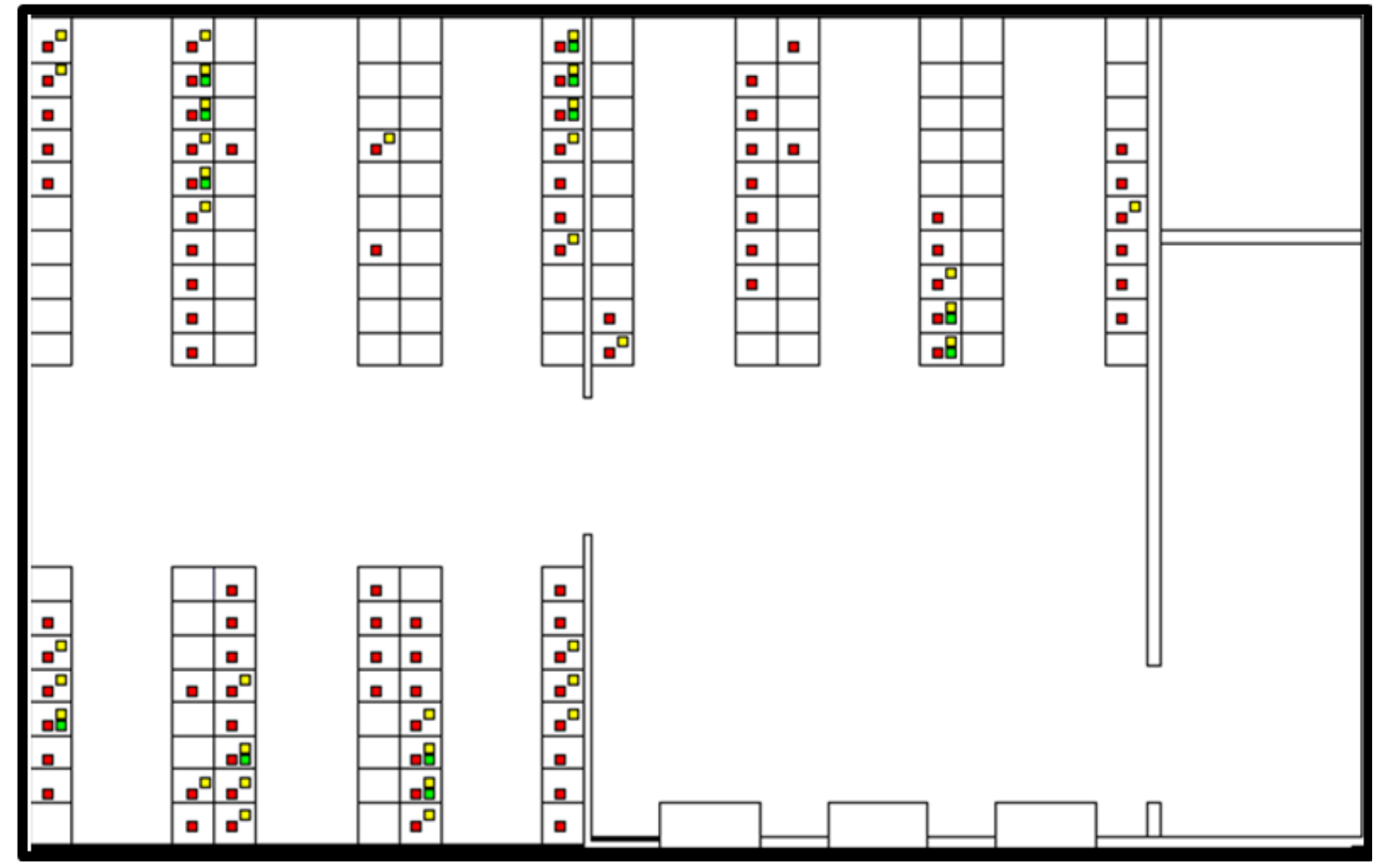

Figura 38 - Interface proporcionada pelo WMS para acompanhar o deslocamento dos produtos (paletes) no armazém. As caixas coloridas presentes na figura indicam a presença de um palete.

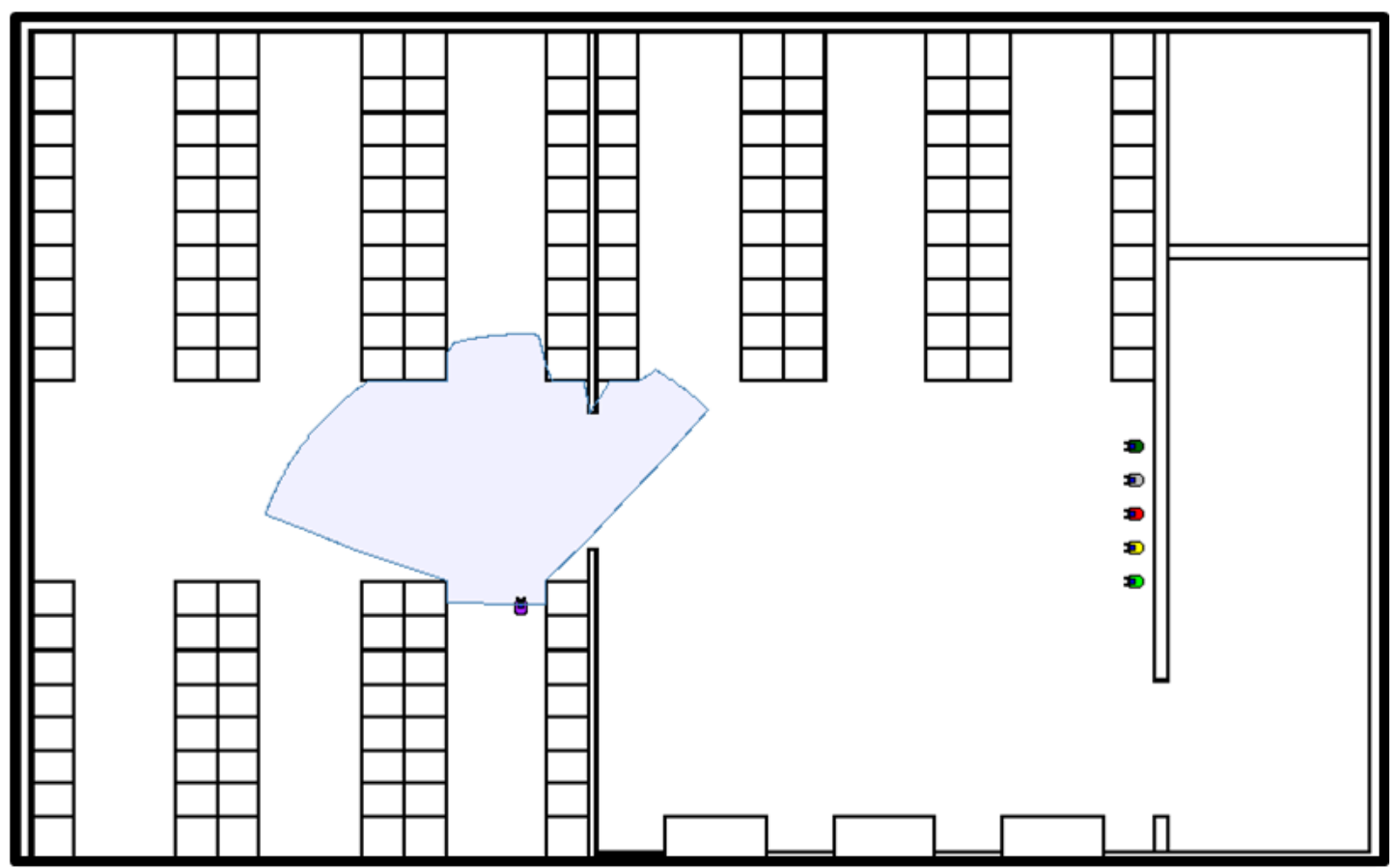

Figura 39 - Ambiente simulado proporcionada pelo Player/Stage onde os AGVs executam as tarefas passadas pelo supervisor. 
Para um determinado conjunto de tarefas passadas ao supervisor foram medidos alguns parâmetros, como: quantidade de tarefas passadas para cada AGV (cada tarefa contém uma lista dos produtos a serem movimentados); quantidade de produtos (paletes) movimentados por cada AGV; tempo total gasto pelos AGVs para finalizar todas as tarefas. Tabela 7 apresenta os dados medidos para a operação do AGVS.

\begin{tabular}{|l|c|c|c|c|c|}
\cline { 2 - 6 } \multicolumn{1}{c|}{} & AGV & AGV & AGV & AGV & AGV \\
\hline Quantidade de tarefas passadas & $\mathbf{1}$ & $\mathbf{2}$ & $\mathbf{3}$ & $\mathbf{4}$ & $\mathbf{5}$ \\
\hline Quantidade de produtos movimentados & 11 & 11 & 11 & 11 & 11 \\
\hline $\begin{array}{l}\text { Tempo total para finalização das tarefas } \\
\text { (minutos) }\end{array}$ & 68 & 55 & 48 & 62 & 63 \\
\hline
\end{tabular}

Tabela 7 - Dados coletados durante a operação do AGVS para um conjunto de tarefas passadas ao supervisor.

Como pode ser observado, o tempo tomado pelos AGVs para executar suas tarefas é da ordem de minutos e, embora não esteja presente na tabela, a frequência de requisições trocadas entre suas unidades é da ordem de dezenas de segundos. O tamanho máximo das mensagens trocadas entre as unidades dos sistemas eram equivalentes ao tamanho de mensagens contendo entre 10000 e 20000 caracteres. Sendo assim, a arquitetura de comunicação proposta oferece uma infraestrutura satisfatória para esta aplicação. É importante ressaltar neste ponto que a arquitetura proposta não é adequada para a implementação de aplicações comerciais, visto que para tal é necessário um maior estudo para garantir a segurança da comunicação.

\subsection{CONSIDERAÇÕES FINAIS DO CAPÍTULO}

A partir dos testes realizados na seção 4.1, pode-se verificar que para mensagens (utilizadas nas requisições) maiores que 1000 caracteres boa parte dos tempos (tempo de resposta) medidos eram gastos com a geração e processamento destas mensagens. Desta forma, foi possível identificar vários pontos relacionados com a duplicação dos objetos da 
classe Parameters para diminuir o tempo de processamento das mensagens e melhorar o desempenho da arquitetura.

Observa-se nos testes deste capítulo que a adição de outros processos para simular cenários de aplicações mais dinâmicos, obteve-se uma piora dos valores medidos. Foi feita uma análise com relação à frequência de requisições ocorrendo simultaneamente, e da duração destes "encontros". Para os cenários adotados nestes testes, verificou-se que o aumento da duração dos "encontros" tem um efeito maior que a sua frequência.

A arquitetura proporcionou um desempenho suficiente para executar o sistema de AGVs, garantindo a troca de informações entre suas unidades e proporcionando mecanismos para facilitar a implementação de sua coordenação. 


\section{CONCLUSÃO}

O aumento no número de dispositivos móveis com grande capacidade de processamento traz como incentivo o desenvolvimento de sistemas distribuídos que possam explorar estas novas tecnologias. Dentro dos sistemas distribuídos, os mecanismos que permitem a troca de dados entre os processos que o constituem possuem um papel importante para o desempenho da aplicação. Uma abordagem interessante para implementar estes mecanismos é por meio do uso de middlewares. O middleware abstrai as funcionalidades básicas oferecidas pelo sistema operacional e hardware para oferecer serviços de alto nível aos desenvolvedores. Estes serviços permitem aos desenvolvedores se concentrarem somente na lógica interna de suas aplicações, reduzindo também seu custo de manutenção.

Incentivado pela necessidade de um mecanismo que garantisse a troca de informações entre as unidades do projeto de AGVs, que é desenvolvido pelo grupo de mecatrônica da Universidade de São Paulo, este trabalho propôs uma arquitetura de comunicação baseada em middlewares que, além de suprir a troca de dados entre os processos da aplicação, oferecesse serviços que facilitam sua coordenação.

$\mathrm{Na}$ revisão bibliográfica foram descritas as principais características nas quais os middlewares se baseiam, apresentando também um mapeamento em um diagrama de camadas de seus serviços oferecidos. Foram apresentados também dois middlewares de comunicação baseados em objetos distribuídos, comumente encontrados na literatura. Para analisar os mecanismos de comunicação utilizados em aplicações robóticas, foram apresentadas as abordagens utilizadas em trabalhos publicados e os mecanismos utilizados em frameworks robóticos.

A partir dos estudos feitos, a arquitetura de comunicação proposta foi desenvolvida inspirando-se no paradigma de comunicação RMI, oferecendo suporte para o conceito de objetos distribuídos. A primeira abordagem da arquitetura foi desenvolvida especificamente para o projeto de AGVs e possuía um formato de mensagens adaptado para esta aplicação. Durante seu desenvolvimento, notou-se que com algumas modificações como, por exemplo, a adição de uma IDL, fosse possível aplicar a arquitetura de comunicação em outras aplicações. Embora estas modificações pudessem aumentar o overhead das mensagens trocadas, a possibilidade de aplicar a arquitetura de comunicação em outras aplicações foi vista como um ponto mais importante. 
A versão final da arquitetura foi projetada para proporcionar um conjunto de serviços suficientemente genéricos para que ela pudesse ser utilizada em um leque maior de aplicações. Para facilitar sua implementação, a arquitetura consiste de uma biblioteca que contém as classes necessárias para estabelecer a conexão e interação entre os processos de uma aplicação. Utilizando-se do conceito de template, oferecido pela linguagem de programação $\mathrm{C}++$, os serviços disponibilizados ou, serviços remotos, podem ser definidos em uma classe diferente das classes que definem a arquitetura. Desta forma, de acordo com as necessidades de cada aplicação, os desenvolvedores podem escolher as classes com os serviços desejados.

As estruturas que compõem a versão final do middleware proposto, assim como seus mecanismos implementados, foram descritos individualmente seguindo o mesmo mapeamento do diagrama de camadas mencionado na revisão bibliográfica. Para demonstrar como a interface do middleware é utilizada, e também como novos serviços podem ser agregados à arquitetura proposta, dois códigos de exemplo (que ofereciam um serviço baseado em sistemas publish-subscribe) foram apresentados. Para permitir a integração da arquitetura de comunicação proposta com programas escritos em outras linguagens de programação e em outros sistemas operacionais, foi demonstrado o uso de serviços web em conjunto com a arquitetura para permitir o controle de um robô a partir de um celular Android. O middleware proposto foi utilizado no projeto AGVS para implementar a interação entre suas unidades e, portanto, este sistema e os mecanismos de comunicação necessários para o funcionamento de cada unidade foram descritos.

Para avaliar o desempenho da arquitetura e analisar o comportamento dos serviços oferecidos, testes de tempo de resposta, throughput e disponibilidade foram realizados. Estes testes foram feitos em diversas configurações experimentais (cenários), permitindo a análise do desempenho da arquitetura tanto em situações ideais, com somente dois processos interagindo, quanto em cenários mais dinâmicos, onde vários processos interagem simultaneamente. Para estimar o impacto da adição de outros processos no desempenho da arquitetura, foi feita uma estimativa da probabilidade de que os processos que realizavam as medidas iniciassem o envio de suas mensagens simultaneamente com os processos adicionais.

A partir destes testes, pode-se verificar que os mecanismos que geravam e processavam as mensagens trocadas entre os processos tinham grande influência sobre o desempenho medido. Uma análise sobre estes mecanismos permitiu o encontro de diversos pontos, relacionados com a duplicação dos objetos da classe Parameters, para diminuir o tempo de processamento das mensagens e melhorar o desempenho da arquitetura. Ao analisar 
os resultados para diferentes cenários adotados, pode-se notar que aumentar o tempo de duração dos "encontros" das requisições simultâneas tinha um efeito ligeiramente maior sobre os resultados do que aumentar a sua frequência de ocorrência.

Ao final do capítulo de resultados, os dados coletados referentes à execução do sistema AGVS (utilizando a arquitetura proposta) em uma determinada rotina foram apresentados. Para esta aplicação, a arquitetura, além de proporcionar uma interface intuitiva para sua utilização, proporcionou um desempenho satisfatório para a operação do sistema. Desta forma, a arquitetura desenvolvida, além de preencher sua proposta inicial de garantir a troca de informações entre as unidades do projeto AGVS, ofereceu uma estrutura que pode ser facilmente adaptada para futuras alterações no projeto sem modificar diretamente as definições da arquitetura de comunicação.

Para aumentar a flexibilidade e desempenho da arquitetura, alguns mecanismos ainda precisam ser melhorados como, por exemplo: permitir que cada processo possua mais de um objeto da classe Function_list associado aos seus métodos disponibilizados (permite a seleção de quais serviços serão disponibilizados para cada outro processo conectado); melhora dos mecanismos utilizados para realizar as requisições, diminuindo o custo de processamento relacionado com a geração e processamento das mensagens trocadas; melhor análise sobre a utilização da memória disponível para alocação de recursos a fim de torná-la mais eficiente; priorização de conexões para garantir a qualidade de serviço. Outra abordagem interessante de ser analisada, e que é fundamental para aplicações comerciais, é a segurança da comunicação. Para tal, uma melhor análise sobre os protocolos de rede (e arquiteturas de rede) utilizados é necessária para identificar quais os melhores mecanismos para garantir a segurança das informações trocadas entre os processos de uma aplicação.

Também em trabalhos futuros, serão realizados testes para comparar o desempenho da arquitetura de comunicação proposta com outros middlewares e frameworks. E será também analisada a possibilidade de utilizar a arquitetura proposta em conjunto com outro framework robótico, em especial, o ROS. 


\section{Referências}

(1) ROTH, M.; SIMMONS, R.; VELOSO, M. Decentralized communication strategies for coordinated multi-agent policies. In: INTERNATIONAL WORKSHOP ON MULTI-ROBOT SYSTEMS, 3., 2005, Washington, D.C. Proceedings... Dordrecht: Springer Netherlands, 2005. p. 93-105.

(2) VAIL, D.; VELOSO, M. Dynamic multi-robot coordination. In: INTERNATIONAL WORKSHOP ON MULTI-ROBOT SYSTEMS, 2., 2003, Washington, D.C. Proceedings... Dordrecht: Kluwer Academic Publishers, 2003. p. 87-100.

(3) BUSNEL, Y. Reinventing mobile community computing and communication. In: IEEE INTERNATIONAL CONFERENCE ON TRUST, SECURITY AND PRIVACY IN COMPUTING AND COMMUNICATIONS, 12., 2013, Melbourne. Proceedings... Melbourne: IEEE, 2013. p. 1450-1457.

(4) MANIAS, E; BAUDE, F. A component-based middleware for hybrid grid/cloud computing platforms. Concurrency and Computation: Practice \& Experience, Chichester, v. 24, n. 13, p. 1461-1477, 2012.

(5) SURI, N et al. Communications middleware for tactical environments: observations, experiences, and lessons learned. IEEE Communications Magazine, Piscataway, v. 47, n. 10, p. 56-63, 2009.

(6) WITKOWSKI, U. Ad-hoc network communication infrastructure for multi-robot systems in disaster scenarios. In: EURON/IARP INTERNATIONAL WORKSHOP ON ROBOTICS FOR RISKY INTERVENTIONS AND SURVEILLANCE OF THE ENVIRONMENT, 2., 2008, Benicassim. Proceedings... Bielefeld: Bielefeld University, 2008. Disponível em: <http://pub.uni-bielefeld.de/publication/2278648 >. Acesso em: 01 jan. 2014.

(7) SCHANTZ, R. E.; SCHMIDT, D. C. Research advances in middleware for distributed systems: state of the art. In: IFIP WORLD COMPUTER CONGRESS, 17., 2002, Montreal. Proceedings... Deventer: Kluwer, B.V, 2002. p. 1-36.

(8) COULOURIS, G.; DOLLIMORE, J.; KINDBERG, T. Distributed Systems: Concepts and Design. 5. ed. Boston: Addison-Wesley, 2011.

(9) EMMERICH, W.; AOYAMA, M.; SVENTEK, J. The impact of research on the development of middleware technology. ACM Transactions on Software Engineering and Methodology, New York, v. 17, n. 4, artigo 19, 2008.

(10) VIVALDINI, K. C. T. et al. Automatic routing system for intelligent warehouses. In: IEEE INTERNATIONAL CONFERENCE ON ROBOTICS AND AUTOMATION, 27. 2010, Anchorage. Proceedings... Anchorage: IEEE, 2010. p. 93-98. 
(11) OBJECT MANAGEMENT GROUP. The common object request broker: architecture and specification revision 2.4. Needham: OMG, 2000. 954 p. (OMG Technical Document formal/00-11-07). Disponível em: 〈http://www.omg.org/cgi-bin/doc?formal/00-11-07.pdf>. Acesso em: 1 jan. 2014.

(12) WOLLRATH, A.; RIGGS, R.; WALDO, J. A distributed object model for the Java system. Computing Systems, Berkeley, v. 9, n. 4, p. 265-290, 1996.

(13) QUIGLEY, M. et al. ROS: an open-source robot operating system. In: IEEE ICRA WORKSHOP ON OPEN SOURCE SOFTWARE, 26., 2009, Kobe. Proceedings... Kobe: IEEE, 2009.

(14) METTA, G.; FITZPATRICK, P.; NATALE, L. YARP: Yet another robot platform. International Journal on Advanced Robotics Systems, Rijeka, v. 3, p. 43-48, 2006. Número especial.

(15) FRAMEWORK de serviços web em C++. Disponível em: <http://wso2.com/products/web-services-framework/cpp/>. Acesso em: 1 jan. 2014.

(16) TANENBAUM, A. S.; VAN STEEN, M. Distributed systems: principles and paradigms. 2nd ed. Upper Saddle River: Pearson Prentice Hall, 2007.

(17) COSTA, M. A. S. Um modelo de middleware adaptativo. 2004. 120 f. Dissertação (Mestrado em Ciência da Computação) - Centro de Informática, Universidade Federal de Pernambuco, Pernambuco, 2004.

(18) MARTINS, M. R A. Integração sistêmica em middleware. 2010. 233 f. Dissertação (Mestrado em Engenharia Elétrica) - Escola Politécnica, Universidade de São Paulo, São Paulo, 2010.

(19) TANENBAUM, A. S. Redes de computadores. 4. ed. Rio de Janeiro: Elsevier Brasil, 2003.

(20) CEDERMAN, D. A study of the behavior of synchronization methods in commonly used languages and systems. In: IEEE INTERNATIONAL SYMPOSIUM ON PARALLEL AND DISTRIBUTED PROCESSING, 27., 2013, Boston. Proceedings... Washington, DC: IEEE, 2013. p. 1309-1320.

(21) MATLOFF, N. Programming on parallel machines. California: University of California, 2012. Disponível em:

<http://heather.cs.ucdavis.edu/ matloff/158/PLN/ParProcBook.pdf>. Acesso em: 1 jan. 2014.

(22) OBJECT MANAGEMENT GROUP. CORBAServices: Common Object Service Specification. Needham: OMG, 1998. (OMG Technical Document formal/98-12-09).

Disponível em: <http://www.omg.org/cgi-bin/doc?formal/98-12-09.pdf>. Acesso em: 1 jan. 2014.

(23) LINDHOLM T.; YELLIN F. The Java virtual machine specification. 2nd ed. Upper Saddle River: Prentice Hall, 1999. 
(24) Chen, CK. et al. Mobile Java RMI support over heterogeneous wireless networks: A case study. Journal of Parallel and Distributed Computing, Orlando, v. 68, n. 11, p. 14251436, 2008.

(25) SCHMIDT D.; LEVINE D.; MUNGEE S. The design of the TAO real-time object request broker. Computer Communications, Amsterdam, v. 21, n. 4, p. 294-324, 1998.

(26) LÓPEZ, J.; PÉREZ, D.; ZALAMA, E. A framework for building mobile single and multi-robot applications. Robotics and Autonomous Systems, Amsterdam, v. 59, n. 3-4, p. 151-162, 2011.

(27) INSTITUTO DE ROBÓTICA CARNEGIE MELLON. Disponível em: <http://www.ri.cmu.edu/>. Acesso em: 1 jan. 2014.

(28) TAVARES, D. M.; BACHEGA, S. J. Proposal for an AGV communication system using a cellbot framework. In: IEEE/IAS INTERNATIONAL CONFERENCE ON INDUSTRY APPLICATIONS, 10., 2012, Fortaleza. Proceedings... Piscataway: IEEE, 2012. p. 1-6.

(29) IÑIGO-BLASCO, P. et al. Robotics software frameworks for multi-agent robotic systems development. Robotics and Autonomous Systems, Amsterdam, v. 60, n. 6, p. 803$821,2012$.

(30) VIVALDINI, K. C. T. et al. Communication infrastructure in the centralized management system for intelligent warehouses. In: INTERNATIONAL CONFERENCE FLEXIBLE AUTOMATION AND INTELLIGENT MANUFACTURING, 23., 2013, Porto. Proceedings... Berlin: Springer, 2013. p. 127-136.

(31) TAMASHIRO, G. et al. Communication architecture for robotic applications. In: INTERNATIONAL CONFERENCE FLEXIBLE AUTOMATION AND INTELLIGENT MANUFACTURING, 24., 2014, San Antonio. Proceedings... [S.1.: s. n.]: [2014?]. In press.

(32) DONAHOO, M. J.; CALVERT, K. L. TCP/IP Sockets in C. 2nd ed. Burlington: Morgan Kaufmann, 2009.

(33) THE APACHE SOFTWARE FOUNDATION. Disponível em: <http://www.apache.org/>. Acesso em: 1 jan. 2014.

(34) ANDROID SDK. Disponível em: <http://developer.android.com/sdk/index.html〉. Acesso em: 1 jan. 2014.

(35) KSOAP2-ANDROID. Disponível em: 〈http://code.google.com/p/ksoap2-android/> Acesso em: 1 jan. 2014. 